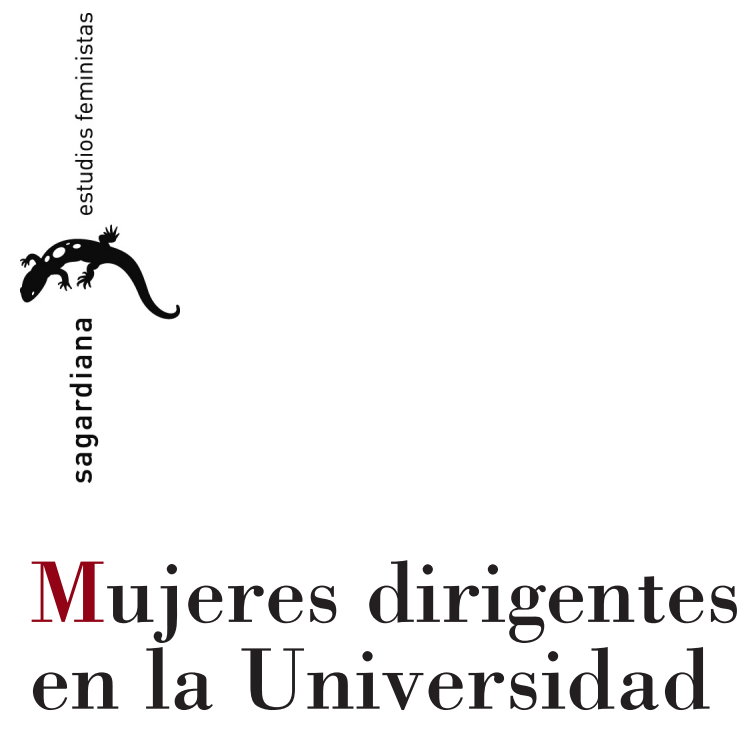

Las texturas del liderazgo

Marita Sánchez Moreno

$$
\text { (ed.) }
$$

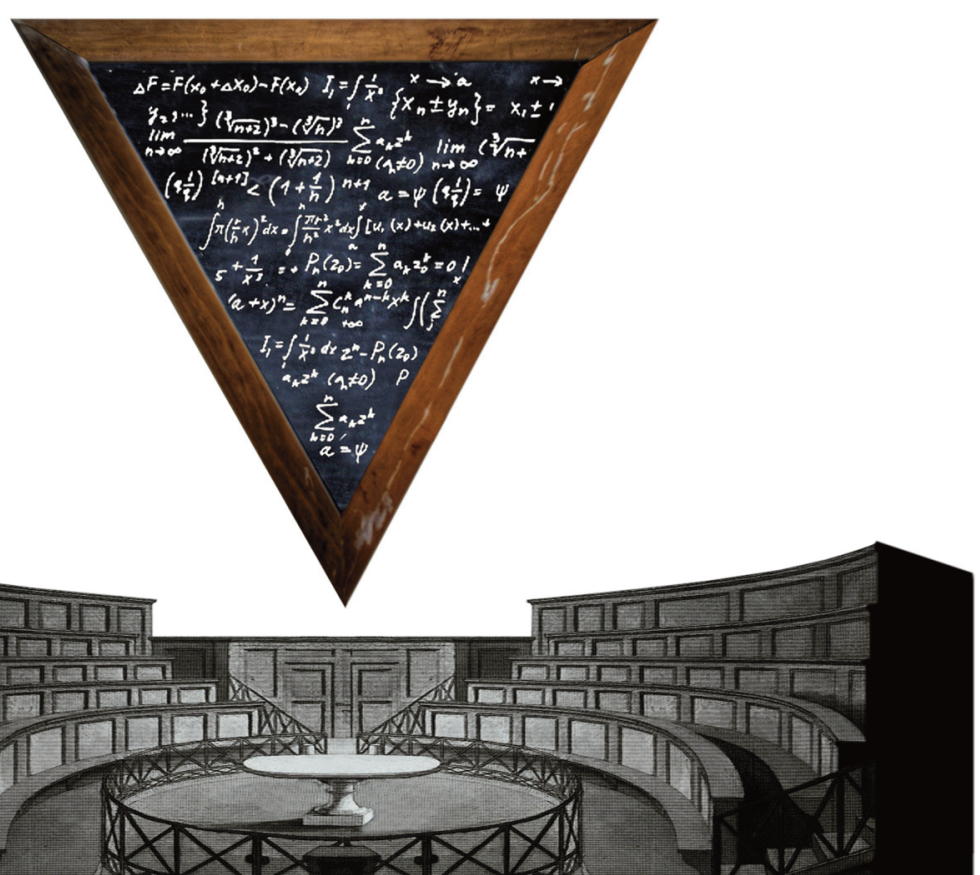



MUJERES DIRIGENTES EN LA UNIVERSIDAD

Las texturas del liderazgo 



\title{
MUJERES DIRIGENTES EN LA UNIVERSIDAD \\ Las texturas del liderazgo
}

\author{
Marita Sánchez Moreno
}

(ed.)

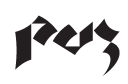

Prensas Universitarias de Zaragoza 
MUJERES dirigentes en la Universidad : las texturas del liderazgo / Marita Sánchez Moreno (ed.). — Zaragoza : Prensas Universitarias de Zaragoza, 2009 190 p. ; 22 cm. - (Sagardiana : estudios feministas ; 12)

ISBN 978-84-92774-63-0

SÁNCHEZ MORENO, Marita

1. Mujeres-España-Situación social. 2. Universidades-España-Personal

378.1-057.17-055.2(460

Cualquier forma de reproducción, distribución, comunicación pública o transformación de esta obra solo puede ser realizada con la autorización de sus titulares, salvo excepción prevista por la ley. Diríjase a CEDRO (Centro Español de Derechos Reprográficos, www.cedro.org) si necesita fotocopiar o escanear algún fragmento de esta obra.

(C) Los autores

(C) De la presente edición, Prensas Universitarias de Zaragoza

1. ${ }^{a}$ edición, 2009

La edición de este libro ha sido parcialmente financiada por el Instituto Aragonés de la Mujer

Colección Sagardiana. Estudios Feministas, n. ${ }^{\circ} 12$

Directora de la colección: M. ${ }^{a}$ Dolores Sánchez González

Prensas Universitarias de Zaragoza. Edificio de Ciencias Geológicas, c/ Pedro Cerbuna, 12. 50009 Zaragoza, España. Tel.: 976761 330. Fax: 976761063

puz@unizar.es http://puz.unizar.es

Prensas Universitarias de Zaragoza es la editorial de la Universidad de Zaragoza, que edita e imprime libros desde su fundación en 1542.

Diseño de cubierta: Óscar Sanmartín

Impreso en España

Imprime: GAMBON Gráfico

D.L.: Z-4468-2009 


\section{INTRODUCCIÓN}

Los profundos cambios sociales, políticos y económicos experimentados por las sociedades modernas en la era de la globalización, el uso masivo de las nuevas tecnologías de la información y los cambios rápidos e inciertos invitan a que nos replanteemos nuestra concepción sobre las organizaciones y, de manera especial, de las organizaciones educativas. Cada vez más se abre camino la idea de que las organizaciones más capaces de proporcionar eficientemente el servicio para el cual han sido diseñadas son las que manifiestan una mayor disponibilidad para adaptarse a los cambios que se producen en su entorno y para dar respuestas creativas ante dichos cambios. La Universidad, como organización, poco a poco va haciéndose eco de dichos cambios e incorporándolos tímidamente en sus actuaciones.

Por otra parte, los estudios acerca del género y del papel de la mujer en la sociedad actual también van cobrando protagonismo. La situación de hombres y mujeres es bien distinta a la de épocas anteriores y son muchas las voces que desde diferentes áreas y disciplinas analizan la situación y el rol de las mujeres en el contexto sociolaboral. Aunque aún queda mucho camino por andar, la mujer se hace cada vez más visible en las organizaciones. Eso es bueno para las mujeres, ya que supone abrir una puerta más en el largo camino hacia la igualdad plena. Lo es también para la sociedad, ya que contribuye a hacerla más justa. Y lo es finalmente para las organizaciones, puesto que la práctica de la dirección asumida por las mujeres adopta con frecuencia modalidades creativas que ponen en cuestión los modos tradicionales de gestión y contribuye a mejorarlos.

Sin embargo, las cifras demuestran que la presencia de mujeres en ámbitos de responsabilidad en las instituciones universitarias 
dista mucho de ser igualitaria. El techo de cristal es una realidad existente en la educación universitaria española según las cifras del informe Académicas en cifras 2007, publicado por la Unidad de Mujeres y Ciencia del Ministerio de Educación. Los datos confirman que las proporciones de representación de las mujeres en las Universidades públicas españolas decrecen considerablemente a medida que asciende su responsabilidad de gestión y su situación académica. Ellas son mayoría entre los titulados en la Universidad pública (60\% en el curso 2005-2006), mientras que el número de catedráticas no alcanza el $14 \%$. Sirva el ejemplo de la Universidad de Sevilla como botón de muestra: contamos con un profesor catedrático de Universidad por cada 2,4 profesores titulares de Universidad mientras que por cada 9,8 profesoras titulares encontramos a una mujer catedrática.

Dada la escasa presencia de las mujeres en los altos cargos universitarios el Foro de Consejos Sociales de las Universidades Públicas de Andalucía ha desarrollado un estudio que concluye diciendo que es imprescindible la promoción explícita y pública de las mujeres «para favorecer su inclusión en los espacios profesionales y de toma de decisiones porque la Universidad, como creadora de cultura y de transformación social, tiene la responsabilidad de trabajar en pro de la igualdad de género, para el propio beneficio de la comunidad universitaria y para que, con su ejemplo, influya en el resto de la sociedad».

Paradójicamente, esta realidad se está produciendo en un país con una Ley de Igualdad y una Ley de Universidades en las que, entre otras cosas, se garantiza una presencia equilibrada entre hombres y mujeres en sus órganos de gobierno.

Se hacen pues imprescindibles un debate público y una reflexión desde la comunidad universitaria sobre esta situación que hagan visibles las dificultades que las mujeres encuentran para desarrollar su carrera profesional y que conduzcan a arbitrar medidas para paliar la situación, y que además sostengan el ánimo para seguir luchando por conquistar espacios de poder.

Entre los factores sutiles de discriminación existe una coincidencia unánime entre los expertos del tema a la hora de señalar la 
ausencia de mujeres en los corredores del poder y la información. Las redes de contactos personales que se establecen entre grupos poderosos y personas influyentes son casi exclusivamente masculinas. Cualquier información de interés circula rápidamente por estas redes y suele llegar tarde y mal, si es que llega, a las mujeres del mismo nivel. Igual ocurre cuando se está constituyendo una comisión, elaborando una lista de nombres para un simposio, organizando un panel o un equipo de gestión. Se piensa en hombres, se llama a hombres, se nombra a hombres. El sistema se perpetúa a sí mismo.

Estas razones nos animaron a elaborar el presente trabajo, que deriva de esa inquietud por presentar la aportación que las mujeres podrían estar prestando a la definición de las Universidades del futuro.

La realización de este estudio ha permitido conjugar dos ámbitos que nos interesaban y en los que desde hace tiempo veníamos trabajando: por un lado, el análisis institucional y el estudio de las organizaciones educativas, especialmente las organizaciones universitarias y, por otro, los estudios de género y los procesos de gestión de mujeres.

El objetivo fundamental ha sido indagar acerca del papel que las directivas desempeñan en la transformación de las organizaciones universitarias en este momento de profundas reformas en la educación superior. Hemos sometido a discusión el liderazgo y las redes de poder desplegados por las mujeres que gobiernan unidades organizativas universitarias y sostenemos que es posible reconocer nuevas formas de liderazgo en el modo en que las mujeres ejercen el poder, las cuales pueden contribuir al desarrollo y la mejora de las organizaciones de educación superior.

Fruto de nuestro interés por este objetivo, el trabajo se plantea tres cuestiones principales. En primer lugar, analizar el perfil de las rectoras, vicerrectoras, directoras de grupos de investigación, decanas y directoras de Departamentos Universitarios, describiendo las condiciones profesionales de su actividad, las barreras que han encontrado para acceder a los cargos así como las motivaciones que les llevaron a optar por ellos, y el estudio de sus 
necesidades formativas, es decir, qué características estiman que son valiosas para el ejercicio de la gestión y de cuáles de ellas reconocen carecer. En segundo lugar, este trabajo trata de comprender de forma específica los procesos de dirección tanto de mujeres que desempeñan cargos de gestión en la Universidad como de aquellas que concretamente se encuentran al frente de Departamentos Universitarios. Para ello, hemos indagado en los estilos o tendencias de liderazgo que presentaban nuestras directivas ante diferentes situaciones propias de su gestión. Además, hemos contrastado esta información con la obtenida a través de la consulta a otros miembros de la comunidad universitaria (profesores, PAS, alumnos). Por último, se aborda cuál es la contribución que estas mujeres responsables de unidades organizativas universitarias ofrecen a sus instituciones y si dichas contribuciones promueven cambios en las mismas.

Para dar respuesta a estas cuestiones este libro se estructura en cinco capítulos. El primer capítulo aborda en una primera parte una descripción de la evolución de la Universidad como institución y las transformaciones recientes, vinculadas a las demandas sociales a las que debe responder. En una segunda parte se presenta el papel de la mujer en la Universidad actual a partir de la revisión bibliográfica y de investigaciones sobre el tema.

El segundo capítulo presenta diversas concepciones sobre el liderazgo y somete a discusión los planteamientos tradicionales acerca de las relaciones entre género y estilos de liderazgo.

El tercer y cuarto capítulos se dedican a la presentación del trabajo empírico ${ }^{1}$ que profundiza en los objetivos que nos habíamos propuesto. En el primero de ellos, se presenta una descripción de las características personales y de algunas circunstancias biográ-

1 En el marco de la investigación: M. Sánchez Moreno (dir.) (2003-2006), La mujer en la dirección y gestión de las organizaciones universitarias: problemática, estilos de liderazgo y contribución al desarrollo institucional, Ministerio de Trabajo y Asuntos Sociales. Instituto de la Mujer, Dirección General de Investigación, Convocatoria de proyectos de I+D+I. Equipo de investigación: Mariana Altopiedi, Elena Hernández de la Torre, José Manuel Lavié Martínez, Julián López Yáñez, Cristina Mayor Ruiz, Paulino Murillo Estepa. 
ficas de las mujeres que desempeñan cargos de responsabilidad en la Universidad española en la actualidad que aparecen como relevantes en la incorporación a los mismos y en la definición de su desempeño. El cuarto capítulo se adentra en analizar los procesos de dirección desarrollados por estas mujeres y, además, procura dar cuenta del modo en el que las circunstancias de sus organizaciones influyeron sobre ellos, así como también de las bases o modalidades de ejercicio de poder sobre las que levantaron su liderazgo.

Por último, el capítulo quinto se dedica a la síntesis de los resultados obtenidos en el estudio así como a presentar, a la luz de los conocimientos adquiridos derivados de nuestro trabajo en el análisis y comprensión del liderazgo ejercido por mujeres responsables de la gestión universitaria, algunas propuestas que puedan servir para orientar futuras líneas de trabajo, dirigidas a la mejora de la gestión en las instituciones universitarias.

En definitiva, este trabajo pretende ser una aportación a los estudios de género y gestión que buscan identificar nuevos modelos y estilos de dirección que hagan más confortable, armoniosa y sostenible la vida en el seno de las organizaciones universitarias. Los resultados obtenidos en el estudio nos proporcionan un conocimiento más exhaustivo acerca de las dinámicas que acontecen en el marco de los cargos de gestión en las Universidades españolas ostentados por mujeres. También nos muestran la flexibilidad y diversidad de prácticas y de modalidades del ejercicio de la influencia de las directivas universitarias. Esperamos, además, que este trabajo sirva para dibujar algunas ideas básicas sobre las que trabajar en el diseño de programas de formación en la gestión de la Universidad.

Tras una detenida lectura del texto pensamos que es legítimo preguntarse si el liderazgo ejercido por mujeres se acopla de manera especial a las condiciones particulares de las organizaciones universitarias, en especial de sus Departamentos. Condiciones que en la actualidad están afectadas por el desacople entre la estructura formal y la social, por fuertes tensiones políticas y por un elevado nivel de incertidumbre. 
Aunque somos conscientes de la sensibilidad que todos estos temas despiertan en el seno de la comunidad universitaria, queremos explícitamente expresar nuestro más sincero agradecimiento a todas aquellas mujeres gestoras universitarias participantes en este estudio por su disponibilidad y receptividad ante las diferentes peticiones que les formulamos. Sin su generosa y desinteresada colaboración este trabajo no hubiera podido realizarse.

Marita SÁNCHez MoREno 


\title{
CAPÍTULO 1 LA UNIVERSIDAD ACTUAL Y LAS MUJERES: ALGUNAS PARADOJAS
}

\author{
Mariana Altopiedi
}

\subsection{Introducción}

La investigación y la teoría sobre las organizaciones educativas han estado ensayando, en las últimas décadas, nuevos conceptos y visiones que, por un lado, muestren la especificidad de estas dentro del marco general de las organizaciones sociales y, por el otro, ayuden a configurar un marco adecuado para la acción organizativa en cualquiera de sus modalidades: la acción directiva, la innovación, la evaluación, la planificación, la coordinación, etcétera. La Universidad, en tanto que organización educativa, ha quedado, como en otras ocasiones, al margen de este esfuerzo teórico de clarificación y de análisis.

Pese a que lo antedicho puede resultar evidente, no lo son tanto las razones de que así ocurra. Probablemente, destaque entre estas la dificultad de los investigadores para pensar sobre una realidad en la que, por lo general, se hallan inmersos. Otra causa puede situarse, en nuestra opinión, en las rápidas transformaciones sufridas por las organizaciones universitarias en los últimos tiempos, que tienden a ocultar o diluir las continuidades en su desarrollo. En este sentido, el hincapié en los aspectos novedosos conduce a perder de vista los procesos que les han dado origen o, en todo caso, han sido condición de su posibilidad.

Desde la perspectiva institucional que aquí adoptamos, por el contrario, entendemos que el análisis situacional de toda organización requiere cierta comprensión de la evolución histórica de la ins- 
titución que en ella se concreta. Este es el sentido de realizar un rastreo en el devenir de la Universidad que permita identificar tanto cambios en su dinámica y su funcionamiento como ciertas continuidades identificables —incluso, en algunos casos- desde sus orígenes. Se trata, por tanto, de una tarea cercana a la del análisis genealógico de Foucault o a la deconstrucción derridiana, orientada a la identificación de los procesos históricos de elaboración de algunas concepciones y saberes hoy aceptados.

Desde este punto de vista, pretendemos poner en cuestión, en alguna medida, una idea ampliamente aceptada en torno a la situación actual de la Universidad y de su relación con el entorno. Nos referimos a una supuesta e indiscutida resistencia de la institución universitaria —en realidad, lo mismo sería más o menos aplicable al conjunto del sistema educativo - al cambio, que se manifestaría, entre otras cosas, en la resistencia a la incorporación de las mujeres a ella, al menos en condiciones de igualdad en relación con los varones. Esta difundida idea es complementaria de otra sobre la que no nos detendremos demasiado, aunque pueda considerarse también susceptible de revisión: la de que las rápidas transformaciones sociales de los últimos años exigen transformaciones en las prácticas tanto organizativas como educativas.

A primera vista, resulta obvia la relación entre ambas cuestiones. Es evidente que el entorno ha sufrido modificaciones marcadas y relativamente repentinas, en relación con las cuales la Universidad parece no haber sabido posicionarse de una manera que le permita responder a las demandas que se le formulan. Paralelamente, ha ido ganando espacio la idea de que las organizaciones más capaces de proporcionar eficientemente el servicio para el cual han sido diseñadas son las que manifiestan una mayor disponibilidad para adaptarse a los cambios que se producen en su entorno y para dar respuestas creativas ante ellos.

Aunque esta visión pueda considerarse discutible, en la situación actual se vuelve insoslayable replantear nuestra concepción sobre las organizaciones educativas -en particular, las universitarias. Esto implica, en buena medida, modificar nuestros esquemas mentales y nuestras teorías para analizarlas y para actuar en ellas. 
En términos generales, la estructura va perdiendo relevancia en nuestras interpretaciones del funcionamiento organizativo, al tiempo que el tejido social la va ganando. En vez de pensar las organizaciones como conjuntos de reglas y roles bien estructurados, cada vez más las pensamos como grupos sociales cohesionados en torno a una red particular de relaciones, un sistema de valores y una dinámica social que se va conformando a lo largo de complejos procesos históricos. Nuestra mirada sobre las organizaciones es cada vez menos reduccionista y cada vez más trata de captar su complejidad interna y la complejidad de sus interacciones con el entorno.

Asimismo, en este marco y por diversos motivos, ha ido calando la idea de que, en la actualidad, las organizaciones -en particular, las universitarias - requieren nuevos roles por parte de los directivos y gestores, así como nuevos enfoques de la acción que estos desarrollan. Esta opinión se asienta en que sus características particulares reclaman liderazgos sofisticados en los que el ejercicio de la autoridad o de la gestión burocrática resulta a todas luces insuficiente (Nidiffer, 2001; Fullan, 2002). La imagen de gestor eficaz se ve cada vez más inadecuada para la dirección de las organizaciones de nuestra modernidad tardía.

Ante la creciente complejidad interna y externa de las Universidades, a sus directivos les compete la obligación intelectual de comprender el contexto sobre el que actúan, sobre el que desarrollan la acción directiva, así como a la propia organización en tanto que construcción histórica y social. Sin ese entendimiento su actuación discurrirá, en cierto modo, ciega, y correrá el riesgo de comprometer la labor, el desarrollo, la paz o la felicidad de quienes trabajan y viven en el mismo contexto. Sin esa comprensión, y sin la capacidad de análisis necesaria para generarla, cualquier proceso de cambio o de desarrollo de la institución se verá comprometido, si no colapsado, por fuerzas desconocidas o no adecuadamente valoradas. Una vez garantizada su capacidad para analizar y comprender la complejidad de la vida institucional, los directivos necesitan adoptar nuevos roles para ejercer una verdadera influencia sobre los procesos de transformación de las instituciones. 
Las ideas precedentes han dado pie al interés por las aportaciones que diversos modos de ejercicio de las funciones directivas pueden realizar al funcionamiento de las organizaciones. Entre las cuestiones en boga se halla la definición de un supuesto estilo propio de las mujeres para desempeñar las labores de gestión y de dirección, que se perfila como deseable. Paradójicamente, sin embargo, la incorporación efectiva de mujeres en funciones de responsabilidad y de toma de decisiones es aún limitada. Dado que el reconocimiento de esta realidad es algo extendido, no nos interesa limitarnos a ponerlo en evidencia sino avanzar en la presentación de algunas ideas dirigidas a promover la reflexión acerca de las condiciones que conducen a esta situación. Esto es lo que procuramos a lo largo de este capítulo.

\subsection{La Universidad actual: continuidades históricas y rupturas}

A primera vista, resulta indiscutible que las Universidades españolas han experimentado, en los últimos años, importantes transformaciones estructurales, en paralelo a un aumento significativo de su producción científica y a una mayor proyección internacional de sus investigadores y equipos de investigación. Este incremento cuantitativo de la investigación científica y tecnológica, así como su mejora cualitativa en términos de rigor, innovación y vinculación con líneas y programas de investigación internacionales de primera línea, ha sido una de las piedras angulares del evidente cambio de las organizaciones universitarias españolas. En cambio, no han sido preocupaciones prioritarias ni la atención a los procesos de formación didáctica de los profesores ni el estudio de los procesos organizativos desarrollados en el marco de la institución. Esto constituye, desde el punto de vista de la investigación en el campo de las organizaciones educativas, una carencia importante que parece necesario subsanar. Entendemos, sin embargo, que esta desatención no es meramente casual ni producto de un «olvido» circunstancial. Por el contrario, se asienta en una larga tradición en el ámbito de la educación universitaria, que es, en todo caso, reactivada por las transformaciones registradas en los últimos tiempos. Tal como 
anunciáramos en la introducción y como pretendemos mostrar a lo largo de este capítulo, entendemos que la actual configuración de la Universidad encuentra sus raíces tanto en los orígenes de la misma como en las diversas circunstancias que han influido en su devenir, en el transcurso de la historia. Partimos, por tanto, de una visión descriptiva de los rasgos asumidos por la organización universitaria en nuestro medio, con objeto de rastrearlos en sus antecedentes y pensar en sus posibles desarrollos futuros. Esta discriminación es, sin embargo, artificial y, por lo tanto, veremos aparecer explicaciones de corte histórico imbricadas en la descripción de la organización universitaria, así como elementos actuales que permitan identificar la permanencia de rasgos originarios de la misma.

\subsubsection{La Universidad en el momento actual:} una aproximación fenomenológica

En reiteradas ocasiones ya, hemos aludido a las modificaciones sufridas por el entorno de las organizaciones universitarias, así como a las respuestas de estas. Es hora, pues, de precisar a cuáles aludimos.

En relación con los tópicos que aquí abordamos, importa atender a las transformaciones asociadas a los profundos cambios económicos, sociales, políticos y culturales experimentados por las sociedades modernas en la era de la globalización, así como a la incidencia del uso masivo de las nuevas tecnologías de la información y de la comunicación que tiende a promover una modificación en las propuestas formativas de las Universidades, así como de las planteadas por otras instituciones de formación que pasan, en alguna medida, a competir con ellas como distribuidoras de conocimientos especializados.

Con respecto al primer grupo de cambios mencionados, destacan las exigencias relativas a la ampliación de la matrícula universitaria, con la consecuente diversificación en el perfil de la misma y de las exigencias que estas diferencias plantean, tanto a causa de las divergencias en los niveles de formación con que los estudiantes llegan a la Universidad como de la variedad de sus 
demandas, derivadas de sus distintas aspiraciones profesionales y laborales. La importancia de estas cuestiones queda reflejada en afirmaciones como la realizada por Tiana en 1998 (p. 177): «Buena parte de los problemas que afronta la Universidad española a mediados de los noventa derivan de su espectacular crecimiento en las últimas décadas».

Tan taxativa aseveración se apoya en evidencias como la del exponencial crecimiento registrado por la matrícula de las Universidades españolas, a partir de la década de 1960, que lleva a que, a mediados de los años 90, la tasa de asistencia a programas de educación superior en España supere a la de los países de la OCDE (Luxán, 1998). Por supuesto, este período de rápido crecimiento solo puede ser entendido a partir de contemplar sus antecedentes, en particular, el lapso de estancamiento de la matrícula universitaria española que lo precedió.

En cualquier caso, es evidente que supone el reemplazo de un modelo tradicional de Universidad por otro masificado. Es este modelo de Universidad de masas el que puede considerarse en crisis como consecuencia de la sobrecarga de demandas que, en ocasiones, resultan contradictorias entre sí.

Como se desprende de lo antedicho y pese a que las peculiaridades de nuestro contexto les imprimen sesgos característicos, los fenómenos señalados no son exclusivos del mismo. Con distintas intensidad y particularidades, estos cambios se aprecian en las Universidades de casi todo el mundo e, incluso, muestran ciertas características similares en toda Europa occidental.

Así, en relación con este ámbito y hace ya una década, Guy Neave (1997) identificaba tres factores como determinantes en la definición de la evolución que habría de seguir la educación superior. Eran los siguientes:

- la rápida y marcada expansión del número de estudiantes;

- el proceso de integración económica y política de la Unión Europea;

- la insuficiencia de los fondos públicos para el sostén de esa etapa del sistema educativo. 
Pese a que el análisis de este último factor excede, en buena medida, el interés de un estudio preocupado por la dimensión organizativa, importa señalar su carácter paradójico en relación con los otros dos, así como su condición de derivado de ellos. En este sentido, parece evidente que la disminución relativa de los recursos - económicos y de toda índole- destinados a la educación universitaria tiene su origen en la enorme ampliación de las demandas planteadas en relación con estos por el incremento de la matrícula, así como en aquellas otras derivadas de la búsqueda de medidas comunes con las que dar respuesta a situaciones que no se circunscriben solo al espacio europeo.

Aun insistiendo en la necesidad de no perder de vista esta cuestión, su consideración no nos resulta prioritaria en tanto solo guarda una relación tangencial con uno de los aspectos básicos que aquí nos planteamos: la presencia de las mujeres en la Universidad. Por el contrario, los otros dos factores de cambio indicados por Neave resultan de mayor relevancia en relación con nuestro ámbito de estudio, por lo que reparamos centralmente en ellos.

En relación con el primero, es evidente que la fuerte ampliación del número de estudiantes se ha visto acompañada de una marcada feminización de la matrícula, al menos en la mayor parte de las carreras universitarias. Este fenómeno es, en cierta medida, paralelo a otro, que Neave contempla como una de las consecuencias del incremento de la población estudiantil: la pérdida de la relativa homogeneidad de la edad de quienes forman parte de ella. A esta cuestión hace referencia el autor al aludir a una de las «unidades de la Universidad clásica» que han encontrado su final en la masificación de la incorporación a esta organización educativa.

Las otras dos «unidades» que considera perdidas son la de la duración de los estudios y la de la del lugar en el que se desarrollan. Evidentemente, la modificación de estas características puede ponerse en relación no solo - como lo hace Neave- con el aumento de la población estudiantil sino también con la incorporación de otros modelos de enseñanza —en particular, los que se apoyan en el empleo de las tecnologías de la información y la comunicación y, en el caso de la última, al incremento de la movilidad geográfica esti- 
mulado, entre otros, por factores tan disímiles como los discursos que enfatizan el valor de la flexibilidad como característica humana coherente con el modelo productivo imperante y la consolidación del Espacio Europeo de Educación Superior.

Pese a su indiscutible importancia en la configuración de las organizaciones universitarias actuales, no nos detendremos en la valoración de este último aspecto. Más interesante para nuestros fines resulta considerar algunas de las cuestiones que se asocian a los otros dos.

A primera vista, no parece caber duda de la vinculación existente entre la reducción de la duración de buena parte de las carreras universitarias - dando lugar a nuevas titulaciones de orientación profesional/laboral- y algunos factores contextuales relevantes. Entre ellos, importa destacar tanto las desiguales aspiraciones, intereses, necesidades y capacidades de un alumnado heterogéneo, como las presiones de sectores privados a favor de una formación ligada al ámbito ocupacional de los futuros graduados.

Desde este punto de vista, la diversificación de la oferta formativa puede verse como manifestación de una tendencia de larga data hacia la profesionalización de los estudios universitarios, alejándolos de la orientación puramente académica de sus orígenes medievales. Pese a que esta creciente disposición hacia la propuesta de estudios de duración relativamente corta y dirigidos a satisfacer las demandas de ciertos sectores del mercado de empleo supone indudables ventajas - tanto a nivel social como de orden individual- no puede soslayarse que tiende a dar lugar a la creación de un circuito formativo menos prestigiado. Esto podría producir cierta segmentación de la oferta formativa de nivel superior, en la que se diferenciaría un circuito de élite y de elevado prestigio, tendente a la producción de conocimiento - en particular, relativo a las ciencias puras- y uno estrictamente dirigido a la difusión de la selección de saberes propios de cada campo profesional, generalmente, de menor duración y orientado a la incorporación de sus usuarios al mercado laboral en puestos de menor jerarquía.

Como puede apreciarse, el fenómeno aludido ofrecería cierta similitud con lo acaecido en algunos campos de conocimiento aso- 
ciados a la definición tradicional de los roles y características femeninos. La incorporación masiva de las mujeres en muchos de ellos - como ocurre en muchas Ciencias Sociales, en la formación para la docencia o en la Enfermería - fue paralela a la pérdida de su interés para el resto del estudiantado, en buena medida, por la reducción del valor - tanto económico como simbólico- de las titulaciones a las que daban acceso.

Uno y otro de los fenómenos mencionados ponen en evidencia una de los desafíos más relevantes que se plantean a la Universidad, el de conjugar su papel como institución de excelencia y su condición masificada. En relación con esta cuestión, y pese a las dificultades teóricas y técnicas de valorar el rendimiento académico, algunas cifras alcanzan para señalar la complejidad de hacer frente a tal contraposición. Así, según datos recopilados por Luxán (1998: 275) para el curso académico 1994-1995, «en los estudios de ciclo largo solo un $37 \%$ de los alumnos de su promoción cumple con éxito los requisitos mínimos de los programas docentes». En el caso de los estudios de ciclo corto, según la misma fuente y para el mismo periodo, la trayectoria exitosa es lograda por el 53,5\% de los estudiantes.

Por otra parte, la contrapartida del señalado proceso de contracción de la duración de las carreras universitarias de grado lo representa, obviamente, la ampliación de la oferta de la formación de postgrado. Este fenómeno, junto con el aumento de la importancia de otras instancias formativas - como las ligadas a los propios centros de trabajo - incide en una creciente diversificación de las agencias encargadas de distribuir conocimiento. Esto pone en cuestión, evidentemente, el papel socialmente asignado a la Universidad como institución encargada de distribuir el conocimiento científico y profesional. Puede, inclusive, llegar a cuestionar su, hasta el momento, indudable hegemonía como productora de este conocimiento, en tanto casi exclusiva responsable de las actividades de investigación.

Aún otro factor puede citarse como interviniente en una similar dirección de cuestionamiento a la Universidad: el incremento de los mecanismos de control legitimados para valorar la calidad de su acción y de sus productos, como sea que esta se defina. En este sen- 
tido, no parece necesario señalar que la generalizada creación de agencias de control y de supervisión supone - al margen de las valoraciones que puedan realizarse tanto sobre la legitimidad de su actuación como acerca de la validez de los mecanismos de evaluación empleados - una importante reducción de la autonomía institucional de la Universidad. Lo paradójico es que este avance de otras instancias sobre el aspecto que puede considerarse más representativo de la identidad de la institución universitaria tiene su correlato en una creciente presión hacia el logro de su autonomía en otros ámbitos, tales como el de su financiamiento.

Se delinea así una marcada tensión entre los discursos que propugnan exigencias de autonomía y de autorregulación y la explícita extensión de los mecanismos de rendición de cuentas. En este marco discursivo, el papel de las administraciones centrales — que hasta no hace mucho tiempo era el de controlar las ofertas formativas y el de asegurar la distribución de los recursos necesarios para llevarlas adelante - ha pasado a ser el de coordinar las iniciativas más o menos libres de las propias organizaciones. Como señala Neave (1997), esto no solo supone una redefinición de las responsabilidades de la administración sino también una marcada desinversión por parte de la misma, en la educación superior. Con el argumento de una devolución de parte de esa responsabilidad a cada organización universitaria, se legitima el recorte de fondos públicos destinados al sostén de esta etapa del sistema educativo y una paralela ampliación de la intervención de mecanismos competitivos - propios de la lógica de mercado - en la distribución de aquellos dedicados a la investigación.

Como consecuencia, las responsabilidades y la carga de trabajo del personal académico de las Universidades se diversifica, pasando a incluir tareas orientadas a la búsqueda de financiamiento para la actividad investigadora. Este, por otra parte, suele limitarse a las acciones a corto plazo y cuyos resultados resulten fácilmente cuantificables corriéndose así el riesgo de dejar relegada la producción académica a largo plazo.

Por supuesto, la situación a la que aludimos varía de manera notoria en función del área de conocimiento en cuestión y de los 
mecanismos que cada organización articule para dar respuesta al señalado incremento de las tareas administrativas a su cargo. En cualquier caso, ha dado lugar a la hipertrofia de las funciones de corte administrativo, gerencial y de gestión que deben absorber las organizaciones universitarias.

En algunas de ellas, esto se traduce en la ampliación del personal administrativo de la organización. Consecuentemente, como subraya Neave (1997), se produce la paradójica situación en la que, para librarse de la burocracia estatal, las Universidades se ven forzadas a reproducir en su interior este tipo de estructura. En otras ocasiones, simplemente, el trabajo de gestión se agrega al que ya realizaba el personal — tanto administrativo como académico- de la organización universitaria, obstaculizando la proclamada búsqueda de eficiencia y de incremento del rendimiento del mismo.

Estas modificaciones introducidas en el funcionamiento de las organizaciones universitarias son, en buena medida, las que han dado pie a la extensión de los discursos en torno del papel gerencial de sus directivos así como al relativo ocultamiento de otros aspectos de su función que, tal como hemos anticipado, son, a nuestro juicio, más importantes en el caso particular de organizaciones educativas como las Universidades.

Tal como plantean distintos autores especializados en el análisis de la situación universitaria (Luxán, 1998; Marcelo y Estabaranz, 2002), a las dos grandes paradojas señaladas —la de la masificación con reducción de los apoyos de toda suerte y la de la demanda de autonomía en un marco de incremento del control externo- se agregan algunas otras que nos interesa considerar. Son, a grandes rasgos, las siguientes:

- La ya mencionada contradicción entre las demandas por el mantenimiento de un modelo universitario de excelencia - generalmente, entendida en términos de manifestaciones cuantitativas del rendimiento académico- que sea, a la vez, de masas.

- La coexistencia de la tendencia a la masificación con la operación de ciertos mecanismos de exclusión que se evidencia, por ejemplo, en la escasa participación de las mujeres en 
algunos campos científicos y, en términos generales, en los cargos de responsabilidad tanto académica como de gestión. En relación con este punto, sorprende la convivencia de discursos que valoran la posible aportación de la incorporación de colectivos poco representados en las organizaciones universitarias - en particular, del de las mujeres- con las mencionadas dificultades para su efectiva participación en ellas.

- La contraposición entre las demandas de internacionalización —encarnadas, por ejemplo, en la adscripción al llamado Espacio Europeo- y la necesaria contextualización de la labor universitaria.

- La contradicción entre el papel de las investigaciones científicas llevadas a cabo en las Universidades como origen de las tecnologías de la información y de la comunicación, y el escaso empleo de las mismas en el ámbito de la formación universitaria.

- La oposición entre los discursos que promueven la apertura y la flexibilización de la formación universitaria y la rigidez de la organización del tiempo de trabajo del profesorado, a corto plazo.

- La tensión entre las demandas de una formación universitaria amplia, general y, en cierta medida, polivalente y las exigencias de especialización de la misma.

- El contraste - relacionado con la oposición mencionada en el punto anterior- entre la condición «terminal» de la formación superior, orientada al empleo, y el cada vez más extendido requerimiento de continuar la formación a lo largo de la vida.

- La contradicción entre el aparentemente escaso interés del conjunto de la sociedad en la Universidad y su funcionamiento, y las expectativas - tanto respecto de su papel en la producción de conocimiento como en el de distribución del mismo- que en ella se depositan.

En nuestra opinión, por otra parte, estas paradojas planteadas en relación con la Universidad no son ajenas a algunas que afectan a la institución educativa en su conjunto. Entre ellas, cabe destacar: 
- La necesidad de compatibilizar el cumplimiento del mandato institucional - transmitir un bagaje cultural considerado universalmente valioso- con las exigencias de respetar la heterogeneidad cultural, étnica y social.

- La relativa deslegitimación del recorte del conocimiento socialmente acumulado que transmite, en tanto que su incorporación ya no garantiza la inclusión social ni la participación en el mercado de trabajo.

- La contraposición entre los valores del esfuerzo implícitos en las propuestas educativas y cuya renuncia implicaría abandonar una característica ideológica central de la institución educativa como la conocemos, y la ética de la satisfacción personal y el «facilismo» (Tedesco, 1995:132) vigente en la sociedad actual.

Todas estas paradojas se derivan, de acuerdo con la argumentación que pretendemos exponer, de la confluencia entre una serie de rasgos identitarios que caracterizan a la institución considerada y las condiciones que en la actualidad enfrentan las organizaciones en las que esta se concreta.

De manera similar, entendemos que las respuestas que articulan las organizaciones a los múltiples cambios y paradojas subrayados hasta aquí — diversas entre sí, huelga decirlo- están condicionadas por las particularidades de cada una de ellas. Presentan, sin embargo, algunas regularidades que pueden ponerse en relación con las aludidas características institucionales. El origen de las mismas puede, en ocasiones, rastrearse incluso en sus momentos fundacionales. En otros casos, cabe reconocer que se han ido configurando de manera progresiva en el devenir institucional. A continuación, describimos algunos de los más importantes de estos rasgos para, posteriormente, ponerlos en relación con algunos aspectos centrales de la historia de la institución universitaria, en general, y de su concreción en nuestro ámbito geográfico, en particular.

En una primera aproximación, para caracterizar a las organizaciones universitarias resulta útil apelar a un concepto propuesto por Weick (1976), el de estructura débilmente acoplada o articulada. Mediante este constructo se describe la particular manera de cier- 
tas organizaciones de usar su estructura y sus funciones organizativas para integrar sus unidades y para garantizar un funcionamiento coherente de las mismas. La característica que las define es la ausencia de estructuras estrictamente lineales de carácter jerárquico notable, que ocasionen que cada unidad dependa de una sola dirección y aseguren el amplio predominio de la comunicación vertical.

Como puede apreciarse en la siguiente enumeración, en la Universidad tal como la conocemos, se verifican — como señalaran López y Sánchez (1994) — todas y cada una de las características que Weick advertía en las estructuras débilmente acopladas:

\section{a) Autonomía de las unidades funcionales}

La marcada autonomía de los Departamentos —en tanto unidades en las que se delegan la mayor parte de las funciones en nuestro sistema universitario- se observa tanto en la ordenación académica (estableciendo el plan docente, elaborando o modificando los planes de estudio, proponiendo nuevas materias optativas, etcétera), como en la gestión administrativa y en la del personal. Son los Departamentos universitarios los encargados de tomar decisiones que en muchas organizaciones, tanto privadas como públicas, corresponden a la dirección central. De hecho, los Departamentos poseen tal autonomía que, salvo en circunstancias excepcionales, sobre la mayoría de sus ámbitos de decisión no interfieren las unidades de la estructura jerárquica superior, como la Facultad, ni sus órganos directivos (equipo decanal) y representativos (Junta de Facultad). Por el contrario, tienden a estructurarse campos de decisión independientes.

\section{b) Ambigüedad de metas}

Evidentemente, la diversidad en todos los sentidos es una cualidad consustancial a cualquier comunidad humana, pero lo que resulta característico de la Universidad es que la autonomía de sus unidades y el carácter funcional de su estructura prestan legitimidad a prácticamente cualquier punto de vista, toma de posición, línea de actuación o de conducta — siempre, por supuesto, dentro del 
marco de su estructura y del respeto de sus normas. Podríamos decir que predomina aquí la tendencia centrífuga frente a la tendencia centrípeta; la disgregación frente al predominio de la cohesión y el funcionamiento integrado característico de otras organizaciones.

c) Ausencia de mecanismos efectivos de control

Como en otros aspectos organizativos, en el de los mecanismos de control se da una alianza entre una estructura organizativa poco preocupada por desarrollar mecanismos efectivos de control, con unas pautas culturales que acaban por consagrar dicha ausencia de control y por mantener la vida académica lo más alejada posible de «miradas molestas».

En buena medida como corolario de estos rasgos que caracterizan su funcionamiento, las organizaciones universitarias adquieren otros, relativos al estilo que define las que consideramos estructuras básicas de toda organización, producto de su relación con un entorno del que tienden a diferenciarse: la cultura y el poder.

\section{d) Los Departamentos como culturas balcanizadas}

Cuando las estructuras están débilmente acopladas, la cultura institucional es, generalmente, la que ocupa el lugar de elemento de cohesión de la organización, asegurando la imprescindible integración de sus elementos (López Yáñez y Sánchez Moreno, 1997). La cultura es un sistema socialmente construido de creencias, valores, modos de interpretar y percibir la realidad y de normas que identifican a los miembros de un grupo. En definitiva, es un conjunto de significados que ese grupo comparte. A lo largo de su historia, todo grupo u organización construye una cultura que, en mayor o menor medida, orienta las acciones, define los problemas y guía las posibles soluciones a los mismos. A fin de asegurar su mantenimiento, los nuevos miembros que se incorporan a la organización son socializados para que sigan ese marco de pensamiento y de esquemas de conducta, a cambio de los beneficios de su integración en el grupo.

En el caso de la institución universitaria es fácilmente apreciable que una de las características centrales de la cultura es la ausencia de una visión sobre la misma que pueda considerarse 
homogénea y compartida por el conjunto de la organización. Obviamente, esto se halla en relación con que su funcionamiento está atravesado por los intereses profesionales y corporativos de sus docentes, por las pugnas que se establecen entre campos de conocimientos y disciplinas más o menos afines, etcétera. Todo esto disminuye, obviamente, su cohesión al tiempo que amplia los márgenes de negociación y de posible conflictividad.

\section{e) La Universidad como arena política}

El amplio margen de autonomía, el débil acoplamiento de la estructura y su carácter eminentemente funcional desplazan importantes cuotas de poder hacia las unidades básicas, en nuestras Universidades, los Departamentos. Estos gestionan y administran este poder, adoptando configuraciones diversas en las que se aprecia la incidencia de las decisiones tomadas por quienes participan en los procesos de dirección que tienen lugar en ellos.

Como hemos anticipado, desde nuestro punto de vista, estos rasgos de la Universidad y las diversas configuraciones que adoptan en cada organización particular solo pueden entenderse tomando en consideración la historia de la institución en cuestión y los avatares de la misma en cada contexto particular. Por tal motivo, en el siguiente apartado, esbozamos algunas reflexiones en torno de las diversas características institucionales aludidas a lo largo de esta presentación, en relación con su origen.

\subsubsection{La Universidad en el momento actual: una aproximación histórica}

Dado que no pretendemos realizar aquí una exposición de la historia de la Universidad, sino comentar algunos aspectos de la misma que vemos más claramente relacionados con las características institucionales que hoy nos muestra, nos centraremos en la reflexión sobre algunos de los rasgos a los que hemos aludido anteriormente. En primer término, y a causa de la relevancia que desde nuestro punto de vista adquiere, nos referimos a la autonomía como particularidad de nuestras Universidades. 
Pese a las discrepancias que se plantean entre los especialistas en relación con la fundación de las primeras Universidades reconocidas como tales (Neave, 1997), resulta indiscutible que el origen de esta institución se halla en la progresiva cristalización de grupos -inicialmente, aglutinados por un interés compartido pero escasamente estructurados- dedicados a la conservación del conocimiento erudito durante la Edad Media. Como señala el ya mencionado Neave, la conformación de las Universidades dio lugar a la configuración de una tercera forma de poder - la organizada en derredor del conocimiento- que coexisten con las dos hegemónicas: la trascendente, encarnada por el Papado, y la temporal.

$\mathrm{Su}$ constitución como poder, en cierta medida, paralelo a los entonces vigentes puede verse en la base de la actual desvinculación entre Universidad y sociedad, que subrayan algunos autores. Este virtual desinterés mutuo puede percibirse tanto en la escasez de apoyos que la sociedad presta a una organización encargada de satisfacer importantes necesidades colectivas —como la producción y la distribución del saber erudito y la capacitación profesionalcomo en el marcado grado de autonomía que la Universidad reserva para sí, frente al conjunto (Montserrat, 1998).

De similar manera, cabe entender la relativa demora en la institucionalización del funcionamiento de las Universidades como un antecedente en el que se asienta su peculiar tendencia a la primacía de los aspectos culturales sobre los estructurales o de orden formal.

Obviamente, resultaría fácil tachar de reduccionista nuestra argumentación si nos limitásemos a afirmar que la causa de la relativa separación entre Universidad y sociedad se halla, exclusivamente, en la matriz fundacional de la primera. Sin embargo, entendemos totalmente legítima la consideración de esta no solo como base en la que se asienta una serie de hechos posteriores sino también como un núcleo de significados en torno al cual se ordenan otros muchos que son constitutivos de la identidad institucional.

$\mathrm{Si}$, en lugar de remontarnos a los orígenes institucionales, pensamos en la historia reciente de nuestra sociedad y de su relación con la Universidad, cabe destacar que en el texto del artículo 27.10 de la 
Constitución de 1978: «Se reconoce la autonomía de las Universidades». Si nos atenemos a los términos del mismo, no se les concede ni atribuye tal característica, sino que se la acepta como dada.

Como nos muestra Souviron (1998), por otra parte, el significado - y, en consecuencia, el alcance- de la idea de autonomía es referencial y relativo. Alude a la capacidad de la institución universitaria de disponer sobre sí, en contraposición a otros poderes que pudieran pretender condicionarla. Al mismo tiempo, depende de las condiciones sociales, culturales y políticas, así como de las costumbres y tradiciones del contexto.

En nuestro caso, es evidente que la consagración de la autonomía universitaria en la Constitución adquiere sentido en contraste con la constricción de esta durante el periodo que precedió a la sanción de la misma.

Se da por supuesto que, en todos los casos, la autonomía institucional solo es legítima en tanto su empleo se dirija al logro de los fines y funciones que se le asignan. Estos, en el caso de la Universidad, no son unívocos. Abarcan, al menos, tres campos que, sin ser por completo independientes, son claramente disímiles. Nos referimos a la investigación, la docencia y la gestión. En relación con cada uno de estos ámbitos, toman forma tensiones que, con finalidad analítica, pueden describirse como establecidas entre dos polos.

En el caso de la investigación, la contraposición se plantea entre la dedicación prioritaria a la investigación básica o a la aplicada, susceptible de obtener recursos provenientes del sistema productivo, a la vez que de repercutir directamente tanto en este como en el conjunto de la sociedad, respondiendo a algunas de sus necesidades.

Si nos referimos a la docencia, gana presencia el discurso de la calidad, generalmente considerada en abstracto y, por tanto, de tal manera que no puede ser puesta en cuestión. Nadie rechazaría la importancia de la calidad en la labor de una organización. El problema, como decíamos, está en la ambigüedad y la polisemia de este término, que acaba dando pie a la antes citada oposición entre un modelo universitario de masas y uno de cariz más elitista, que puede traducirse tanto en una confrontación de concepcio- 
nes dentro de la organización como en el establecimiento de circuitos formativos paralelos.

En el caso de la gestión, se hace indudable que debe orientarse a facilitar la concreción de los fines institucionales. Lo cual nos remite nuevamente a la discusión acerca de las cuestiones comentadas hasta aquí. En sí misma y con la excepción de los puestos más elevados de la jerarquía universitaria, la tarea de gestión se percibe como accesoria y escasamente relevante desde el punto de vista del profesorado aunque, como hemos señalado, ciertas labores de corte administrativo se hallan cada vez más presentes entre las tareas del mismo.

En cualquier caso, tal como hemos anunciado al comienzo de este capítulo, resulta innegable el predominio de la primera de estas funciones, en términos de su valoración y su prestigio. Siguiendo con la línea argumental adoptada, podríamos rastrear el origen de esta sobreestimación en el inicial papel de la Universidad como institución cerrada sobre sí y encargada de custodiar un saber inaccesible a la mayoría, más que como difusora del mismo. Se asocia, asimismo, con la anteriormente comentada tendencia a la conformación de circuitos universitarios paralelos, con fines diversos y que merecedores de distintos grados de estima. Esta preeminencia de la investigación, por otra parte, se encuentra vinculada, como pone de manifiesto Luxán (1998) con la valoración de los productos individuales — como suele considerarse a la producción intelectual- por encima de los organizativos, en el caso de las organizaciones educativas, el alumnado formado. Evidentemente, esto deriva en buena medida de la prioridad de lo individual sobre lo colectivo, propia de nuestra cultura.

Esta última cuestión pone sobre el tapete el papel de las organizaciones universitarias como espacios de visibilidad que no solo sirven a los fines del conjunto sino también a los intereses -en muchas ocasiones, contrapuestos- de los sujetos que forman parte de ellas.

Esta coexistencia de finalidades y objetivos genera indefectiblemente, como venimos exponiendo, cierto grado de confrontación, no siempre explícita ni abierta. Entre otros ámbitos de disputa se halla, evidentemente, el de la legitimidad como miembro — tanto en 
la condición de individuo como de miembro de un colectivo- de la organización. En este sentido, no resulta sorprendente que los grupos sociales tradicionalmente excluidos de la actividad académica encuentren aún alguna dificultad para insertarse en la institución universitaria.

En la actualidad y en nuestro medio, estos obstáculos no son totales ni necesariamente explícitos, como podía ocurrir en otros momentos históricos. Más bien, suelen presentarse como subrepticias restricciones al avance en la jerarquía académica o al acceso a posiciones directivas que impliquen la toma de decisiones. Un ejemplo en el que esta tendencia se aprecia con claridad es en el caso de las mujeres, en tanto colectivo originariamente excluido de la Universidad. En el siguiente apartado, avanzamos algunos datos e interpretaciones en relación con la situación de las mujeres en la Universidad, hoy.

\subsection{Las mujeres en la Universidad de hoy}

Tal como hemos comentado anteriormente, una de nuestras ideas de partida es que la Universidad española ha sufrido drásticos cambios en los últimos años, entre los que destaca la ampliación del acceso de las mujeres a los diversos estamentos organizativos. Sin embargo, esta incorporación no puede considerarse homogénea en los diversos estamentos institucionales ni pareja a la representación masculina. A lo largo de este epígrafe, se presentan datos —obtenidos tanto de la revisión bibliográfica y de diversas investigaciones sobre el tema como de la información obtenida mediante el estudio llevado a cabo por nuestro grupo de investigación- acerca de la desigual presencia de la mujer en la Universidad, en distintos papeles y cargos, al tiempo que se argumentan las interpretaciones en torno de ellos que defendemos.

\subsubsection{La mujer en los distintos niveles de la Universidad}

Si bien resulta indiscutible el rápido incremento de la inclusión de las mujeres tanto en la matrícula de estudiantes universitarios 
como en el número de docentes de esta etapa formativa, no pueden soslayarse hechos relevantes como el de que esta incorporación se aprecia especialmente en los niveles más bajos de la jerarquía académica. Asimismo, nos parece necesario comprender la progresiva feminización de la matrícula universitaria como parte del proceso de masificación de la organización. Siguiendo a Luxán (1998), el inicio del mismo en España puede establecerse en 1960. Por su parte, la completa equiparación en la composición por géneros de la población estudiantil se sitúa en 1986, cuando las mujeres superan el $50 \%$ de la misma.

Una evolución bastante paralela se da, asimismo, en otros contextos geográficos. A modo de contraste, cabe observar que también en el caso de México, es a partir de la década de 1980 cuando la proporción de hombres deja de superar a la de mujeres entre el estudiantado en el nivel de grado. En el caso de los estudios de postgrado, en cambio, en la Universidad mexicana los hombres continúan predominando — siendo el $57 \%$, en el año 2000- en la composición de la matrícula. Esta varía, de manera similar, en función del área de conocimiento de la que se trate, tanto en el caso mexicano como en el de España. Como señala Luxán (1998: 259), «por citar los extremos si un $70 \%$ del alumnado son mujeres en los estudios de Humanidades, tan solo un $25 \%$ lo son en los de carácter técnico».

La comentada concentración en el área dedicada a los estudios humanísticos es coherente con la evidente feminización del profesorado, en nuestro contexto. Sin embargo, la mayoría de las mujeres que trabajan en la enseñanza se concentran en las primeras etapas educativas y su presencia va descendiendo hasta ser claramente minoritaria en la Universidad. Así, según los datos obtenidos del Anuario Andaluz de las Mujeres 2001, en el curso 98/99 había un 32,49\% de profesoras universitarias frente a un $67,51 \%$ de profesores a nivel nacional y en Andalucía, un 30,72\% de profesoras frente a un 69,28 \% de profesores del mismo nivel de enseñanza. En la composición del alumnado universitario, en cambio, ya en 1996 la participación femenina había alcanzado un 53,1\% y, según una reciente publicación del Ministerio de Educación, en el curso 2005-2006, alcanzaba el 60,3\%. 
Los datos presentados no resultan en absoluto sorprendentes si nos aproximamos a ellos desde una perspectiva histórica. Pese a que existen datos acerca de la presencia de algunas destacadas mujeres en las aulas de las Universidades de Salamanca y Alcalá de Henares, en los siglos XV y XVI, es obvio que tenía un carácter totalmente excepcional. Esto se confirma cuando, en 1785, el reconocimiento del grado de doctora a María Isidra Guzmán de la Cerda es especialmente autorizado por Carlos III. Aún en 1845 —al menos, según señala la tradición- Concepción Arenal se vestía de hombre para asistir a la Facultad de Derecho de la Universidad de Madrid.

Será solo con la I República, en el curso 1872-73, cuando las Universidades de Barcelona, Valencia, Valladolid y la Central de Madrid (en ese orden) comiencen a aceptar mujeres entre sus estudiantes. Posteriormente, otras Universidades seguirán este ejemplo, con la excepción de la de Oviedo, que no lo hizo sino a final de siglo. A pesar de esto, según recuerda el trabajo de Flecha García (1996), las graduadas encuentran entonces dificultades para obtener su título. Inclusive, entre 1882 y 1887, a través de una Real Orden de 16 de marzo, se niega la matrícula universitaria a las mujeres.

En 1888, la Real Orden de 11 de junio ratifica, regulándolo con carácter general, el reconocimiento del derecho de las mujeres a estudiar en la Universidad. Esta normativa, sin embargo, es desconocida por muchas autoridades académicas, por lo que su aplicación resulta irregular y da lugar a la presentación de múltiples recursos legales.

Además de los obstáculos surgidos del desconocimiento legal - casual o no- las mujeres que pretendían acceder a los estudios universitarios debieron, durante bastante tiempo, lidiar con discursos dirigidos a desalentarlas. Así, según recuerda Mingo (2006), el secretario de Instrucción Pública del gobierno constitucionalista mexicano, en 1915, las exhorta de modo directo en este sentido: «no seáis universitarias, no seáis académicas».

Aunque quizás de manera menos explícita, la operación de estos discursos se trasluce también en nuestro país. Así, por ejemplo, una vez regularizada la presencia de las mujeres como estudiantes en 
las Universidades españolas, siguieron presentándose objeciones al ejercicio de las profesiones para las que se capacitaban. Especialmente, se manifestaban recelos hacia la posibilidad de que una mujer ejerciese como docente universitaria, lo que solo ocurre en 1906, con la llegada de Emilia Pardo Bazán a la Facultad de Filosofía y Letras de la Universidad Central de Madrid (Figueroa Íñiguez, 1996). Aun entonces, y pese a su ya extensa trayectoria literaria, la nueva profesora es rechazada tanto por el claustro como por el estudiantado.

Por otra parte, todavía en épocas recientes — como señala el estudio sobre las catedráticas españolas de García de Cortázar y García de León (1997) — mientras las mujeres equiparan a los hombres en la composición del alumnado, apenas alcanzaban el $30 \%$ de las plazas de profesores del curso 94/95. Además, esta proporción no muestra variación sustancial en los veinte años previos a esa fecha, a pesar de los cambios demográficos y de la aparente igualación de oportunidades de la mujer.

Es de destacar, al propio tiempo, que la representación femenina va disminuyendo a medida que se asciende en la escala jerárquica. A modo de ilustración, basta señalar que se veía limitada a $555(9,6 \%)$ en el escalafón de los catedráticos, en el mes de octubre de 1994. En el curso 98/99, esta proporción solo había ascendido hasta el 14,86\% en el ámbito nacional, mientras que en Andalucía alcanzaba el $12,75 \%$. Tampoco en la actualidad ha variado esta tendencia, lo cual se refleja en que las cátedras de las Universidades públicas están ocupadas en un $86 \%$ por hombres, siendo la representación femenina un escaso 13,9 \%. En el caso del profesorado titular, esta disparidad disminuye, siendo la presencia de mujeres en este escalafón un $36,5 \%$.

Como resultaría previsible, por otra parte, la distribución de la representación femenina no es igualitaria entre las distintas áreas de conocimiento. Las áreas de Humanidades y de Ciencias Sociales cuentan con una mayor cantidad de mujeres entre sus catedráticos, aunque su proporción solo alcanza el $21 \%$ y el $15,9 \%$, respectivamente, según los últimos datos disponibles, correspondientes al curso 2005/2006. Esta cifra muestra un interesante crecimiento si 
se considera que se situaban en el $15,9 \%$ y el $11,1 \%$, en el curso 94-95, tomado como referencia por el estudio de García de Cortázar y García de León antes mencionado.

Una interesante puntualización de estas autoras citadas es el de que la cantidad de mujeres catedráticas con que cuenta un área no se corresponde con su dimensión total. El factor más vinculado a un incremento en la representación femenina entre las catedráticas de un área determinada identificado por este estudio es el carácter «novedoso» o «no tradicional» de la misma. En cambio, aquellas más «clásicas» o que cuentan con una tradición académica más arraigada son las que parecen mostrar mayores resistencias a la incorporación de mujeres en sus cuerpos de catedráticos (García de Cortázar y García de León, 1997). En este mismo sentido, las autoras llaman la atención sobre la mayor apertura que muestran las Universidades de reciente creación a la incorporación de personal docente femenino.

Estas últimas interpretaciones corroboran, en buena medida, la perspectiva aquí adoptada, subrayando la relación entre la historia institucional y los rasgos que muestran las organizaciones que la concretan.

Pese a que los resultados globales pueden todavía valorarse como negativos en tanto aspiramos a una distribución igualitaria de los cargos jerárquicos entre los géneros, cabe reconocer - como indican García de Cortázar y García de León (1997) — una cierta aceleración de la promoción de las mujeres profesoras de Universidad. Esta tendencia se hace evidente tanto en la elevada proporción que estas representan entre el conjunto de catedráticos que obtuvieron ese cargo durante el año previo a la recolección de los datos empleados en el aludido estudio como en la variación entre las cifras que este refleja y las correspondientes al momento actual.

La desigualdad en la distribución por géneros de los reconocimientos académicos es también señalada por la investigación de Mingo (2006), desarrollada en relación a la Universidad Nacional Autónoma de México (UNAM). En ella se destaca, por ejemplo, que en la adjudicación de premios académicos otorgados por la organización desde mediados de la década de 1980 hasta el año 2000, la representación masculina rondaba entre el $69,3 \%$ y el $81 \%$, alcan- 
zando un $89 \%$ en el caso de las distinciones de eméritos. Lo llamativo, como subraya la investigadora, es que entre los reconocimientos al estudiantado, las mujeres suelen aparecer en mayor proporción que los hombres. Así, por ejemplo, el 71,5\% de quienes obtuvieron reconocimientos por haber logrado una puntuación media de 10 en el curso 1996-1997 eran mujeres.

Si buscamos avanzar en el análisis de la composición del profesorado universitario de mayor jerarquía, descubrimos que la descripción que el estudio de García de Cortázar y García de León que veníamos comentando realiza de las catedráticas españolas coincide, en buena medida, con los rasgos que investigaciones relativas a la variable de género advierten en las mujeres que alcanzan niveles elevados en la escala profesional. Otros, en cambio, resultan peculiares del ámbito estudiado.

Entre las características comunes a estas catedráticas, cabe destacar la pertenencia a grupos sociales privilegiados, así como haber atravesado situaciones vitales particulares que condicionaron su desarrollo (orfandad, problemas familiares, predominio del matriarcado en sus familias o una especial relación con el padre). A los factores de orden familiar, se agregan otros que tienden, también, a reiterarse:

— La soltería y/o no tener hijos.

- El refuerzo aportado por la posición del marido.

- Las dobles redes de poder (los vínculos propios y los del marido, por ejemplo).

- La ambigüedad en la percepción del rol femenino: la coexistencia del «síndrome de la abeja reina» y la negación de la influencia de la variable de género (por un lado, destacar como mujer en un campo de hombres y, al mismo tiempo, negar que esa variable sea relevante).

- El representar un «modelo de transición» propio de un proceso de aculturación en curso que hace de las mujeres entrevistadas «mitad profesionales/mitad amas de casa».

- El no ser feministas, llegando a posturas tan poco esperables como la de restar importancia al establecimiento de políticas de igualdad. 
- El autolimitarse en el ascenso a posiciones de poder, para cuyo ejercicio no han sido educadas y que, por tanto, les exige un sobreesfuerzo respecto del que requiere de los hombres.

Como hemos adelantado, varios de estos rasgos —en especial, los mencionados en último término- replican los encontrados en mujeres que destacan en otros campos profesionales y contextos socioculturales o geográficos. Entre ellos, en particular, la escasa valoración que estas mujeres parecen realizar del factor género como interviniente en su carrera profesional. En este sentido, la mitad de las catedráticas consultadas por García de Cortázar y García de León (1997) manifestaba haber tenido que enfrentar las mismas dificultades que sus colegas varones. El resto, en cambio, admitía la incidencia de las cargas familiares (que sí reconocían todas las consultadas cuando se les preguntaba directamente por ellas), de cierta discriminación de parte del entorno y de la falta de confianza en sus posibilidades por parte de las propias mujeres. Todos estos son —como anticipábamos- factores señalados por otras múltiples investigaciones en torno del género y de su incidencia en el desarrollo profesional (a modo de ejemplo: Aisenberg y Harrigton, 1993; Glazer-Raymo, 1999; Warren y O'Connor, 1999; Erkut, 2001; GlazerRaymo, 2003; Ropers-Huilman, 2003; Wolf-Wendel y Ward, 2003).

Si nos centramos en la participación de las mujeres en la gestión universitaria - uno de nuestros principales intereses de estudio- encontramos que los datos son igual o más llamativos que los que veníamos comentando. En términos generales, la presencia de las mujeres en los puestos de gestión en la Universidad, especialmente en los niveles jerárquicos más altos, no ha experimentado un incremento tan notable como el registrado en su incorporación al profesorado y - menos aún- al alumnado de esta etapa educativa (Heward, 1996; García de Cortázar y García de León, 1997; GlazerRaymo, 1999; Warren y O'Connor, 1999; Ropers-Huilman, 2003). Sirve de ilustración la taxativa afirmación de Mingo (2006: 15), a propósito del caso de la UNAM: «en los cargos de toma de decisiones los varones siguen predominando de manera clara».

Esta afirmación parece resultar totalmente válida, en el caso de la Universidad pública española, a juzgar por los datos disponi- 
bles. A modo de ejemplo, observamos que en el conjunto de las Universidades Andaluzas, en el año 2000, había una única rectora, once vicerrectoras, una gerente y ninguna secretaria general. Siete años más tarde, en todo el estado español, la cifra de rectoras llegaba a cuatro, de las que solo tres trabajaban en Universidades públicas. En cuanto a las vicerrectoras, en esa misma fecha, se contabilizaban 126 -es decir, un 28,9\% del total. Aún menor era la representación de las mujeres en Decanatos (16,4 \%), Direcciones de Escuelas Universitarias $(28,4 \%$ ) y Direcciones de Departamentos $(19,3 \%)$.

Como puede observarse en los datos ofrecidos, la presencia de mujeres en cargos unipersonales varía según estos sean asignados o distribuidos por elección. Como señala el propio Ministerio de Educación a través de la publicación citada, la mayor presencia de vicerrectoras puede derivarse de un deliberado intento de compensar la desigualdad en la representación de uno y otro sexo.

En relación con la participación de las mujeres en la gestión de las Universidades españolas, el estudio llevado a cabo por nuestro grupo de investigación arroja algunos datos interesantes que importa destacar. En primer término, de acuerdo con las respuestas brindadas, más de la mitad de estas mujeres $(54,4 \%)$ llevaban entre uno y cuatro años en el cargo de gestión ocupado en el momento de contestar el cuestionario. Es decir que eran relativamente novatas en ellos. Sin embargo, un $83.1 \%$ de estas mujeres habían desempeñado en alguna ocasión previa cargos de gestión en la Universidad, con una duración de entre dos y seis años (54,4\%). Los cargos que con anterioridad habían sido ocupados con mayor frecuencia eran el de secretaria de Departamento, el de directora de Departamento y el de vicedecana. Un 9,6\%, además, declaraba haber ocupado hasta un tercer cargo de gestión con anterioridad. Esta tendencia a repetir en la gestión es, desde nuestro punto de vista, un dato significativo que puede hallarse en relación con la inclinación al esfuerzo y al sacrificio frecuentemente atribuida a las mujeres.

Entre los cargos que ocupaban, predominaban la dirección de Departamentos, con un $28 \%$ de las respuestas, y los vicedecanatos, con un $22,1 \%$. También la participación de decanas, de secretarias 
de Departamentos y de directoras de grupos de investigación era significativa en el total de consultadas, con un $9,6 \%$, un $8,8 \%$ y un $6,6 \%$, respectivamente. Las vicerrectoras, por su parte, constituían el 3,7 \% de la muestra y las secretarias de Facultad, el 2,2 \%.

Otros cargos que aparecían eran los de subdirectora de escuela universitaria (5,9\%), subdirectora de Departamento (1,5\%), adjunta al jefe de estudios $(0,7 \%)$, directora de servicio de la Facultad $(1,5 \%)$ y jefe de estudios $(1,5 \%)$.

En consonancia con el enfoque adoptado en este trabajo, nos interesa ir más allá de la mera recopilación de datos para avanzar en la formulación de algunas ideas que expliquen la circunstancia aludida. Es lo que procuramos en el siguiente apartado.

\subsubsection{Las mujeres y el poder en la Universidad}

Tal como hemos anticipado en la introducción de este capítulo, creemos que la indagación sobre el acceso de las mujeres al poder en las organizaciones universitarias y acerca de las formas de ejercerlo que ellas prefieren es, en estos momentos, particularmente interesante. Y esto por varias razones. La primera es que el modelo de liderazgo tradicional -asumido mayoritariamente por hombres, en tanto han sido históricamente quienes alcanzaron puestos de dirección con mayor frecuencia- parece ser insuficiente para responder a las demandas del funcionamiento propio de las organizaciones actuales, necesitadas de mayor flexibilidad y dinamismo en sus respuestas al medio. En este sentido, conocer el modo en que las mujeres ejercen el poder - aparentemente, más adecuado a estas condiciones - puede ayudarnos a mejorar las organizaciones y su gobierno.

Otra causa importante radica, asimismo, en que la experiencia de las mujeres que se colocan al frente de las organizaciones podría ayudarnos a hacer más igualitario y más justo el acceso al poder en el marco organizativo y, por extensión, social.

Desde nuestro punto de vista, entonces, la llegada de las mujeres al poder en las organizaciones no solo es potencialmente benefi- 
ciosa para las mujeres sino también para las organizaciones y para el conjunto de la sociedad. No es solo que nos da la oportunidad de volver a pensar las formas que reviste el poder, esta vez desde una perspectiva de género, sino que, además, nos permite analizar en la práctica determinadas formas de liderazgo — aparentemente, más usuales en las mujeres- que podrían resultar más adecuadas para las organizaciones modernas, en particular para un tipo tan particular como las organizaciones educativas.

A la luz de los datos comentados en el epígrafe anterior, es evidente que el acceso a los puestos directivos en las organizaciones universitarias —en particular, a aquellos que suponen mayor responsabilidad y participación en la toma de decisiones- no es fácil para las mujeres. Aun siendo cautelosos en la realización de afirmaciones al respecto, no cabe duda de que las posibilidades de ocupar un puesto de la mayor jerarquía en la Universidad — sea de tipo académico o de gestión- son menores para una mujer que para un hombre en similares condiciones.

Este fenómeno de selección invisible - al que se alude con frecuencia mediante la metáfora del «techo de cristal» (Asplund, 1988; Tierney y Bensimon, 1996; Glazer-Raymo, 1999; Van Vianen y Fischer, 2002; Wolf-Wendel y Ward, 2003)— hace que todavía sea minoritaria la presencia femenina en los puestos más elevados en la escala jerárquica. Pero, de acuerdo con los resultados de múltiples investigaciones, las trabas que enfrentan la mayoría de las mujeres que alcanzan puestos relevantes continúan después de acceder a estos, pues una vez en dichos puestos deben trabajar más y mejor que sus homólogos masculinos para recibir un reconocimiento, generalmente, menor (Nicolson, 1997; Glazer-Raymo, 1999).

De acuerdo con algunos estudios significativos en este terreno, los funcionamientos organizativos más tradicionales — por lo regular, caracterizados por el predominio de estructuras jerarquizadas y burocratizadas - y basados en la experiencia de hombres, concuerdan especialmente mal con la forma de ver el mundo preponderante entre las mujeres (Bensimon, 1993; Calás y Smircich, 1993).

A este tipo de cuestiones, que podemos ubicar del lado de la dinámica organizativa, se añaden otras derivadas de las condiciones 
propias de las mujeres. Entre estas últimas, destaca el hecho de que ellas se permiten en mucha menor medida que los hombres mantenerse al margen de preocupaciones ajenas a la vida profesional, tales como la vida familiar y las exigencias que esta plantea (WolfWendel y Ward, 2003).

Reconocer la intervención de factores propios de la subjetividad de cada mujer en la búsqueda —o la limitación de esta- de reconocimiento formal en las organizaciones profesionales que integra no supone atribuir estos a una supuesta «condición femenina» de carácter innato o biológicamente determinado. Por el contrario, entendemos que los rasgos de personalidad que se manifiestan como condicionantes del ascenso de las mujeres tienen su origen en algunas tradiciones y creencias sociales que han frenado históricamente el desarrollo profesional de las mismas. Así lo ponen de manifiesto estudios como los de Alvesson y Billing (1992) o Glazer-Raymo (1999) que destacan, especialmente:

- La tradición judeo-cristiana que coloca el papel de la mujer en el hogar, contribuyendo así a retrasar la incorporación de la mujer al trabajo remunerado.

- Ciertas teorías sobre el desarrollo evolutivo que sostuvieron el argumento de la incapacidad de las mujeres para soportar altos niveles de estimulación mental.

- Las sospechas que pueden cernirse sobre aquellos - hombres, en su mayoría- que favorecen el ascenso de una mujer a un puesto de gestión.

En coincidencia con lo que venimos exponiendo, de manera ciertamente esquemática y a partir de la profusa literatura existente sobre el acceso de las mujeres a los puestos de dirección en diferentes ámbitos profesionales y contextos sociales, políticos y culturales (Aisenberg y Harrigton, 1993; Glazer-Raymo, 1999; Warren y O'Connor, 1999; Erkut, 2001; Glazer-Raymo, 2003; Ropers-Huilman, 2003; Wolf-Wendel y Ward, 2003) podemos hablar —basándonos en la clasificación de Hawley et ál. (1988)— de dos grandes tipos de barreras que se oponen, de manera más o menos abierta y explícita, al mismo: 
1. Barreras externas o contextuales, que van desde la discriminación directa u hostigamiento en razón del sexo a la oferta de un salario menor que el de los varones en puestos equivalentes, la falta de apoyo o la abierta obstrucción del avance por parte de otros miembros de la organización que ocupan posiciones jerárquicas, la ausencia de un adecuado mentorazgo, así como de modelos femeninos de liderazgo. En este grupo se incluyen, quizás paradójicamente, aquellas políticas de igualdad que, a la larga, no han hecho mas que conformar una situación de desigualdad (en particular las políticas de discriminación positiva que permitieron una rápida incorporación de las mujeres a organizaciones que, una vez dentro, bloquearon o dificultaron la promoción de estas mujeres o su llegada a los puestos directivos).

2. Barreras culturales o socializadas, entre las que se hallan algunos mitos instalados en la esfera cultural y que resulta muy difícil erradicar — nos referimos, por ejemplo, a la supuesta "preferencia» de las mujeres por la enseñanza sobre la investigación, en el caso de la Universidad; el supuesto miedo al fracaso de las mujeres como argumento para explicar su desigual acceso a los puestos de dirección; determinadas expectativas sobre diferentes niveles de eficacia y capacidad intelectual, ligadas a los estereotipos de género; el supuesto estrés ocasionado a las mujeres por el desempeño de múltiples roles para hacer compatibles el trabajo y la familia, etcétera. Se suma a estas ideas la convicción —defendida, incluso, por muchas mujeres- de que, tras los primeros pasos de la incorporación de las mujeres al mundo del trabajo, las desigualdades se han desvanecido y ahora son los más cualificados los que obtienen los mejores puestos. La realidad contradice tajantemente esta impresión, demostrando que la segregación y la desigualdad continúan.

En relación con esta última cuestión, hemos de señalar que las mujeres participantes en nuestro estudio ponían de manifiesto el estar concienciadas acerca de la falsedad de esta pretendida igualdad de oportunidades para avanzar en la jerarquía universitaria. Así, el 70,1 \% de las respuestas mostraba su acuerdo con la afirmación «Las políticas existentes en materia de maternidad son insufi- 
cientes para que las docentes estén en igualdad de condiciones respecto a sus compañeros varones a la hora de acceder a los cargos de gestión». En este aspecto, las mujeres consultadas se mostraban muy contundentes al manifestarse en desacuerdo con la existencia de «ayudas económicas y de otro tipo que permiten que actualmente una docente con hijos/as pequeños/as pueda desempeñar cargos de gestión». No es extraño, por tanto, que las mujeres de nuestra muestra reclamen mayoritariamente el desarrollo de las políticas de apoyo a la maternidad. La afirmación «Para que las mujeres ocupen cargos de gestión es necesario mejorar las políticas existentes para apoyar la maternidad» concentró los acuerdos del 80,2 \%. Asimismo, la mayoría de las participantes en el estudio consideraban que las insuficientes políticas de apoyo relacionadas con la maternidad, como ayudas económicas o de otro tipo que faciliten y permitan a las docentes con hijos pequeños desempeñar cargos de gestión, habían dificultado, en alguna medida, su labor como gestoras.

En cuanto a las impresiones de las gestoras consultadas por nuestro grupo de investigación acerca de la percepción social sobre las mujeres que ocupan puestos de gestión, algunos resultados merecen subrayarse. Por ejemplo, el acuerdo mostrado por las consultadas con la afirmación «El alumnado se comporta ante una mujer que ocupa un cargo de gestión con igual respeto que ante un hombre». Con respecto a la percepción de las gestoras de nuestra muestra sobre la importancia que sus compañeros y compañeras docentes concedían al hecho de que una mujer ocupase cargos directivos, las respuestas se encontraban muy distribuidas entre cuatro de las seis posibilidades de elección, siendo la opción más elegida (con un 30,5 $\%$ de las respuestas) la que expresaba un grado importante de aceptación. En consonancia con esto, las mujeres gestoras de nuestra muestra no percibían (al menos, un $81 \%$ de ellas así lo manifestaba) ser objeto de burlas o bromas por parte de sus compañeros varones.

Lo antedicho es, por supuesto, susceptible de diversas interpretaciones. Por una parte, es bastante probable que, efectivamente, en el marco de las organizaciones universitarias en las que se desempeñaban las participantes en el estudio, la presencia femenina fuera aceptada por el conjunto de los miembros. Recordemos, por otra 
parte, que la mayoría de las mujeres que integraban la muestra de nuestra investigación y respondieron el cuestionario llevaba entre once y quince años (el 31,5\%) y entre dieciséis y veinte años (el $25,2 \%$ ) en la misma Universidad. Se registraba, incluso, una generalizada tendencia a que cada una de las mujeres encuestadas hubiera desarrollado su actividad en una única institución. Cabe, por tanto, pensar que la aceptación de su labor se veía favorecida por la larga data de su incorporación a la organización.

Por otro lado, hemos de señalar algunos datos que parecen contradecir la visión expuesta en relación con el ítem anterior. Así, un $48 \%$ de las mujeres consultadas pensaba que su relación con los compañeros docentes había sufrido algún cambio a partir de su asunción del cargo de gestión, mientras que un $50 \%$ pensaba lo contrario. Las del primer grupo destacaban varios aspectos en los que la transformación se había producido: «distanciamiento y enfrentamiento por el ejercicio del poder» $(18,4 \%)$; cierta «reducción de confianza» y la consideración por parte de algunos compañeros como «oponentes» en las relaciones que mantenían con ellos. Por último, algunas mujeres afirmaban que sus compañeros las consideraban «controladoras» en el ejercicio del cargo y en su relación con ellos. Por otra parte, señalaban también que, desde su papel de gestoras, «se comparten más actividades» con los compañeros $(14,7 \%)$.

Indudablemente, en estos resultados han de tener gran incidencia factores no controlables por medio del cuestionario, como son la personalidad de la consultada — que puede condicionar una visión más o menos positiva de su vínculo con los otros- y las peculiaridades de la cultura de cada organización, en buena medida asociadas al área de conocimiento (es de suponer que el ejercicio de la gestión por parte de una mujer sea más habitual en áreas en las que la incorporación femenina se dio con anterioridad, por ejemplo) y a la historia de cada organización universitaria en particular, entre otros aspectos.

En este sentido, algunas investigaciones, como la de Kettle (1996), subrayan que las características del ambiente de trabajo condicionan fuertemente las posibilidades de ascenso de las profesoras. A partir del análisis de entrevistas realizadas con cuatro aca- 
démicas que ocupaban posiciones de mediano rango, la autora del estudio citado caracteriza su situación como de abandono, en tanto los criterios de promoción enfatizan las características típicamente masculinas y la pertenencia a redes de intercambio basadas en el patrocinio, que suelen excluir a las mujeres. Al mismo tiempo, identifica un clima institucional «amistoso» y «jerárquico pero no machista» como favorecedor de la incorporación femenina con menores niveles de angustia.

Apoyando nuestra idea de que es en el ámbito de los Departamentos universitarios donde se define la situación profesional de las mujeres, Brown Packer (1995) señala que la dinámica institucional de los mismos es más relevante en este sentido que la del conjunto de la organización o el área de conocimiento. Sobre la base de una investigación desarrollada en el contexto de las Universidades norteamericanas, establece una tipología de cuatro niveles de igualdad entre los géneros - basada en la metáfora de una puerta como símbolo del pasaje entre dos niveles-que permite la clasificación de los Departamentos. Estas categorías son:

- La puerta cerrada. Espacios en los que, pese a la ilegalidad del rechazo a la incorporación femenina, se mantienen actitudes discriminatorias.

- La puerta giratoria. Ambientes aparentemente abiertos a la incorporación de la mujer pero tan incómodos que dificultan su permanencia.

- La puerta entreabierta. Semejante al nivel anterior, pero permeable a algunas mujeres que reúnen características específicas.

- La puerta abierta. Supone un trato igualitario entre los géneros.

Evidentemente, los datos cuantitativos obtenidos a través de un instrumento de carácter cerrado como lo es un cuestionario no parecen suficientes para extraer conclusiones sobre los rasgos organizativos de las Universidades - o de aquellas unidades de las mismasen las que desempeñaban su trabajo las gestoras participantes en nuestra investigación. Sin embargo, nos parece posible conjeturar - y la información cualitativa obtenida en la segunda fase del estu- 
dio se orienta a apoyar esa idea- que estas universitarias se veían mayoritariamente inmersas en contextos organizativos concordantes con el segundo y el tercero de los descritos en la categorización precedente. Es decir, aunque eran aceptadas su ascenso solía verse implícitamente limitado u obstruido, salvo en aquellos casos en que su condición excepcional — debida a motivos tan diversos como las características personales o la coyuntura en que su incorporación a la labor gestora tenía lugar- era indiscutidamente aceptada.

En cualquier caso, la mayor parte de las investigaciones tiende a coincidir en que un ambiente hostil hacia las mujeres resulta predominante en los Departamentos universitarios. Ante esta situación, las principales estrategias que tienden a mostrar las profesoras para afrontar esta situación (Guil Bozal, 2002) son:

- La masculinización, que supone, a partir de la renuncia a otros aspectos de la propia vida, una aproximación al estilo de desempeño de los hombres. Por esta razón, resulta una opción aparentemente prestigiada en relación con ellos, pero poco valorada por las mujeres.

- La docilidad, que implica la aceptación de un lugar subordinado al de los colegas varones.

- La independencia, basada en el rechazo de la renuncia a cualquier faceta de la vida, profesional o personal. Exige un mayor esfuerzo, pero es la más valorada.

En nuestra opinión, tampoco esta opción por la alternativa más difícil o costosa desde la perspectiva de quien la asume es casual. Se apoya, por el contrario, en una serie de tradiciones a las que hemos aludido anteriormente, que sitúan la capacidad de sacrificio entre las características femeninas más valoradas. La operación de esta tendencia se aprecia, asimismo, en muchas de las respuestas que nos daban las gestoras consultadas, en tanto demostraban priorizar el cumplimiento de las obligaciones de toda índole sobre cualquier otra cuestión.

Por otra parte, los valores y la visión del mundo y de las organizaciones que tienden a asumir las mujeres son discordantes, según Asplund (1988), con la concepción dominante, tradicional- 
mente implantada y defendida por los hombres. Pueden, por tanto, interferir en el desarrollo profesional de las mujeres en tanto el esfuerzo que requiere implicarse lo suficiente como para progresar en un mundo cuya lógica y sus valores no se entienden o no se comparten puede ser excesivo, sobre todo si su contrapartida son los escasos beneficios que, por lo general, se obtienen.

En este sentido, no puede soslayarse que, en nuestra sociedad la crianza de los hijos ha estado hasta hace poquísimo tiempo —aun hoy la solicitud de permisos de paternidad suscita sorpresa y es objeto de análisis en las emisiones de noticias- casi exclusivamente a cargo de las madres. Por tanto, momentos cruciales en la vida de una persona, como los relacionados con el nacimiento y la crianza de los hijos, suelen llevar a las mujeres a desistir del esfuerzo por alcanzar mayores logros en su desarrollo profesional o a posponer determinadas decisiones acerca del mismo. Lea y Leibowitz (1992) y Wolf-Wendel y Ward (2003) han discutido este particular conflicto de rol de género y su influencia sobre la carrera profesional de las mujeres.

En relación con esta cuestión, algunos datos personales y familiares de las mujeres participantes en el estudio realizado por nuestro grupo de investigación parecen interesantes. Así, por ejemplo, pese a que ninguna mujer de nuestra muestra se hallaba por debajo de los 33 años de edad ${ }^{1}$ — es decir, eran mayoritariamente mujeres en edad de convertirse en madres- el 37,5\% de ellas no tenía ningún hijo a su cargo. Sí, en cambio, los tenía el 49,3\%, porcentaje que se repartía entre las que tenían uno $(14,7 \%)$ y dos hijos $(34,6 \%)$. En un $69,9 \%$ de los casos vivían en pareja o casadas y el $19,9 \%$ se encontraban solteras.

Por otra parte, solo un 5,1\% de las mujeres encuestadas tenía que atender a otras personas que se hallaran a su cargo — como padres, abuelos, suegros... En cuanto a la realización de las tareas

1 El 48,3\% de la muestra se situaba en el intervalo comprendido entre los 36 y los 45 años, aunque el punto álgido se presentaba entre los 41 y 45 años. El mismo porcentaje de mujeres que ocupaban cargos de gestión correspondía al intervalo comprendido entre los 33 y 35 años $(8,5 \%)$ y al comprendido entre los 56 y 60 años $(8,5 \%)$. 
domésticas, el $75 \%$ de las mujeres participantes recibían alguna ayuda externa (asistente/a), el 10,3\% afirmaba no tener ayuda y el $7,4 \%$ contaba con la colaboración de su pareja y/o de sus hijos.

Estos escuetos datos sugieren que la ausencia o escasez de obligaciones familiares es un factor que condiciona de modo relevante la asunción de la responsabilidad que representa el ejercicio de un cargo de gestión en la Universidad. Como contrapartida, según las opiniones recogidas por nuestro estudio, una vez asumido ese compromiso, los deberes familiares no suponen una merma en la dedicación a la tarea. Las tres opciones más elegidas — con un 69,2 \% de las respuestas, en conjunto- ante esta cuestión fueron las que representaban el mayor grado de rechazo a la afirmación «Cuidar $\mathrm{mi}$ hogar y mi familia requiere un esfuerzo que resto a mi profesión». Idéntica tendencia se pone de manifiesto en las respuestas de rechazo obtenidas ante la afirmación «Mis obligaciones familiares me impiden dedicar más tiempo y atención a mi trabajo». Frente a esta pegunta, la opción predominantemente seleccionada por las gestoras consultadas fue la que representaba el mayor grado de rechazo con el $44,8 \%$ de las respuestas, mientras que las tres opciones de acuerdo con la afirmación solo suponían, en total, el 21,7 \% de las mismas.

Como contrapartida, la amplia mayoría de las mujeres consultadas tampoco permitía que las obligaciones profesionales restasen una cuota significativa de su dedicación a las responsabilidades familiares. En este sentido, la afirmación «Destacar o ascender en mi trabajo es para mi más importante que dedicar mucho tiempo a mi casa o a mi familia» obtuvo un rechazo global del 83,9\%.

El equilibrio que se requiere para compaginar la familia y el trabajo - dirección en la que apuntan las respuestas anteriormente comentadas - exige, según la mayoría de las consultadas, un enorme esfuerzo que cargan sobre sus espaldas. Eso mismo es lo que indica el alto porcentaje de aceptación obtenido por la afirmación «Compaginar la atención a la familia y al trabajo solo es posible a costa de un esfuerzo excesivo" (67,7\% de las respuestas, en total). Sin embargo, debe destacarse el relativamente alto porcentaje que muestra algún grado de rechazo ante dicha afirmación (32,3\%), que 
nos parece muy significativo y puede explicarse apelando a las argumentaciones de algunas investigaciones acerca de la tendencia de las mujeres a minimizar las dificultades que encuentran en el desarrollo de su carrera profesional.

En la línea de negación de las dificultades antes señalada, se encuentra el mayoritario rechazo $(82,7 \%)$ hacia la afirmación «Desempeñar cargos de gestión me ha traído muchas dificultades y problemas en la relación con mi pareja y/o mi familia». Sin embargo hay que considerar que un $17,3 \%$ de las respuestas a este ítem mostraban algún grado de conformidad con dicha afirmación, lo que podría representar una dificultad añadida, para un número significativo de mujeres, respecto al acceso y la permanencia en puestos de gestión.

Sin embargo, ante la siguiente sentencia «Desde que ocupo un cargo de gestión tengo menos tiempo para estar con mi familia», un porcentaje elevado de las mujeres consultadas se inclinan por el acuerdo $(51,4 \%)$, frente al porcentaje de las que se inclinan por el desacuerdo (48,5\%). Creemos que el análisis de los resultados en este planteamiento, combinado con los resultados de los anteriores muestra que, aunque las mujeres no anteponen su desarrollo profesional a la atención a la familia, un porcentaje importante de ellas encuentra que la obligada dedicación al primer ámbito supone inevitablemente una merma del tiempo dedicado al ámbito familiar. Cabe suponer que esto represente para ellas una fuente de tensión $\mathrm{y}$, consiguientemente, de desgaste emocional que podría hallarse en la base de la falta de iniciativa o entusiasmo para avanzar hacia puestos de mayor jerarquía en la gestión de la Universidad que suele achacarse a las mujeres.

En cualquier caso, entendemos que es en parte por esta aparente reticencia femenina a asumir posiciones de liderazgo en las organizaciones que sigue estando «muy difundida entre gerentes y altos funcionarios la idea de que las mujeres resultan, por naturaleza, inadecuadas para ciertos tipos de trabajo y son en realidad incapaces de desempeñar tareas técnicas, gerenciales y de dirección, mientras que son realmente adecuadas para ocupaciones monótonas, repetitivas y rutinarias o para el trabajo asistencial» (Webb, 1993:39). 
Nosotros creemos que, en realidad, de lo que se trata es de que siguen primando los modelos de mando que responden a patrones masculinos y que, en definitiva, resultan consonantes con el modo de funcionamiento aceptado en las organizaciones, de todo tipo, de nuestro medio. Quizás una de las características más generalizadas entre las organizaciones sea el predominio del estilo burocrático de funcionamiento. Ese era, precisamente, uno de los problemas fundamentales que las directivas de nuestro estudio manifestaban haber encontrado en el desarrollo de sus tareas de gestión. A esta dificultad se añadían otras también frecuentemente identificables en nuestras organizaciones universitarias: la existencia de privilegios adquiridos por determinados miembros de la unidad organizativa de referencia, la preeminencia de un funcionamiento organizativo jerárquico y eficientista y la falta de colaboración del personal administrativo. Otros problemas de este mismo signo, pero señalados con menor frecuencia, fueron la dificultad para formar un equipo de confianza, la falta de colaboración del antecesor en el puesto y la falta de respeto a sus decisiones.

Estas cuestiones ponen de relieve, según nos parece, que el género condiciona a las personas a la hora de insertarse en una organización, del tipo que fuese. Esto no parece novedoso. En cambio, lo que, desde nuestra perspectiva - y, en cierto modo, también desde la del sentido común- no deja de sorprender es que el género haya estado tan ausente, como categoría y como perspectiva, del análisis de las organizaciones.

Pese a su influencia en la estructuración de la sociedad, el género no es considerado a la hora de explicar los procesos organizativos y el funcionamiento de las organizaciones. Seguramente, esta invisibilidad del género tiene que ver con la aceptación generalizada de la visión masculina del mundo como la lógica implícita que rige el funcionamiento organizativo (Bensimon, 1993; Coronel Llamas, Moreno y Padilla, 2002). Pero también guarda relación con la persistente imagen de las organizaciones como máquinas, en lugar de sistemas sociales en los que todo un flujo de relaciones abiertas y emergentes corre por debajo de la estructura formal. Verdaderamente, es difícil pensar en términos de género cuando se mira a una 
máquina. Sin embargo, no lo es tanto cuando lo que vemos es un sistema social en el que todo es socialmente construido y, por tanto, también puede ser criticado o reconstruido. Y no hablamos aquí solo del papel que juega el género, sino también de otras categorías como las de liderazgo o de poder (Ropers-Huilman, 2003), que aparecen naturalizadas ante los ojos del observador ingenuo, pero no deberían estarlo ante los de un analista que pretenda comprender el funcionamiento de la organización. Es en este punto en el que, como afirman algunos autores (Calás y Smircich, 1993; Perreault, 1993; Gherardi, 1995) las tradiciones teóricas feministas y de estudio sobre las organizaciones sociales pueden aliarse de forma táctica y temporal para el logro de ciertos intereses comunes.

En el caso particular de las Universidades, por otra parte, la desconsideración del género como dimensión de análisis de la realidad organizativa encuentra razones, que — según la perspectiva de análisis que hemos adoptado- se vinculan, en buena medida, al origen y a la historia de la institución universitaria.

En este sentido, huelga señalar que, en sus momentos fundacionales, la Universidad era una institución casi en exclusiva masculina. Y, aunque en grado variable en función del momento y del lugar, esta característica se mantuvo durante la mayor parte de la historia institucional. Dado que atender a una dimensión invariable resulta escasamente productivo con fines de análisis, se entiende que no se haya considerado la incidencia del género en la configuración de las dinámicas organizativas hasta hace muy poco tiempo. De igual manera, se comprende que la prolongada ausencia de atención a un aspecto del proceso organizativo haya acabado por volverlo invisible. Es una de las tareas del análisis institucional crear visibilidad en relación con cuestiones que vienen permaneciendo ocultas pero no por eso inoperantes en la definición del funcionamiento de las organizaciones.

En este intento de poner en evidencia los mecanismos de deslegitimación del género como dimensión condicionante del funcionamiento organizativo, puede resultar ilustrativo atender a las reacciones que la inclusión de las mujeres en la gestión universitaria fue generando a lo largo del tiempo. 
De acuerdo con los datos presentados anteriormente, es evidente que la primera respuesta de las organizaciones universitarias fue de abierta resistencia a la incorporación de las mujeres. En un momento posterior, la opción fue admitir su entrada, aunque limitándola, en la medida de lo posible, a los niveles organizativos más bajos. Podríamos, por tanto, aludir a un claro discurso de discriminación que, en distintos momentos y situaciones, se plasmaba en argumentos diversos y más o menos explícitos.

En los últimos tiempos, por el contrario, parece advertirse un radical cambio en el discurso. No solo no se esgrimen manifestaciones contrarias a la participación de las mujeres en las organizaciones, sino que se aplaude su incorporación a lugares de liderazgo que hasta hace poco parecían estarles vedados. Sin negar el cariz de avance en términos de democratización de las organizaciones que esto puede representar, creemos que debe adoptarse una actitud crítica ante el ensalzamiento de supuestos estilos femeninos homogéneos, ya que pueden contribuir a perpetuar estereotipos.

En apoyo de esta idea, cabe señalar que no es infrecuente que las mujeres académicas adquieran un carácter de «extranjeras incluidas» evidenciado en la desvalorización sufrida por los espacios ocupados por ellas, mientras los más prestigiosos se reservan a los hombres (Heward, 1996). Desde este punto de vista, la ya citada metáfora del «techo de cristal» parece inapropiada porque no da cuenta de los factores que actúan para mantener a las mujeres en los escalones más bajos de la escala jerárquica —el «suelo de piedra», al que permanecen unidas.

Paradójicamente, creemos que las características positivas que la literatura suele atribuir a las mujeres como líderes pueden haberse sumado a las más tradicionalmente atribuidas — que las presentaban como incapaces para el trabajo intelectual- para profundizar su condición amenazante (Kerman, 1995) dentro de los círculos académicos.

La supervivencia de prejuicios y visiones estereotipadas se aprecia con claridad en que las mayores limitaciones del desarrollo profesional de las mujeres académicas se refieren —como señalan, 
en relación con distintos contextos geográficos y culturales, Guil Bozal (2002) y Du Pleissis (2000) — a la investigación. La docencia, en cambio, parece verse menos afectada, lo que puede explicarse por su mayor cercanía a los roles tradicionalmente femeninos de cuidado y atención hacia los demás. Coincidían en esto las mujeres gestoras participantes en nuestro estudio, en tanto opinaban que su trabajo de gestión les afectó principalmente reduciendo sus posibilidades de dedicar tiempo a las tareas de investigación, mientras que entre los aspectos que más frecuentemente se mencionaban como «muy poco afectados» se encontraban los referidos a la docencia y la atención a los alumnos en las tutorías.

No olvidemos que, de acuerdo con nuestra perspectiva, la situación femenina en la Universidad no deja de ser un caso particular de la situación que viven los profesores universitarios en general. En los últimos años (Du Pleissis, 2000; Neave, 1997), esta se ha ido modificando en la dirección de una intensificación del trabajo académico, el incremento de su regulación, y la expansión de las desigualdades entre los Departamentos y los centros, así como dentro de las Universidades y entre ellas. La introducción de criterios jerárquicos de tipo empresarial puede haber erosionado, como indican algunos autores, el estilo colegial de administración tradicional en algunas Universidades. En el caso de las mujeres, esto ha redundado en una concentración en los niveles más bajos de la escala jerárquica, así como en una expansión de sus puestos de trabajo en el marco de los contratos de corta duración, generalmente vinculados en exclusiva a la tarea de enseñanza. En consecuencia, las mujeres pasan más tiempo enseñando que los hombres, por lo que las obligaciones docentes suelen identificarse como un obstáculo en su promoción profesional, ligada a la producción de investigaciones y de publicaciones.

Ante tantas dificultades, cabe preguntarse qué puede motivar a las mujeres docentes a ejercer cargos de gestión. Y, nuevamente, creemos que eso puede contribuir a poner en cuestión los modos de funcionamiento organizativo aceptados.

De acuerdo con los resultados de nuestro estudio, las principales motivaciones que llevaron a las mujeres consultadas a asumir 
responsabilidades en la gestión universitaria fueron el desarrollo de un proyecto de grupo (razón a la que el 28,7 \% de las respuestas atribuye gran influencia en el acceso al cargo), la satisfacción personal y la oportunidad de mejora, con un $27,9 \%$ y un $24,3 \%$ de respuestas en esa categoría, respectivamente). Como puede verse, se trata fundamentalmente de valores ligados al interés general antes que al estrictamente particular, y de carácter simbólico antes que material.

Por el contrario, aspectos de mayor impacto personal y repercusión concreta, tales como la liberación de horas de docencia, el incremento en la remuneración o el prestigio concedido a los cargos públicos, que pudieran pensarse como relevantes a la hora de asumir este tipo de responsabilidades, no influyeron en absoluto en las decisiones de un $43,6 \%$, un $36 \%$ y un $33,8 \%$, respectivamente, de las mujeres consultadas. Como contrapartida, solo un $1,5 \%$ en las dos primeras y un 2,2 \% en la última categoría las consideraban «muy influyentes» en su decisión de desempeñarse en la gestión universitaria.

Estos últimos datos permiten, de acuerdo con la perspectiva que defendemos, proponer la hipótesis de que la supuestamente infundada resistencia de las organizaciones universitarias a la incorporación de elementos que pudieran resultar transformadores - como, en el caso considerado, mujeres en la gestión organizativa- representan un intento de mantener rasgos identitarios arraigados en la historia institucional. Dado que la renuncia a ellos podría suponer una fuente de tensiones que pusiera en riesgo la estabilidad organizativa, podría estar planteándose una situación paradójica en la que tanto el mantenimiento del statu quo como la modificación del mismo ofrecen peligros. La resolución de esta tensión dependerá, desde nuestro punto de vista, tanto de las circunstancias en las que cada organización se encuentre como de las posiciones adoptadas por sus miembros, muy especialmente, por quienes se ocupan de dirigirlas. 


\section{Referencias bibliográficas}

AisenberG, N., y M. HARRIngton (1993), «Rules of the Game», J. Glazer, E.M. Bensimon, y B.K. Townsed (eds.), Women in Higher Education: A Feminist Perspective (pp. 387-398), Needham Heihts, MA: Gin Press.

Asplund, G. (1988), Women Managers. Changing Organizational Cultures, Chichester: Wiley \& Sons.

Astelarra, J. (2005), Veinte años de políticas de igualdad, Valencia: Ediciones Cátedra.

Bensimon, E.M. (1993), «A Feminist Reinterpretation of President's Definition of Leadership», en J. Glazer, E.M. Bensimon, y B.K. Townsed (eds.), Women in Higher education: a Feminist Perspective (pp. 465-474), Needham Heihts, MA: Gin Press.

BRown PARKER, B. (1995), «Irritating the Sacred Grove: Stages of Gender Equity Development», en L. Morley y V. Walsh (eds.), Feminist Academics. Creative Agents for Change, Londres: Taylor \& Francis.

CALÁs, M., y L. Smircich (1991) «Voicing Seduction to Silence Leadership», Organizations Studies, 12 (4): 567-602.

- (1993), «Re-writing Gender into Organizational Theoring: Directions from Feminist Perspectives», en J. Glazer, E.M. Bensimon, y B.K. Townsed (eds.), Women in Higher Education: A Feminist Perspective (pp. 97-117), Needham Heihts, MA: Gin Press.

Du PLEISSIS, R. (2000), «Teaching, Research and Gender and Possibilities of "Scholarship"”, AUS Status of Women Committee Mini-Conference, 17 de agosto 2000 .

ERKUT, S. (2001), Inside Women's Power: Learning from Leaders, Boston: Center for Reasearch on Women, Wellesley College, y Winds of Change Foundation.

FigueroA Í́̃iguez, M.J. (1996), Mujer y docencia en España, Madrid: Escuela Española.

Flecha GarCíA, C. (1996), Las primeras universitarias en España, Madrid: Narcea.

García de Cortázar, M., y M.A. García de LeÓn (1997), «Mujeres en minoría. Una investigación sociológica sobre las catedráticas de Universidad en España», Opiniones y actitudes, 16, Madrid: Centro de Investigaciones Sociológicas.

GHERARDI, S. (1995), Gender, Symbolism and Organizational Cultures, Londres: Sage.

Glazer-Raymo, J. (1999), Shattering the Myths. Women in Academe, Baltimore: The Johns Hopkins University Press. 
Glazer-Raymo, J. (2003), «Woman Faculty and Part-Time Employment. The Impact of Public Policy», en B. Ropers-Huilman (ed.), Gendered Futures in Higher Education. Critical Perspective for Change (pp. 97-109), Nueva York: State University of New York Press.

Guil Bozal, A. (2002), «El viaje de Penélope», en El telar de Ulises, 2 (<http://www.us.es/bibemp/ulises/ulises2/Penelope.htm>).

HewaRD, C. (1996), «Women and Carers in Higher Education: What Is the Problem?», en L. Morley y V. Walsh (eds.), Breaking Boundaries: Women in Higher Education, Bristol: Taylor \& Francis.

Kerman, L. (1995), «The Good Witch: Advice to Women in Management», en L. Morley y V. Walsh (eds.), Feminist Academics. Creative Agents for Change, Londres: Taylor \& Francis.

KetTle, J. (1996), «Good Practices, Bad Attitudes: An Examination of the Factors Influencing Women's Academic Careers», en L. Morley y V. Walsh (eds.), Breaking Boundaries: Women in Higher education, Bristol: Taylor \& Francis.

LeA, D., y Z. Leibowitz (1992), Adult Career Development. Concepts, Issues and Practices, Alexandria: The National Career Development Association.

LóPez YÁÑEZ, J., y M.R. SÁNChez MoReno (1997), Para comprender las organizaciones escolares, Sevilla: Repiso.

Marcelo García, C., y A. Estebaranz García (2002), «Marco general de investigación sobre la enseñanza en la Universidad», en C. Mayor Ruiz (coord.), Enseñanza y aprendizaje en la educación superior, Barcelona: Octaedro-EUB.

Mingo, A. (2006), ¿Quién mordió la manzana? Sexo, origen social y desempeño en la Universidad, México: UNAM, Fondo de Cultura Económica.

Ministerio DE EdUCACión y Ciencia (2007), Académicas en cifras, Madrid: MEC-Unidad de Mujeres y Ciencia.

Montserrat Garrocho, J. (1998), «Los apoyos del Sistema», en J.M. Luxán (ed.), Política y reforma universitaria, Barcelona: Cedecs Editorial.

NeAve, G. (1995), «Las políticas de calidad: desarrollos en enseñanza superior en Europa occidental», Revista de Educación, 308, 7-29.

- (1997), «Prevenir o curar. La Universidad como objeto de investigación», en G. Neave (ed.), Educación superior: historia y política. Estudios comparativos sobre la Universidad contemporánea, Barcelona: Gedisa editorial.

- (2001), «Reconsideración del estado evaluador», en G. Neave (ed.), Educación superior: historia y política. Estudios comparativos sobre la Universidad contemporánea (pp. 211-240), Barcelona: Gedisa editorial. 
Nicolson, P. (1997), Poder, género y organizaciones. ¿̇Se valora a la mujer en la empresa?, Madrid: Narcea.

Perreault, G. (1993), «Contemporary Feminist Perspectives on Women and Higher Education», en J. Glazer, E.M. Bensimon, y B.K. Townsed (eds.), Women in Higher Education: A Feminist Perspective, Needham Heihts, MA: Gin Press.

Ropers-Huilman, B. (2003), Gendered Futures in Higher Education. Critical Perspective for Change, Nueva York: State University of New York Press.

Souviron MoReniLLA, J.M. (1998), «La autonomía universitaria: previsiones constitucionales y su desarrollo normativo», en J.M. Luxán (ed.), Política y reforma universitaria, Barcelona: Cedecs Editorial.

TEDESCO, J.C. (1995), El nuevo pacto educativo. Educación, competitividad y ciudadanía en la sociedad moderna, Madrid: Anaya.

Tiana Ferrer, A. (1998), «La demanda de estudios universitarios y el acceso a la Universidad», en J.M. Luxán (coord.), Política y reforma universitaria, Barcelona: Cedecs, 177-189.

Tierney, W.G., y E.M. Bensimon (eds.) (1996), Promotion and Tenure. Community and Socialization in Academe, Nueva York: State Univesity of New York Press.

Van Vianen, A., y A. Fischer (2002), «Illuminating the Glass Ceiling: The Role of Organizational Culture Preferences», Journal of Occupational and Organizational Psychology, 75, 315- 337.

Vander Stoep, S.W., E.M. Anderman y C. Midgley (1994), «The Relationship among Principal "Venturesomeness", a Stress on Excellence, and the Personal Engagement of Teachers and Students», School Effectiveness and School Improvement, 5 (3), 254-271.

WARREN, L., y E. O'ConNor (1999), Stepping out of the Shadows. Women in Educational Management in Ireland, Dublín: Oak Tree Press.

WEBB, J. (1993), «Las relaciones de valoración diferenciadas según el genero», en J. Firth-Cozens y M.A. West (comps.), La mujer en el mundo del trabajo, Madrid: Morata.

- y G. Vulliamy (1996), «A Deluge of Directives: Conflict between Collegiality and Managerialism in the Post-ERA Primary School», British Educational Research Journal, 22 (4), 441-459.

Wolf-Wendel, L. y WARD, K. (2003), «Future Prospects for Women faculty. Negotiating Work and Family», en B. Ropers-Huilman (ed.), Gendered Futures in Higher Education. Critical Perspective for change, Nueva York: State University of New York Press. 


\title{
CAPÍTULO 2 \\ EL LIDERAZGO A DEBATE: \\ NUEVAS PERSPECTIVAS \\ SOBRE UN VIEJO CONOCIDO
}

\author{
José Manuel Lavié Martínez
}

\subsection{El liderazgo: un «viejo conocido»}

El liderazgo es un tema que se ha visto envuelto permanentemente de cierta mística y fascinación entre quienes se dedican al estudio de las organizaciones. Desde muy pronto, los teóricos de la organización se han esforzado por delinear el liderazgo como algo distinto de la gestión, atribuyendo a los líderes ciertas cualidades personales para dirigir a los demás a través de la inspiración y la motivación, en lugar de mediante el control jerárquico. A pesar de que los esfuerzos por clarificar en qué consiste eso que llamamos «liderazgo» — dónde reside su causa última y cómo funciona en la práctica- han sido, en su mayor parte, infructuosos, lo cierto es que la idea del líder con grandes ideas y visiones, capaz de incitar al compromiso e impulsar a las personas a tomar parte en grandes proyectos compartidos, ha sido probablemente magnificada. Como ya argumentasen Meindl y otros (1985) hace algo más de dos décadas en un influyente artículo, el continuo cuestionamiento en torno a la viabilidad del liderazgo, como concepto y como área de estudio, ha convivido con una concepción «romantizada» del mismo que constituye una parte importante de la realidad social que construimos en nuestros análisis informales y teorías formales de las organizaciones. 
La forma de entender el liderazgo ha ido evolucionando durante las pasadas décadas a tenor de los cambios producidos en la conceptualización de las organizaciones. Las visiones prevalecientes en cada momento en torno a estas últimas han conformado, en gran medida, el modo en que el liderazgo es construido. La así llamada «revolución cultural» de principios de los ochenta fue, sin duda, uno de los principales hitos que propició la redefinición y revitalización del liderazgo en un momento en que como campo de estudio era objeto de importantes dosis de escepticismo y cierto sentido de «agotamiento» intelectual. En esta época, un importante volumen de trabajos - fundamentalmente libros de corte divulgativo destinados a un público no académico- reelaboraron como «nueva» la idea de que las organizaciones son algo más que estructuras, roles, especificaciones formales de funciones y descripción de tareas. Además de todas estas variables estructurales, las organizaciones tienen culturas; esto es, series de normas, valores, artefactos y pautas que operan desde un plano más informal y, con frecuencia, tácito, regulando el comportamiento organizativo. Los argumentos eran los idóneos para la entrada en escena de un nuevo modelo de liderazgo, que enfatizaba — consecuentemente- las dimensiones simbólicas y de transformación cultural que se encuentran insertas en las relaciones entre líder y seguidores. Esta comprensión del liderazgo en términos «visionarios» y de impronta simbólica encontró cabida en los modelos transformacionales desarrollados al amparo del llamado «nuevo» paradigma del liderazgo. Las ortodoxias del momento eran proclives a una retórica del líder teñida de matices heroicos, que lo dibujaban -y continúan haciéndolo- como un individuo capaz de transformar su organización y las percepciones y motivaciones de los individuos que la integran. La organización educativa ha sido especialmente adepta a este tipo de construcciones, que atraviesan la literatura sobre el cambio planificado, dibujando a los directivos como agentes de cambio investidos con capacidades transformacionales.

Más recientemente, toda esta retórica heroica y romántica, que tiende a relacionar el liderazgo con grandes ideas, visiones y conversaciones que incitan al compromiso e impulsan a las personas a tomar parte en grandes misiones, ha sido en cierta media atempe- 
rada por nuevas visiones del liderazgo «postransformacional». En estas, sin abandonar totalmente la épica transformadora y de acomodación de los intereses individuales al «bien colectivo» de la organización, se acentúa igualmente la importancia de que tales capacidades de transformación se encuentren dispersas por toda la organización, en lugar de concentradas en uno o pocos individuos esto es, que el liderazgo sea distribuido.

Pues bien, hasta la articulación en la teoría y la práctica organizativas de todos estos nuevos desarrollos, el líder siempre se ha escrito en masculino (singular, podría añadirse). La mujer, desde los modelos tradicionales, ha quedado privada de cualquier posibilidad de vinculación porque, por definición, tales modelos son masculinos. Solo los discursos que han comenzado a definir el liderazgo como un proceso de transformación simbólica antes que de transacción formal, y como una práctica de «poder con» antes que de "poder sobre», han permitido la entrada en escena de modelos más amables con prototipos de comportamiento cercanos al estereotipo femenino. Y de ahí, como veremos en este capítulo, hasta llegar a defenderse en las mujeres incluso una "ventaja femenina» en el liderazgo y la dirección de las organizaciones.

En este capítulo nos proponemos revisar los ejes argumentales que han propiciado la incorporación del género a los debates sobre el liderazgo, ilustrándolos con ejemplos tomados de las directivas que participaron en nuestro estudio. Asimismo, trataremos de argumentar las potencialidades e insuficiencias de tales debates en referencia, especialmente, al contexto de la gestión universitaria.

\subsection{Liderazgo y género: un diálogo que comienza «contaminado»}

El género ha sido una cuestión tradicionalmente negada o, en el mejor de los casos, minusvalorada en el estudio de las organizaciones. Solo durante las dos últimas décadas hemos asistido a esfuerzos notables que han tratado de desafiar la supuesta neutralidad de la teoría organizativa y de desestabilizar la ceguera generalizada de esta hacia las cuestiones de género. A pesar de esta pro- 
gresiva visibilidad del género, los enfoques más importantes continúan ignorando las relaciones existentes entre las formas y procesos organizativos y el género. En este sentido, la invisibilidad del género persiste en la escasez de esfuerzos sistemáticos que se aproximen al género no en términos de una «cuestión de (o sobre) mujeres», sino como un principio profundo constitutivo de organizar y de la organización, y como una categoría situada para el análisis organizativo.

No es aventurado sostener que la investigación organizativa en general, y de modo más concreto la referida a organizaciones educativas, se ha mostrado poco atenta a la evolución a la que ha estado sujeto el concepto de género en las Ciencias Sociales. En efecto, las perspectivas sociológicas en torno al género han ido evolucionando con el tiempo. Como resultado de esta evolución, las primeras acepciones del género como rasgo individual o como categoría social han dado lugar progresivamente a nociones más complejas que lo contemplan como un proceso social y como un principio básico de la estructura social y de las interpretaciones culturales. Dentro de los estudios organizativos, en cambio, el género se ha quedado frecuentemente estancado en visiones simplistas de diferencias categóricas hombre-mujer. La principal implicación de esta escasa teorización del objeto de estudio ha sido la persistencia de una concepción del género-como-variable que ha reducido la amplitud de posibilidades de la investigación sobre género a una preocupación instrumental de cortas miras, en la que el género tiende a identificarse con lo femenino y esto último con una categoría no problemática y homogénea que deriva su significado de un sistema binario de clasificación.

Un claro ejemplo de este «copamiento» discursivo del campo lo encontramos en la literatura sobre «mujeres-en-la-gestión», convenientemente replicada y mimetizada en la investigación educativa, y que en muchos casos se ha convertido en la expresión más visible de lo que significa estudiar las organizaciones desde una perspectiva de género. Aunque un análisis pormenorizado de esta línea de investigación —así como su pertinente crítica- escapan de nuestro foco de atención en este capítulo, su consideración tiene interés para nosotros por varios motivos. 
En primer lugar, esta literatura resulta interesante porque refleja el sesgo gerencial dominante que invade la investigación organizativa en general, en la que la gestión representa «el contexto y la motivación para el estudio de las organizaciones» (Grey, 2005: 17). No resulta sorprendente, entonces, que una de las áreas de investigación más prolíficas en los estudios sobre género y organización tenga que ver con el tópico del liderazgo y la gestión. La investigación queda así encapsulada dentro de estas coordenadas, con la implicación de que el estudio del género en las organizaciones suele reducirse a una preocupación por las diferencias de estilo de liderazgo en función del sexo.

En segundo lugar, buena parte de esta literatura es paradigmática de la concepción reduccionista del género que maneja en ocasiones la investigación organizativa, donde los «estudios de género» suelen confundirse o equipararse con los «estudios de mujeres», y donde estos últimos reproducen los debates feministas tradicionales sobre igualdad/diferencia para dar respuesta -y no para reconstruir- a los planteamientos académicos del momento. Así, en línea con estos debates, y circunscrita a una visión de las organizaciones como lugares en los que las diferencias se hacen patentes y consecuentes, la literatura sobre «mujeres-en-la-gestión» ha cambiado gradualmente su atención de explicar la dudosa capacidad de las mujeres para liderar a exaltar los estilos de liderazgo «femeninos» como supuestamente superiores (Ashcraft, 2004). Tal como discutimos con más detalle en el siguiente apartado, esta línea de investigación plantea, a partir de los argumentos de la «diferencia de las mujeres» de distintos feminismos (cultural, radical, y liberal tardío), que la socialización distintiva de rol de género que reciben las mujeres puede resultar beneficiosa tanto para ellas mismas como para las organizaciones. Como grupo social —se argumenta- las mujeres poseen particulares modos de ver, conocer, organizar y liderar, en virtud de los cuales realizan aportaciones genuinas al liderazgo. Este «giro femenino» en el liderazgo como resultado de la exaltación del polo de la diferencia ha significado una reevaluación positiva de los estereotipos de género de las mujeres gestoras, en un momento en el que las destrezas de comunicación y colaboración que se atribuyen a estas últimas cobran protagonismo. 
Finalmente, este interés por las formas distintivas de gestionar y liderar de las mujeres nos proporciona un buen ejemplo —uno entre tantos otros - de cómo la literatura popular sirve para alimentar los argumentos académicos y articular así un discurso poco riguroso pero altamente atractivo.

Pero, antes de seguir profundizando en nuestro análisis sobre las potencialidades y fracturas del estudio del liderazgo desde una perspectiva de género, consideremos con más detalle cuáles han sido los términos en los que el debate sobre esta cuestión se ha establecido hasta el momento.

\subsection{El liderazgo femenino: los términos del debate}

Como acabamos de sugerir, en la mayor parte de la literatura las relaciones entre género y liderazgo se han enfocado de un modo ciertamente reduccionista. Desde esta perspectiva limitada, el género se ha entendido antes como una variable de análisis que como un marco analítico o una categoría organizadora del análisis de la realidad institucional. La principal preocupación, en consecuencia, se ha definido en términos de un debate que se interroga por las posibles diferencias de sexo en procesos organizativos tradicionales como el liderazgo. La cuestión de si las mujeres y los hombres que ocupan puestos de liderazgo se comportan de modo distinto constituye, en efecto, uno de los tópicos más ampliamente debatidos en la literatura especializada.

En líneas generales, puede afirmarse que el debate en torno a la existencia del llamado estilo «femenino» de liderazgo presenta un carácter marcadamente conceptual, o incluso ideológico, mientras que su base empírica es escasa y ofrece, de acuerdo con las principales revisiones realizadas sobre el tópico, resultados poco concluyentes. De hecho, como señala Blackmore (1996), esta cuestión tiene su correspondencia en el debate cultural más amplio que se interroga por la diferencia y la similitud entre géneros, y que ha tenido una especial resonancia en los escritos feministas y en los desarrollos de la teoría de los roles sociales. Si hombres y mujeres son socializados en roles distintos, y tal proceso diferencial nos 
remite a construcciones sociales sobre el comportamiento deseable y/o esperable en función del sexo, cabe plantearse de qué modo dicho bagaje relacionado con las prescripciones de rol de género se ve afectado por las prescripciones derivadas del rol organizativo. En el caso concreto del liderazgo, puesto que este se ha considerado tradicionalmente una propiedad reservada a los miembros varones de la organización - quienes, consecuentemente, han definido la «norma» en tales puestos- el debate se plantea en estos términos: conforme las mujeres van ganando acceso a los cargos de gestión, ¿desarrollan estilos de liderazgo iguales o diferentes a los de sus colegas varones, entendidos tales estilos como patrones de comportamiento relativamente estables que exhiben los líderes?

En los últimos años, la literatura especializada ha venido ofreciéndonos diversas aproximaciones que tratan de sistematizar los términos de este debate. La mayoría de ellas, no obstante, suelen incorporar posiciones dicotómicas que difieren entre sí en las nociones de género que manejan y en el lugar en que estas se ubican dentro del continuo definido por los polos igualdad/diferencia. Así, en un extremo de ese continuo se encuentra lo que podríamos denominar un enfoque centrado en reclamar la igualdad de hombres y mujeres en el ejercicio del liderazgo. De acuerdo con este enfoque, hombres y mujeres son esencialmente iguales, de manera que el problema puede definirse como uno de acceso a estructuras y procesos que se consideran neutrales. La desigualdad de las mujeres se entiende, pues, como resultado de restricciones de orden social e institucional, que pueden erradicarse desmantelando estas barreras estructurales a la igualdad. La lógica subyacente a este discurso es que, al eliminar las barreras estructurales y procedimentales, una masa crítica de mujeres ganará acceso, por su propio mérito, al poder formal.

Desde este enfoque, por tanto, hermanado con la teoría política liberal y el feminismo liberal (Calás y Smircich, 1996), se ha reclamado el acceso a puestos de responsabilidad basado en el mérito individual. Las estrategias de igualdad de género promovidas desde esta perspectiva se centran fundamentalmente en cambiar a las mujeres de modo individual, no a las culturas en que trabajan, de modo que aquellas se parezcan más a los hombres: formación para 
adquirir las destrezas propias de un campo del que, hasta el momento, habían permanecido ajenas. Para asegurar la igualdad de oportunidades, las mujeres deben ser formadas para cubrir las carencias propias de su socialización diferencial y llegar, de este modo, a alcanzar un nivel y desempeño equiparable al de sus colegas varones. Hay que «arreglar a las mujeres» (Ely y Meyerson, 2000: 107) para que desarrollen las destrezas y estilos que se consideran necesarios para el éxito.

En el otro extremo del continuo se situarían aquellos discursos que han adquirido amplia resonancia en círculos populares, e incluso académicos, durante las últimas décadas, y que se inscriben en lo que podríamos denominar un enfoque orientado a celebrar la diferencia. En nuestro caso nos interesa examinar especialmente este último polo, no solo porque se ha constituido en la versión dominante a la hora de explicar los procesos de liderazgo desde una óptica de género, sino porque incluso los feminismos de orientación más liberal que inicialmente defendieron la igualdad de oportunidades basada en la igualdad entre sexos y abogaron por una noción ambigua de liderazgo «andrógino», han reinterpretado sus argumentos dando cabida a ciertas versiones de los discursos de la diferencia (Calas y Smircich, 2006). ${ }^{1}$

En abierto contraste con lo que ocurre con los planteamientos que buscan mejorar las deficiencias de la mujer para el liderazgo, desde esta perspectiva se ensalza la diferencia en tanto que constitutiva del género, y se enfatiza el valor positivo de las cualidades

1 En términos generales, el feminismo liberal ha perseguido la eliminación de los estereotipos asociados al género. En algunos casos, se ha propuesto con esta intención la noción de un ser «andrógino» como posible solución a la discriminación basada en el sexo (Tong, 1998). La noción del liderazgo andrógino, revigorizada en la literatura contemporánea sobre liderazgo como el estilo más apropiado para alcanzar un alto rendimiento en las organizaciones, constituye una de las respuestas del feminismo liberal a la teoría de los roles de género. De acuerdo con esta perspectiva, las mujeres con éxito en puestos de liderazgo son las que consiguen una integración - en lugar de polarización- de rasgos tanto femeninos como masculinos. Se resuelve de este modo las percepciones negativas que suelen atribuirse al liderazgo femenino, una de las principales razones argumentadas para justificar la escasa representación de las mujeres en los puestos de gestión educativa. 
tradicionalmente asociadas con las mujeres. De acuerdo con el feminismo radical o cultural (Tong, 1998) que alimenta los argumentos en este extremo del debate, las mujeres poseen particulares modos de ver, conocer, organizar y liderar, que constituyen su particular aportación como colectivo al liderazgo. Los argumentos que se utilizan en este polo orientado a la diferencia no son, sin embargo, homogéneos. Alvesson y Billing (1997), por ejemplo, establecen una distinción entre la posición de la «contribución especial» y la posición de los «valores alternativos». Mientras la segunda asume en las mujeres intereses, prioridades y actitudes vitales básicas radicalmente distintas a las de los hombres, y defiende en consecuencia el desarrollo de organizaciones alternativas orientadas por la práctica feminista, la primera articula una versión más débil de la perspectiva feminista que se ajusta bien a las preocupaciones comunes de tipo gerencial.

Quienes se sitúan en el polo de la diferencia suelen plantear la cuestión en términos dicotómicos, que quedan bien capturados por la célebre distinción entre estilos comunales y agénticos de liderazgo (Eagly y otros, 2000, 2001). Las características agénticas o instrumentales, relacionadas generalmente con los hombres, definen una tendencia a la asertividad, el control, la ambición, la competitividad, la independencia y la confianza. Por su parte, las características comunales o emocionales, relacionadas generalmente con las mujeres, se refieren a la preocupación por el bienestar de los otros, y definen comportamientos tales como la escucha atenta, el apoyo, o la orientación a solucionar problemas de tipo relacional o interpersonal.

Partiendo de esta diferenciación clásica de los roles femeninos y masculinos, se asume que hay ciertas cualidades que se identifican con un estilo de liderazgo «femenino» o «masculino». Aunque cualquiera de estos estilos puede ser adoptado tanto por hombres como por mujeres, la asunción básica y las expectativas que de ella se derivan es que los hombres desarrollan un estilo predominantemente masculino, mientras que las mujeres uno fundamentalmente femenino. De acuerdo con esta asunción, los hombres en puestos de responsabilidad tienden a desarrollar estilos más autoritarios, orientados a la tarea y transaccionales, mientras que las mujeres 
exhiben estilos más democráticos, interactivos u orientados a las relaciones, y transformacionales.

Algunos estudios tienden apoyar esta posición, concluyendo diferencias de género en destrezas de gestión tales como la comunicación, el desarrollo individual y la gestión del tiempo, y describen el estilo de liderazgo de las mujeres como más transformacional que el de sus colegas varones. Similarmente, apoyados en el discurso del liderazgo femenino, estos trabajos describen a las mujeres en puestos de responsabilidad como líderes que prefieren operar desde bases personales de poder; que se implican en un estilo de gestión participativo y de trabajo en equipo; que poseen una visión que son capaces de comunicar eficazmente; y que promueven la confianza mutua y el respeto.

La literatura educativa ha reproducido con cierto mimetismo este debate, desarrollando argumentos que tienden a reforzar la existencia de un estilo «femenino» de liderazgo educativo. La investigación sobre gestión en instituciones educativas es, por así decirlo, pródiga en ejemplos próximos a este polo del continuo. Gray (1989, 1993), por ejemplo, ha desarrollado un modelo de liderazgo en educación basado en la distinción entre un paradigma «femenino» - caracterizado por rasgos típicamente femeninos, tales como la conciencia de las diferencias individuales, el cuidado, la intuición, la tolerancia, la creatividad, el carácter informal, la no competitividad y la subjetividad - y un paradigma «masculino» — definido en términos de evaluativo, disciplinado, competitivo, objetivo, formal, altamente regulado, conformista y normativo. La investigación de Coleman (2000), sobre directoras de institutos de secundaria en Inglaterra y Gales, apoya fuertemente esta visión de que la mayoría de las mujeres gestionan sus centros de un modo estrechamente vinculado a lo que podría identificarse como un estilo de liderazgo colaborativo y orientado a las personas. En nuestro país, la escasa investigación realizada sobre este tópico, y referida fundamentalmente a instituciones educativas no universitarias, reitera este lugar común sobre las bondades del estilo de liderazgo que ponen en marcha las mujeres en cargos directivos (Carrasco, 2004; Díez y otros, 2004). 


\subsection{Percepciones sobre el liderazgo femenino en la Universidad}

Nuestra propia investigación ha tratado de incorporar este mismo debate al estudio de la mujer en la gestión universitaria. En concreto, nos hemos interesado por conocer y analizar las percepciones que tanto las gestoras universitarias como sus compañeros y compañeras tienen sobre el carácter distintivo que las mujeres tienen a la hora de dirigir y liderar en la Universidad. Así, a través de múltiples entrevistas y observaciones realizadas en escenarios representativos de distintos contextos de la gestión universitaria (distintos cargos, distintas áreas de conocimiento, etcétera), hemos construido distintos relatos que, tomando en cada caso como protagonista a una mujer directiva, pretenden dar cuenta de primera mano de la visión que los propios actores tienen sobre el papel de la mujer en la gestión universitaria. Aunque será en sucesivos capítulos donde ofreceremos al lector un relato más pormenorizado de estas historias, hemos optado por incluir en este capítulo una breve referencia sobre las definiciones que los y las participantes en nuestro estudio manejan en torno a la cuestión del «liderazgo femenino».

En términos generales, las diferencias en los estilos de gestión basadas en el género resultan menos visibles para los hombres que hemos entrevistado que para las mujeres. No obstante, no solo la mayoría de los hombres, sino también un número considerable de mujeres han atribuido las características que perciben en sus directivos a factores de índole personal o cultural que no guardan relación directa con el género. De acuerdo con esta interpretación dominante, los estilos de gestión lo son de modo específico para cada individuo por sus rasgos personales o culturales, con independencia del género (entendido fundamentalmente en términos de sexo biológico).

Paradójicamente, esta tendencia a desligar el género de cualquier explicación sobre el comportamiento en los puestos de gestión convive en los discursos de nuestros participantes con la enumeración de una serie de características que aquellos/as tienden a identificar como típicas de lo que podría entenderse como un «estilo femenino» de liderazgo. Entre estas características, resultan de especial significación las que a continuación describimos. 
En primer lugar, a la mujer suele reconocérsele un estilo distintivo de ejercicio del poder y la autoridad. En consonancia con lo planteado en la literatura sobre el tema, se trataría de un perfil que, impregnado de notables tintes «maternales», integra autoridad, delicadeza y diplomacia en un delicado equilibrio en el despliegue de las habilidades de dirección. Similarmente, entre las protagonistas de nuestro estudio es fácil encontrar bastantes ejemplos de una clara orientación hacia las relaciones sociales y de consideración de los aspectos personales en la gestión. Conseguir el bienestar de las personas constituye uno de los principales objetivos que justifican su estancia en el cargo. Por lo tanto, una primera conclusión que nos parece importante respecto al liderazgo de las mujeres en cargos de gestión universitaria es que, junto a una firme resolución en la toma de decisiones, existe una clara orientación hacia la gestión de las relaciones interpersonales y al uso de habilidades sociales — las que habitualmente agrupamos bajo la metáfora de «tener mano izquierda».

Otro rasgo señalado sistemáticamente como característico del estilo de gestión de las protagonistas de nuestro estudio es su gran implicación en las tareas, acaparando estas incluso su tiempo personal. Esta forma de operar, consistente en anteponer los intereses colectivos a los personales, es propia del rol tradicional femenino, forjado asimismo en cierta idealización del sacrificio personal.

Finalmente, no podemos decir que la mayor disposición hacia el trabajo en equipo sea un rasgo mayoritario en los casos estudiados. Sin embargo, como ya hemos sugerido anteriormente en este capítulo, algunas investigaciones han destacado como un rasgo innovador de los liderazgos ejercidos por mujeres la tendencia a compartir el liderazgo y a buscar el apoyo de un equipo en el ejercicio de la dirección, a diferencia de los hombres, que actuarían de acuerdo con patrones más individualistas.

Además de todas estas cuestiones (un estilo negociador y a la vez resolutivo de ejercicio del poder, una clara orientación hacia el cuidado de las relaciones interpersonales, una tendencia al liderazgo en condiciones de no-visibilidad, y un firme compromiso personal con la tarea), hay otros rasgos con los que nuestros informantes se 
han referido al comportamiento femenino en la gestión. La distinción entre uso «monocrónico» y «policrónico» del tiempo, por ejemplo, tiende a reiterarse en las tentativas de descripción, respectivamente, de los modos masculino y femenino de hacer en la gestión. De acuerdo con esta clasificación, las mujeres tienden a mostrar una mayor versatilidad en el manejo de situaciones que requieren la atención simultánea a asuntos o tareas diversas, mientras que los hombres suelen mostrarse más limitados en el despliegue de estas capacidades, tendiendo a resolver las cuestiones de modo secuencial y no simultáneo. Asimismo, en los relatos de nuestros y nuestras participantes las mujeres tienden a ser representadas como más conciliadoras, más perfeccionistas, menos competitivas y más comprometidas socialmente con la familia. En tales relatos también se reitera la idea de que el aspecto físico de una mujer condiciona fuertemente la imagen que proyecta en la realización de su trabajo, mientras que esta cuestión es secundaria a la hora de juzgar el desempeño de los directivos varones. Finalmente, a las mujeres se les atribuye un mayor pragmatismo y un modo más resolutivo de encarar los problemas de la organización, frente a la visión más estratégica 0 , si se prefiere, el estilo más «político» que suelen exhibir los hombres.

\section{5. ¿Existe, entonces, un estilo femenino de liderazgo?}

A lo largo de este capítulo hemos puesto de relieve cómo, en su esfuerzo por tratar de hacer a las mujeres más visibles en la gestión, la teoría organizativa ha adoptado estrategias bien conocidas por los desarrollos feministas: tratar de asemejarlas más al prototipo masculino, validar las características tradicionalmente adscritas al estereotipo femenino y, con menor frecuencia, luchar por abolir o minimizar las categorías de género en su conjunto. De todas ellas, las preocupadas por la celebración y la revalorización de lo femenino (esto es, las orientadas hacia el polo de la diferencia) han ocupado y ocupan un lugar destacado. A merced de ellas se ha generado todo un discurso que, bajo el cliché del llamado «liderazgo femenino», aboga por la incorporación de la mujer a los puestos de responsabilidad en aras de sus supuestas cualidades diferenciales basadas 
en el género. De hecho, como hemos señalado, la aparición de los «nuevos» enfoques del liderazgo transformacional coincide con el desarrollo de una mayor sensibilidad hacia las experiencias de las mujeres en las organizaciones y, consecuentemente, en los procesos de gestión y de liderazgo y, de modo especial, con la aceptación y consolidación del discurso en torno al «liderazgo femenino».

Más allá del acuerdo que pueda existir entre los y las participantes en nuestro estudio de atribuir a sus directivas una serie de patrones o estilos distintivos de liderar, lo cierto es que la noción del llamado «liderazgo femenino» se ha convertido en un lugar común - y débilmente contestado- en la literatura de corte populista e, incluso, académica. Aunque no es nuestro objetivo en este capítulo sistematizar una crítica en torno a la idea del «liderazgo femenino», sí queremos llamar la atención sobre los peligros que puede determinar lo que podríamos denominar una lectura «esencialista» o radicalizada del mismo. De acuerdo con nuestra propia lectura del tema, los discursos en torno al «liderazgo femenino» son susceptibles de, al menos, dos posibles lecturas. Por un lado, la idea de que existe un patrón distintivamente femenino de comportamiento en el ejercicio del liderazgo puede interpretarse como un ideal normativo, esto es, como un referente que, lejos de relacionar determinadas pautas de comportamiento con determinados atributos corporales o genéticos (esto es, sexuales), reclama nuevas imágenes y enfoques para promover el cambio en las organizaciones. Por otro lado, esa misma idea puede verse sujeta a una interpretación esencialista, que reduce el estilo femenino a un constructo empírico. De acuerdo con esta lectura esencialista, las mujeres son entendidas como una categoría homogénea a la que se le atribuye cierta superioridad moral, contribuyendo de este modo a perpetuar los estereotipos de género y, con ellos, las estructuras de división del trabajo que los hacen posibles (Billing y Alvesson, 2000). Pues bien, es en relación a esta segunda lectura - la más extendida, por lo demás- donde encontramos una serie de argumentos que necesitan ser reconsiderados críticamente.

En primer lugar, si nos atenemos estrictamente a la investigación disponible, resulta imprescindible apuntar que, empíricamente, los discursos esencialistas del liderazgo basado en la diferencia de 
sexos no se sostienen por una evidencia robusta. Aunque algunas investigaciones tienden a apoyar esta posición (Burke y Collins, 2001; Stanford y otros, 1995), en líneas generales, puede afirmarse que el debate en torno a la existencia del llamado estilo «femenino» de liderazgo presenta un carácter marcadamente conceptual, o incluso ideológico, mientras que su base empírica es escasa y ofrece, de acuerdo con algunas revisiones realizadas sobre el tópico (AlimoMetcéteraalfe, 1995; Butterfield y Grinnell, 1999; Eagly y Johnson, 1990; Riehl y Lee, 1996) resultados poco concluyentes. Sus argumentos, sin embargo, suelen tomarse como indicativos de una realidad empírica que, desde la perspectiva adoptada en este trabajo, realiza diversas asociaciones problemáticas, a saber:

- Una identificación entre lo femenino y la mujer, de acuerdo con la cual todas las mujeres comparten una serie de atributos de comportamiento y una serie de orientaciones similares en su forma de entender el mundo y actuar en él.

- Una identificación entre lo femenino y lo feminista, de acuerdo con la cual todas las mujeres tienen una conciencia similar sobre el modo en que las construcciones de género conforman sus identidades y definen su rol en el mundo y en las organizaciones.

- Una identificación entre el estilo deseado y el estilo realmente exhibido, que omite la importancia que tienen las contingencias situacionales y las normas culturales implícitas en definir y conformar el modo en que finalmente se comportan las personas responsables de la gestión.

En segundo lugar, esta lectura «esencialista» comporta en ocasiones una radicalización del constructo «liderazgo femenino». En este sentido, existe en la actualidad un considerable volumen de trabajos que tienden a revalorizar «lo femenino» en contextos organizativos que tradicionalmente han operado sobre asunciones y patrones de comportamiento típicamente masculinos. Se trata de un discurso que tiende a ganar popularidad en círculos empresariales, educativos y, hasta cierto punto, en el sentido común, y que reclama la celebración de los valores femeninos y la valoración de la diversidad en la coyuntura actual de la gestión. Este discurso es conver- 
gente - en apariencia- con los «nuevos» y más suaves discursos sobre gestión que se centran en la buena gestión de las personas como la nueva fuente de productividad en las organizaciones flexibles postmodernas. Los textos de gestión - fundamentalmente los destinados a un público no académico - hablan, en este sentido, de la «ventaja femenina» en el liderazgo (Helgesen, 1990; Rosener, 1990). De acuerdo con la autora feminista Sally Helgesen (1990), los talentos, las experiencias y las destrezas que poseen las mujeres son precisamente las que se necesitan para el liderazgo en la economía postindustrial, lo que está creando oportunidades sin precedentes para que las mujeres desempeñen un rol crucial en liderar el cambio transformacional en nuestras organizaciones. Una postura similar es la mantenida por Rosener (1990), que argumenta en estos términos los beneficios derivados de incorporar la «ventaja femenina» en los puestos de gestión:

[...] una nueva ola de mujeres se está abriendo paso en la alta gestión, pero no a través de la adopción del estilo y los hábitos que se han manifestado eficaces para los hombres, sino recurriendo a las destrezas y actitudes que han desarrollado a partir de su experiencia compartida como mujeres. [...] Están teniendo éxito a partir de -y no a pesar de- ciertas características generalmente consideradas «femeninas» y poco apropiadas para los líderes. El éxito de estas mujeres muestra que un estilo de liderazgo no tradicional se ajusta bien a las condiciones de algunos entornos de trabajo, y pueden incrementar las oportunidades de una organización de sobrevivir en un mundo incierto. (pp. 119-120).

Desde esta perspectiva, por tanto, la presencia de las mujeres en puestos de responsabilidad se justifica porque aquellas son capaces de desarrollar estilos de liderazgo acordes con los nuevos modelos organizativos "postmodernos» centrados en las relaciones horizontales y el trabajo en equipo. De una manera consistente con este discurso de la «ventaja femenina» en las organizaciones productivas, también en las instituciones educativas se ha reclamado una mayor presencia de liderazgo femenino en aras de un funcionamiento organizativo más eficaz. Coleman (2000), por ejemplo, concluye en su investigación sobre directoras de secundaria que, puesto que las mujeres tienden a operar de una manera colaborativa y orientada a capacitar a los demás, «su falta de representación también indica 
una pérdida de liderazgo potencialmente eficaz en las escuelas» (p. 26). Siguiendo esta misma lógica discursiva, un argumento similar podría esgrimirse para la gestión de las Universidades en tiempos de turbulencia, cambio y transición.

Desde una lectura crítica, sin embargo, el discurso de la «ventaja femenina» corre el riesgo de ser apropiado por una lógica productiva. Algunos trabajos señalan la ironía que reside en que las organizaciones comiencen a valorar los rasgos «femeninos» como potencialmente favorecedores de cierta ventaja competitiva, y desvelan que tras un aparente descentramiento de los tradicionales discursos masculinistas lo que en realidad puede estar ocurriendo es una reordenación estratégica de los mismos. No resulta difícil, de hecho, establecer conexiones entre el ensalzamiento de las supuestas virtudes femeninas para el liderazgo organizativo en la era del cambio y la instrumentalización de la que la mujer puede ser objeto en todo este proceso. Tal como discutimos en el capítulo 4, el creciente protagonismo de la mujer en la gestión de las organizaciones universitarias —especialmente en la gestión intermedia- adquiere una significación menos igualitaria también cuando se contempla como una respuesta a las crisis institucionales.

\subsection{A modo de conclusión}

En este capítulo hemos discutido algunas de las contradicciones que pueden derivarse de una lectura esencialista — dominante, por lo demás- del discurso del liderazgo femenino, que comporta una visión de hombres y mujeres como variables o portadores de posiciones distintivas e internamente homogéneas. Apoyándonos en el análisis de los significados expresados por un colectivo de directivas y sus respectivos compañeros, hemos tratado de ampliar los límites del discurso del liderazgo femenino más allá de esta lectura esencialista.

De acuerdo con nuestra particular lectura del devenir histórico que ha acompañado el «extraño» binomio que forman organización y género, la incorporación de una perspectiva de género al estudio del liderazgo ha permanecido atrapada en las mismas estructuras y lógi- 
cas de comprensión que pretende superar, acomodándose a los discursos dominantes y, por tanto, reproduciéndolos y minimizando la vocación transformadora que cabía esperar de los discursos críticos basados en una lectura de género de la realidad organizativa. Esto es, en lugar de ofrecer una alternativa al ejercicio del liderazgo que cuestione las asunciones y principios básicos sobre los que descansa la idea misma de liderazgo como categoría, el análisis organizativo desde una perspectiva de género ha tendido a acomodarse, tácitamente, a los esquemas interpretativos dominantes, manifestando una limitada capacidad para imaginar el mundo más allá de las relaciones binarias y estereotipadas «masculino-femenino» y, lo que es más importante, para desvelar las estructuras de poder que subyacen a su origen y las sostienen. De acuerdo con estos esquemas interpretativos, el debate en torno a las relaciones entre género y liderazgo se ha establecido en términos reduccionistas y dicotómicos - propios de una lectura moderna y «masculina» del mundo- que refuerzan, antes que interrogan, los estereotipos vigentes. Desde nuestro punto de vista, esto es así en un doble sentido:

- Por un lado, la incorporación de la perspectiva de género al estudio del liderazgo ha limitado el interés epistemológico al debate, fuertemente polarizado, en torno a la diferencia y la similitud entre los estilos de liderazgo exhibidos en función del sexo.

— Por otro lado, la defensa de un supuesto «estilo femenino» de liderazgo se ha venido realizando de modo igualmente dicotómico y de acuerdo con las categorías de liderazgo establecidas. En este sentido, la aportación de la perspectiva de género, tanto a las teorías clásicas del liderazgo como a las nuevas, ha consistido en una reinterpretación de las mismas, asignando el rasgo de «masculino» a una serie de los estilos definidos (por ejemplo, «autocrático», «orientado a la tarea», «transaccional») y el de «femenino» al estilo opuesto o complementario (por ejemplo, «democrático», «orientado a las relaciones», «transformacional»).

Es probable que, tal como ya han señalado otros autores (Alvesson y Billing, 1992; 1997: 178), sea más productivo en este punto 
abandonar nuestra obsesión por buscar diferencias de género en el ejercicio del liderazgo, y explorar en su lugar cómo las normas de género regulan el comportamiento organizativo y cómo distintos tipos de liderazgo contribuyen a la construcción de masculinidades y feminidades en las culturas organizativas.

Finalmente, los discursos articulados por algunas participantes nos invitan a pensar en el liderazgo femenino como un proyecto asociado al cambio de significados y de valores en lugar de a patrones diferenciales de comportamiento vinculados al sexo. El discurso del estilo femenino, por tanto, no tiene sentido desde la perspectiva del sexo de la persona que lo desarrolla, sino en referencia a lo que, hasta el momento, ha sido el modelo dominante de entender el liderazgo en la Universidad. Este puede calificarse como «masculino» no tanto porque todos los hombres muestren una predisposición a comportarse de un determinado modo cuando asumen un cargo, sino porque tradicionalmente han sido los hombres quienes han tenido acceso a esto y quienes, por tanto, han participado como colectivo en la construcción social de estos modos de hacer dominantes.

\section{Referencias bibliográficas}

Alimo-Metcalfe, B. (1995), «An Investigation of Female and Male Constructs of Leadership and Empowerment», Women in Management Review, 10(2), 3-8.

Alvesson, M., y Y.D. Billing (1992), "Gender and Organization: Towards a Differentiated Understanding», Organization Studies, 13/12, 73-102.

- (1997), Understanding Gender and Organizations, Londres: Sage.

- (2000), "Questioning the Notion of Feminine Leadership: A Critical Perspective on the Gender Labeling of Leadership», Gender, Work and Organization, 7(3), 144-157.

AsHCRAFT, K.L. (2004), "Gender, Discourse and Organization: Framing a Shifting Relationship», en D. Grant, C. Hardy, C. Oswick y L. Putnam (eds.), The Sage Handbook of Organizational Discourse, Londres: Sage.

BlackmoRe, J. (1996), «"Breaking the Silence”: Feminist Contributions to Educational Administration and Policy», en K. Leithwood, J. Chapman, D. Corson, P. Hallinger y A. Hart (eds.), International Handbook of Educational Leadership and Administration, Dordrecht: Kluwer Academic Publishers. 
BuRKE, S., y K.M. ColLins (2001), «Gender Differences in Leadership Styles and Management Skills», Women in Management Review, 16(5), 244-256.

BUtTERFIELD, D.A., y J.P. GRINNELL (1999), «"Reviewing” Gender, Leadership and Managerial Behavior: Do Three Decades of Research Tell Us Anything?», en G.N. Powell (ed.), Handbook of Gender and Work (223238), Thousand Oaks: Sage.

Calás, M., y L. SMircich (1996), «From the Woman's Point of View: Feminist Approaches to Organization Studies», en S. Clegg, C. Hardy y W. Nord (eds.), Handbook of Organization Studies (218-257), Londres: Sage.

- (2006), «From the "Woman's Point of View" Ten Years Later: Towards a Feminist Organization Studies», en S.R. Clegg, C. Hardy, T.B. Lawrence y W.R. Nord (eds.), The Sage Handbook of Organization Studies (segunda edición), Londres: Sage.

CARRASCO, M.J. (2004), «El liderazgo femenino ante la mejora educativa», en A. Villa (coord.), Dirección para la innovación: Apertura de los centros a la sociedad del conocimiento, Bilbao: Ediciones Mensajero.

Coleman, M. (2000), «The Female Secondary Headteacher in England and Wales: Leadership and Management Styles», Educational Research, 42(1), 13-27.

DíEz, E.J., y E. TERRón (2004), «Barreras en el acceso de las mujeres a puestos directivos en las organizaciones educativas», en J. López, M. Sánchez y P. Murillo (eds.), Cambiar con la sociedad, cambiar la sociedad. Actas del $8{ }^{\circ}$ Congreso Interuniversitario de Organización de Instituciones Educativas, Sevilla: Secretariado de Publicaciones de la Universidad de Sevilla.

EAGLy, A.H., y M.C. JohanNESEN-Schmidt (2001), «The Leadership Styles of Women and Men», Journal of Social Issues, 57(4), 781-797.

— y B. Johnson (1990), «Gender and Leadership Style: A Meta-Analysis», Psychological Bulletin, 108 (2), 233-256.

- W. Wood y A.B. DiekMan (2000), «Social Role Theory of Sex Differences and Similarities: A Current Appraisal», en T. Eckes y H.M. Trautner (eds.), The Developmental Social Psychology of Gender, Mahwah: Erlbaum.

Ely, R.J., y D.E. MEYerson (2000), «Theories of Gender in Organizations: A New Approach to Organizational Analysis and Change», Research in Organizational Behaviour, vol. 22, 103-151.

GraY, H.L. (1989), «Gender Considerations in School Managament: Masculine and Femenine Leadership Styles», en C. Riches y C. Morgan (eds.), Human Resource Management in Education, Milton Keynes: Open University Press. 
GrAY, H.L. (1993), «Gender Issues in Management Training», en J. Ozga (ed.), Women in Educational Management, Buckingham: Open University Press.

GREY, C. (2005), Studying Organizations, Londres: Sage.

Helgesen, S. (1990), The Female Advantadge: Women's Ways of Leadership, Nueva York: Doubleday.

MeIndL, J., S. ERLich y J. DUkeRich (1985), «The Romance of Leadership», Administrative Science Quarterly, 30(1), 78-102.

RieHL, C., y V.E. LEE (1996), «Gender, Organizations and Leadership», en K. Leithwood, J. Chapman, D. Corson, P. Hallinger y A. Hart (eds.), International Handbook of Educational Leadership and Administration, Dordrecht: Kluwer Academic Publishers.

Rosener, J.B. (1990), «Ways Women Lead», Harvard Business Review, noviembre-diciembre, 119-125.

Stanford, J.H., B.R. OAtES y D. Flores (1995), «Women's Leadership Styles: a Heuristic Analysis», Women in Managament Review, 10(2), 9-16.

Tong, R. (1998), Feminist Thought: A Comprehensive Introduction (segunda edición), Boulder: Westview. 



\title{
CAPÍTULO 3 EL PERFIL DE LAS MUJERES QUE DESEMPEÑAN CARGOS DE GESTIÓN EN LA UNIVERSIDAD
}

\author{
Paulino Murillo Estepa
}

\subsection{Un estudio sobre las mujeres que ocupan cargos en las Universidades españolas}

En los dos siguientes capítulos vamos a abordar algunos de los resultados más relevantes procedentes del ya mencionado estudio desarrollado por nuestro equipo de investigación, cuyo propósito general fue conocer los estilos de liderazgo de un conjunto de directivas de organizaciones universitarias españolas, los roles desempeñados, los problemas y las necesidades formativas percibidos por ellas, así como su contribución a la construcción de la cultura de sus unidades académicas. Este capítulo concretamente dará cuenta del perfil de las mujeres que ocupan cargos en la Universidad.

Vamos a sintetizar a continuación los propósitos iniciales que guiaron nuestro estudio, a fin de definir nuestros intereses y dar cuenta del proceso que se siguió en la indagación.

Dos fueron los objetivos fundamentales que orientaron nuestro trabajo:

- Analizar el perfil de las rectoras, vicerrectoras, directoras de grupos de investigación, decanas y directoras de Departamentos universitarios, describiendo las condiciones profesionales de su actividad y el estudio de sus necesidades formativas. 
- Describir, comprender y analizar los procesos de dirección tanto de mujeres que desempeñan cargos de gestión en la Universidad como de aquellas que concretamente se encuentran al frente de Departamentos universitarios.

De manera más concreta, las intenciones de trabajo del equipo de investigación, entre otras, pasaron por describir las condiciones organizativas en las que estas mujeres desarrollan su actividad profesional, identificar perfiles profesionales de los grupos, así como los estilos de liderazgo de los diferentes colectivos estudiados.

Por otro lado, nos interesó también describir las características contextuales en las que las directivas universitarias desarrollaban su actividad, indagar en las relaciones entre función directiva y desarrollo profesional de las docentes universitarias y describir la intervención de las Directoras de Departamento en la construcción de la cultura organizativa en el ámbito departamental.

\subsubsection{Metodología de la investigación}

La investigación de la que se desprenden los datos a los que vamos a hacer referencia en los siguientes apartados y capítulos se desarrolló en dos fases. La primera tuvo un carácter descriptivo y se basó en los datos obtenidos a partir de dos cuestionarios diseñados ad hoc. El primero de ellos, el Cuestionario de opinión de mujeres que ejercen cargos directivos en la Universidad (COMECADU), fue respondido y devuelto por 136 directivas que representaban el $31,26 \%$ de las 435 que componían la muestra de mujeres que en aquel momento desempeñaban cargos de gestión en las Universidades españolas. Dicho cuestionario indagaba acerca del perfil profesional de las participantes en el estudio, además de los roles desempeñados, sus estilos de liderazgo, los problemas y las necesidades formativas percibidos por ellas, así como su contribución a la construcción de la cultura de sus unidades académicas.

Un segundo cuestionario estuvo dirigido a las personas que trabajaban en las unidades dirigidas por las participantes en el estudio. Su propósito fue contrastar la visión que de sí mismas ofrecieron las directivas en el primer cuestionario, en particular respecto a 
la forma de ejercer el poder, así como analizar el impacto que dicho ejercicio estaba teniendo sobre el funcionamiento institucional de dichas unidades. Para ello nos concentramos en los Departamentos, que eran las unidades que presentaban mayor interés para el mencionado propósito. Hicimos una selección de estos basada en los siguientes criterios: $a$ ) distribución equilibrada por comunidades autónomas, $b$ ) por tipo de Universidad, de acuerdo con su gestión pública o privada, $c$ ) por área de conocimiento del Departamento, y d) en función del estilo de liderazgo de la directiva correspondiente. Este cuestionario fue respondido por 91 docentes, pertenecientes a diecisiete de los diecinueve Departamentos consultados.

Algunas de las conclusiones más destacables de esta primera fase fueron las siguientes:

- Desde el establecimiento de la población del estudio se evidenció el desequilibrio en el acceso a los cargos de gestión por parte de profesoras y profesores, siempre a favor de estos.

- Se identificó la tendencia predominante hacia un estilo de liderazgo flexible y adaptativo que utiliza una amplia gama de fuentes de poder en función de las exigencias de cada situación.

- Se identificó el predominio en las directivas de una visión policrónica de la gestión y la resolución de problemas.

- El interés por el cuidado de las relaciones sociales y la atención a las necesidades de los miembros de la organización apareció como característica importante.

- Se reconoció el deterioro de la dedicación a las tareas de investigación como principal consecuencia del ejercicio de cargos de gestión.

En la segunda fase de la investigación, de carácter cualitativo, se seleccionaron ocho casos para su estudio en profundidad, sobre la base de diferentes criterios. En primer lugar se consideró la orientación predominante del estilo de liderazgo, a partir de los datos obtenidos en las respuestas dadas en el primer cuestionario.

A continuación, para la selección definitiva, al igual que en la selección de los Departamentos de la fase anterior, se consideró la 
búsqueda de un cierto equilibrio entre los demás criterios: a) Comunidad Autónoma de procedencia; $b$ ) área de conocimiento; $c$ ) gestión pública o privada de la Universidad y $d$ ) cargo de la directiva a seleccionar.

La información para el análisis de los casos se obtuvo a través de entrevistas y observaciones de campo, así como de reuniones y estudio de documentos. Respecto a las entrevistas, estas se realizaron tanto a la directiva protagonista de cada uno de los estudios de caso como a algunos de los agentes de la unidad en cuestión, incluyendo al menos a una persona consolidada en la institución, una persona joven en la misma, un miembro del personal de administración y servicios y, en algunos casos, a estudiantes. Las entrevistas se realizaron siguiendo guiones semiestructurados que, en el caso de las directivas, se referían a su trayectoria personal y profesional, cuestiones relacionadas con el desempeño del cargo (experiencias y percepciones, prioridades y preocupaciones, estilo u orientación, problemas encontrados, condicionantes en el acceso y necesidades formativas), valoración de su gestión, así como algunas cuestiones sobre aspectos institucionales: proyectos realizados, acontecimientos significativos, conflictos, relaciones con otras entidades, historia institucional, cambios experimentados, etcétera. Por otra parte, el guión de las entrevistas dirigidas al resto de los agentes de la unidad estudiada incluía preguntas sobre el rol que desempeñaban en la organización y su trayectoria en ella, acerca del desempeño en la gestión de la directiva protagonista del caso, sus características como gestora y estilo de liderazgo, y acerca de las condiciones organizativas en las que dicha directiva desarrolla su trabajo (satisfacción personal, problemas relevantes, oportunidades de mejora, proyectos e iniciativas, ambiente de trabajo).

Además se analizaron documentos (actas de Consejos de Departamentos, comunicaciones formales, agendas, proyectos en curso, etcétera) y se observaron actos de gestión, como consecuencia de un acompañamiento sistemático de la directiva protagonista durante un periodo de tiempo negociado con ella, en las actividades programadas en su agenda como, por ejemplo, Juntas de Facultad, Consejos de Departamentos, reuniones del equipo directivo, etcétera. También los encuentros informales mantenidos con las entrevistadas, 
pese a no ser registrados, proporcionaron una rica información sobre su estilo de liderazgo. Las visitas tuvieron una duración que osciló entre uno y tres días, de acuerdo con la disponibilidad de los miembros de cada organización.

Las entrevistas fueron grabadas en audio y posteriormente transcritas para su análisis. En dicho análisis se utilizó un sistema de siete categorías:

- Trayectoria personal y profesional, categoría que englobaba la información biográfica de la persona entrevistada, a fin de poner en relación sus circunstancias personales con el desarrollo de su vida profesional.

- Acceso al cargo, categoría que reunía información mediante la que poder describir el momento y las razones del acercamiento a las labores de gestión, por parte de la protagonista del caso, considerando tanto las circunstancias como las expectativas.

- Percepciones sobre el género, con objeto de reunir las opiniones relativas a la incidencia de la variable género en la vida profesional de la protagonista, considerando también sus experiencias y percepciones sobre la influencia de dicha variable en el desarrollo profesional.

- Desempeño del cargo/tarea, a fin de conocer las actividades de gestión que desempeñaba la protagonista, así como el modo en el que las llevaba a cabo y el impacto que tenían sobre ella. En esta categoría se consideraron tanto las necesidades formativas de cada una de las protagonistas como sus percepciones sobre los aspectos de la tarea que más se priorizan o descuidan, así como las preocupaciones sobre su cumplimiento y los sentimientos y actitudes con respecto a las actividades de gestión y estilo de liderazgo.

- Problemas detectados en relación con la tarea, con objeto de recopilar las diferentes dificultades que las directivas encontraban en el desempeño de su función, tanto en su relación con otros colegas y grupos como las relativas a la unidad organizativa en la que estaban implicadas. Todo ello, junto a las dificultades de tipo individual relacionadas con la organización de la tarea, el empleo del tiempo y el ejercicio del cargo. 
- Opiniones generales, como categoría para recoger la forma de pensar de las directivas, también del resto de personas entrevistadas, acerca del género, el liderazgo y la función directiva.

- Historia y condiciones institucionales, categoría referida a las características institucionales que, de acuerdo con la posición asumida en la investigación, podía incidir en el desarrollo organizativo y en el ejercicio del liderazgo y las funciones de gestión en la Universidad. Esta categoría contemplaba también la recogida de información sobre proyectos, conflictos organizativos, relaciones institucionales con diferentes instancias, etcétera.

Este sistema de categorías fue el utilizado tanto para las entrevistas realizadas con las directivas como para aquellas que tuvieron como interlocutores al resto de los agentes participantes en la investigación. A la hora de codificar, se empleó un sistema de codificación múltiple: descriptiva e interpretativa, y utilizamos el programa de análisis de datos cualitativos AQUAD 5 para el procesamiento y análisis del conjunto de la información.

Los informes de cada caso se realizaron por parejas de investigadores. A continuación, cada informe fue revisado por el resto del equipo de investigación, como medio de control de la implicación de los investigadores en relación con su objeto de estudio. Una vez se hubo elaborado el informe de cada caso, y remitido a cada una de las directivas participantes en el estudio de caso, se realizó un análisis transversal con objeto de poder establecer regularidades entre ellos y poder extraer conclusiones a la luz de la literatura específica.

\subsection{Algunos referentes sobre el tema de estudio}

La igualdad de género en los cargos de gestión de las Universidades españolas, también en las categorías profesionales, sigue siendo un objetivo sin conseguir, a pesar de su reconocimiento y de las iniciativas tomadas desde diferentes sectores en pro de su consecución. Cualquier análisis actual sobre la realidad de nuestras Universidades nos muestra con claridad como en estas, aun estando llenas de mujeres, son los hombres los que lideran el mayor número de 
proyectos de investigación y quienes tienen más poder de decisión, aparte de ser quienes tienen el mayor porcentaje en las categorías profesionales más altas.

El Foro de los Consejos Sociales de las Universidades Públicas de Andalucía, en un informe presentado en la ciudad de Huelva, según el cual la paridad está ausente en la mayoría de los órganos unipersonales de gobierno de las Universidades andaluzas ( $E l$ Correo de Andalucía, 22 de noviembre de 2007), ofrece algunos datos que reflejan la realidad a la que nos estamos refiriendo. Por ejemplo, en cuanto a los órganos de gestión y dirección, actualmente la presencia de mujeres solo supera el $40 \%$ en las Secretarías Generales de las Universidades y en las Secretarías de los Consejos Sociales, lo que no deja de ser llamativo, pero los datos más determinantes aparecen en el apartado de los cuerpos docentes. Las nueve Universidades públicas andaluzas cuentan con 1113 catedráticos frente a 150 catedráticas, según los datos del informe Académicas en cifras elaborado por el Ministerio de Educación y Ciencia. Esto significa que en lo que respecta a las cátedras, las mujeres representan un 11,87\%, lejos aún del $20 \%$ que ha de alcanzarse en 2011, según las directrices marcadas en el nuevo modelo de financiación de las Universidades públicas andaluzas (2007-2011).

Lo anterior significa que si bien es cierto que el avance social producido, en cuanto a cambios evolutivos que tienen como protagonista a la mujer, ha sido espectacular, ${ }^{1}$ esto no se ha traducido en su acceso a los puestos directivos, de gestión y/o de representación. A pesar de ello, según algunos informes, ${ }^{2}$ la tendencia es clara y bien distinta: el siglo actual será el siglo de la consolidación de la presencia social de la mujer.

1 En 1900, el 71,4\% del sector femenino era analfabeto; en 2001, solo el 3,4 \%. En 1960, el porcentaje de mujeres con estudios superiores era de un 0,14\%. En la actualidad, el $13 \%$ de la población femenina tiene formación universitaria.

2 Conclusiones del estudio Actividad y territorio. Un siglo de cambios de la Fundación BBVA y el Instituto Valenciano de Investigaciones Económicas (IVIE), elaborado por los profesores Francisco Goerlich, Matilde Más, Joaquín Azagra y Pilar Chorén. 
A pesar de los avances producidos en los últimos años con respecto a la representación de la mujer en cargos directivos de las Universidades y otras organizaciones empresariales y sociales, lo cierto es que dicha representación es todavía pequeña en la mayoría de los países del mundo y, por supuesto, en nuestro país. No obstante, se da un fenómeno curioso en la percepción de algunos autores con respecto a este tema, sobre todo a la hora de definir algunos conceptos. En este sentido, Daily, Certo y Dalton (1999) plantean la relación que desde su punto de vista existe entre «cargo directivo» y «liderazgo», y si bien piensan que las mujeres que ocupan cargos directivos, en general, han aumentado, no ocurre lo mismo en cuanto a las posiciones de liderazgo que desarrollan. Pero tal vez esto no sea solo cuestión de términos o conceptos, y sí pueda ser indicativo de la confirmación de la teoría de exclusión social, que llega a explicar el escaso número de mujeres que logran romper el «techo de cristal» de los órganos directivos de la mayor parte de las organizaciones. $\mathrm{Y}$ es que todavía existen sesgos de género y estereotipos en los altos órganos de cualquier organización.

El hecho real de que las mujeres vayan ocupando cada vez más cargos directivos en las Universidades españolas responde al crecimiento de la presencia de la mujer en todos los ámbitos de la sociedad. No obstante, hay que reconocer que las mujeres, aun cumpliendo con los roles que la cultura social les ha asignado, pueden seguir avanzando en su desarrollo desde el punto de vista laboral. Aunque los hombres participen en las tareas del hogar, el liderazgo en ese espacio lo suele ostentar la mujer, que además desempeña el rol de madre, el de mujer, incluso el de esposa. Son roles que, por lo general, siguen estando ahí y lo siguen desempeñando las mujeres, más que los hombres, con independencia del papel que les corresponda desempeñar en la gestión y dirección de las organizaciones profesionales a las que pertenecen.

Las mujeres, en general, llegan a tener una visión más global y completa de los problemas a los que se tienen que enfrentar, al igual que suelen aportar una visión más sensible a la resolución de los mismos. Es decir, la mujer suele tener más capacidad que los hombres para aunar lo académico e intelectual con lo humano y lo sen- 
sible. Esto, junto a su capacidad de captar la complejidad de una manera más completa que los hombres, hace que llegue a presentar características diferentes a las de estos, independientemente de los temas culturales que puedan agudizar o no tales diferencias. Desde este punto de vista, el ámbito académico se constituye en un ámbito formidable de desarrollo de las mujeres, si bien por la diversificación de roles por un lado, y por la falta de oportunidades por otro, el acceso no siempre resulta fácil.

El caso es que la incorporación de la mujer a los órganos directivos es una realidad, pero todavía una realidad incompleta. El espacio ocupado por el ámbito doméstico y familiar, que tanto ha incidido en la incorporación plena de la mujer a la Universidad, va cediendo terreno, y cada vez se acepta menos vivir en relación de desigualdad con la pareja, siempre que ello pueda afectar al proyecto de desarrollo laboral y profesional. Pero la evolución de estos acontecimientos todavía resulta un proceso lento. Y es que la desigualdad depende de factores externos, pero también de otros intrínsecos directamente relacionados con el sistema de valores asumido y transmitido socialmente, pero que puede llegar a ser determinante en cuanto a las creencias, motivaciones, sentimientos y deseos de la mujer respecto a la valoración del desarrollo de su trayectoria y proyecto de vida.

Una de las conclusiones que Barberá, Sarrió y Ramos (2000) presentan en su estudio, dentro de la iniciativa comunitaria de empleo NOW, sobre la dificultad de promoción profesional de las mujeres a puestos de responsabilidad, es que los principales obstáculos vienen determinados por la cultura institucional, los estereotipos de género, y la asunción por parte de las mujeres de las responsabilidades familiares como un «deber» asociado a su rol de género.

En este contexto, nos vamos a referir en los siguientes apartados, en primer lugar, al análisis de algunas opiniones relevantes sobre el trabajo de gestión y acceso al mismo, para a continuación enlazar con el perfil de las mujeres que ocupan cargos de gestión en las Universidades españolas. Vamos a efectuar un recorrido por los perfiles personales y profesionales de estas académi- 
cas, partiendo primero de un perfil general, para detallar más adelante los perfiles concretos en función de los determinados cargos que ocupan.

\subsection{Opiniones sobre el trabajo de gestión y su acceso al mismo}

Una diferencia que aparece reiteradamente entre los hombres y las mujeres que ocupan cargos de gestión es el modo en que dicho cargo repercute sobre sus vidas personales y profesionales (WolfWendel y Ward, 2003). Por tal motivo, fue una de las dimensiones hacia las que orientamos nuestra indagación.

Las mujeres de nuestro estudio opinaron que su trabajo de gestión les afectó de diversas maneras. Principalmente les afectó en la posibilidad (dificultad más bien) de dedicar tiempo a las tareas de investigación, que fueron las más afectadas. Igualmente la disponibilidad de tiempo personal, para dedicarlo a actividades extra-profesionales resultó notablemente afectada. Entre los aspectos que consideraron «muy poco afectados» por las tareas de gestión se encontraron - como ha sido comentado en capítulos anterioreslos referidos a la docencia y la atención a los alumnos en las tutorías, así como el tiempo dedicado a la familia, que apareció como el aspecto menos afectado. La conclusión más evidente de estas respuestas podría ser que las mujeres directivas realizan grandes esfuerzos — que ellas mismas reconocen - para salvaguadar la atención familiar en medio de las exigencias propias del cargo, para lo cual deben pagar el precio de renunciar a una determinada cantidad de tiempo libre o de ocio. Esto último aparece, en diversos estudios sobre el tema, como una de las mayores divergencias entre las vivencias de los hombres y las mujeres que ocupan cargos de gestión. Mientras que, como hemos indicado, el ejercicio del cargo repercute de manera significativa sobre las vidas personales y profesionales de ellas (Wolf-Wendel y Ward, 2003), tiene un impacto relativamente escaso en las de ellos. 
TABLA 1

OPINIONES SOBRE EL TRABAJO DE GESTIÓN Y ACCESO AL MISMO

\begin{tabular}{|l|c|c|c|}
\hline & $\begin{array}{c}\text { Muy poco/ } \\
\text { Poco afectado }\end{array}$ & $\begin{array}{c}\text { Algo } \\
\text { afectado }\end{array}$ & $\begin{array}{c}\text { Bastante/ } \\
\text { Muy afectado }\end{array}$ \\
\hline Docencia & $51,5 \%$ & $12,5 \%$ & $22,8 \%$ \\
Investigación & $16,2 \%$ & $11,8 \%$ & $64,8 \%$ \\
Tutorías & $50,7 \%$ & $14,7 \%$ & $16,2 \%$ \\
Atención alumnos & $44,1 \%$ & $24,3 \%$ & $15,4 \%$ \\
Familia & $38,2 \%$ & $27,2 \%$ & $23,6 \%$ \\
Tiempo personal & $21,4 \%$ & $13,2 \%$ & $51,4 \%$ \\
\hline
\end{tabular}

Otro de los aspectos sobre el que indagamos tuvo que ver con el modo en que el ejercicio del cargo afectaba a la relación con los compañeros. En este sentido, un $48 \%$ de las mujeres consultadas mostró su conformidad en cuanto a que se produjeron cambios en dicha relación, mientras que un 50 \% manifestó que el hecho de ocupar algún cargo no había afectado la relación que mantenían con sus colegas.

Las mujeres que reconocían cambios en su relación con los compañeros aludían a que estos se producían, fundamentalmente, debido a cierto «distanciamiento y enfrentamiento por el ejercicio del poder». Otras causas se encontraban en el hecho de tener que compartir más actividades, lo que hacía que se produjera cierto alejamiento, así como también por cierta «reducción de confianza», al ser consideradas por los compañeros, en algunas ocasiones, como «oponentes» en las relaciones que mantienen con ellos. Por último, algunas mujeres pensaban que sus colegas las consideraban demasiado «controladoras» en el ejercicio del cargo y en su relación con ellos.

También quisimos conocer las motivaciones que las llevaron a asumir responsabilidades en la gestión universitaria. En este sentido, las mujeres consultadas consideraron que los criterios fundamentales que manejaron a la hora de tomar dicha decisión fueron el interés por el desarrollo de un proyecto de grupo (considerado como influyente o muy influyente por casi un $45 \%$ de las participantes), la 
oportunidad de mejora y la satisfacción personal (valorados ambos por cerca del $60 \%$ de las respuestas como factor influyente o muy influyente). Por el contrario, los aspectos que menos influyeron fueron la liberación de horas de docencia (un 55,9\% de las respuestas corresponde a las categorías combinadas de muy poco o poco influyente), así como la remuneración (que reúne un 67,9 \% de respuestas en las categorías que lo entienden como menos influyente) o el prestigio concedido a los cargos públicos (que se aproxima al $60 \%$ de respuestas en esas mismas categorías).

En cuanto a los problemas fundamentales que las directivas de nuestro estudio encontraron en el desarrollo de sus tareas destaca, en primer lugar, el exceso de burocracia que tuvieron que soportar como consecuencia del desempeño del cargo. A este problema las participantes en el estudio añadieron el de los privilegios adquiridos por determinados miembros de la unidad organizativa de referencia, los derivados de un funcionamiento organizativo jerárquico y eficientista, y los provocados por la falta de colaboración del personal administrativo. Otros problemas que fueron señalados en menor grado fueron la dificultad para formar un equipo de confianza, la falta de colaboración del antecesor en el puesto y la falta de respeto a sus decisiones. Por otro lado, la mayoría de las participantes en el estudio consideraban insuficientes las políticas de apoyo relacionadas con la maternidad, como ayudas económicas o de otro tipo que faciliten y permitan a las docentes con hijos pequeños desempeñar cargos de gestión.

Las gestoras universitarias de nuestro estudio pensaban que, en general, se valora muy poco su dedicación a las tareas de gestión, tanto por parte de superiores, colegas, estudiantes o del personal de administración y servicios. Sin embargo, no se sentían valoradas negativamente por sus propios compañeros en la gestión, parcela en la que ellas también mostraron una opinión bastante positiva, sobre todo si consideramos que un $95 \%$ mostró su satisfacción en este sentido, si bien la mitad de las mismas manifestó, al mismo tiempo, la necesidad de mejorar en determinados aspectos.

Respecto a las opiniones y percepciones de las consultadas en relación con los factores que han incidido en su acceso al cargo, así 
como las implicaciones que este ha tenido en el resto de los aspectos de su vida podemos decir que en lo que respecta a la relación entre el trabajo y el ámbito privado un porcentaje bastante mayoritario de las entrevistadas $(78,4 \%)$ se inclinaba por las opciones de rechazo a la afirmación «Mis obligaciones familiares me impiden dedicar más tiempo y atención a mi trabajo», si bien, en alguno de los casos estudiados en profundidad, la opinión manifestada es diferente a la expresada en el cuestionario por esta mayoría.

Además, un amplio porcentaje de las mujeres consultadas no considera tampoco que las obligaciones profesionales resten una cuota significativa de su dedicación a las responsabilidades familiares. La afirmación «Destacar o ascender en mi trabajo es para mi más importante que dedicar mucho tiempo a mi casa o a mi familia» obtuvo un rechazo global del 83,9\%.

El equilibrio que se requiere para compaginar la familia y el trabajo - dirección en la que apuntan las cuestiones anterioresexige, según la mayoría de las consultadas un esfuerzo excesivo que cargan sobre sus espaldas. Eso indica el alto porcentaje de aceptación obtenido sobre la afirmación «Compaginar la atención a la familia y al trabajo solo es posible a costa de un esfuerzo excesivo» (67,7 \% en total). Sin embargo, debe reseñarse también el porcentaje que muestra algún grado de rechazo ante dicha afirmación $(32,3 \%)$, el cual también resulta significativo.

Mayoritariamente $(82,7 \%)$ fue rechazada la afirmación «Desempeñar cargos de gestión me ha traído muchas dificultades y problemas en la relación con mi pareja y/o mi familia». Sin embargo hay que considerar que un 17,3\% muestran algún grado de conformidad con dicha afirmación. Ello podría representar una dificultad añadida, para un número significativo de mujeres, respecto al acceso y la permanencia en puestos de gestión.

Cuando cuestionamos acerca del fomento del desarrollo profesional de las mujeres, una amplia mayoría de las entrevistadas $(70,1 \%)$ se muestra de acuerdo con la afirmación «Las políticas existentes en materia de maternidad son insuficientes para que las docentes estén en igualdad de condiciones respecto a sus compañeros varones a la hora de acceder a los cargos de gestión». Además, 
nuestras mujeres consultadas se muestran muy contundentes al manifestar su desacuerdo con la existencia de «ayudas económicas y de otro tipo que permiten que actualmente una docente con hijos/as pequeños/as pueda desempeñar cargos de gestión».

No es extraño, por tanto, a tenor de los resultados anteriores, que las mujeres de nuestra muestra reclamen mayoritariamente el desarrollo de las políticas de apoyo a la maternidad.

Por otro lado, algunas de las preguntas del cuestionario indagaban sobre la opinión que nuestras directivas poseían acerca de la percepción social de las mujeres que ocupaban puestos de gestión. En este sentido se mostraron de acuerdo con la afirmación «El alumnado se comporta ante una mujer que ocupa un cargo de gestión con igual respeto que ante un hombre». En cuanto a la percepción de las gestoras de nuestra muestra sobre la importancia que sus compañeros y compañeras docentes conceden al hecho de que la mujer ocupe cargos directivos, las respuestas se distribuyeron entre cuatro de las seis posibilidades de elección, si bien la opción más elegida $(30,5 \%)$ fue la relacionada con la afirmación «Mis compañeros/as docentes consideran positivo que una mujer ejerza cargos de gestión».

La percepción que manifestaron sobre sí mismas a la hora de pensar en su capacitación para ejercer cargos de gestión fue elevada ya que mayoritariamente $(92,4 \%)$ afirmaron estar de acuerdo con la declaración «Considero que tengo las capacidades necesarias para ejercer puestos de gestión o dirección». Puesto que se trata de un cuestionario dirigido a mujeres gestoras, cabe interpretar que estas han contestado comparando sus capacidades con las de sus compañeros varones que ejercen puestos de gestión y que se consideran iguales a ellos en cuanto a dichas capacidades.

De manera similar pensamos que cabe interpretar los resultados obtenidos a partir de la afirmación «Acceder a un cargo de gestión ha reforzado mi sentimiento de valía profesional», en la que un $72,4 \%$ de las respuestas se situaron en el abanico de respuestas en torno al acuerdo. No obstante, no hay que desconsiderar que el $27,6 \%$ de las mujeres consultadas parece desvincular el desempeño de puestos de gestión de su realización profesional. Quizás debamos suponer que dicho porcentaje de mujeres consideran que su sentido 
de logro profesional solo se ve realizado a partir del desempeño de las tareas más características del trabajo en la Universidad, la docencia y la investigación.

Finalmente, se puede reconocer un importante grado de acuerdo entre las mujeres gestoras consultadas $(73,9 \%)$ en torno a la afirmación «Ejercer un cargo de gestión me ha restado tiempo de ocio». De igual forma, la afirmación «Acceder a un cargo de gestión me ha supuesto más quebraderos de cabeza y preocupaciones» recaba un acuerdo mayoritario del 80,6\% de las mujeres consultadas.

\subsection{El perfil profesional}

En relación con los aspectos profesionales de las mujeres que respondieron el primero de los cuestionarios al que hemos hecho referencia en el apartado anterior obtuvimos un importante bagaje de información. En primer lugar, hemos de hacer referencia a que la mayor parte de las mujeres que ocupan puestos de responsabilidad en la Universidad posee un significativo nivel de experiencia docente. Si bien este es un factor primordial a la hora de ejercer responsabilidades tanto en hombres como en mujeres, parece ser que a la mujer se le tiene más en cuenta o se le considera más. De este modo, cerca de un $30 \%$ de las académicas que ocupan cargos tienen una experiencia docente de entre dieciséis y veinte años, y casi el $25 \%$ de entre once y quince años, por lo que nos podemos atrever a afirmar que son personas que conocen a fondo la cultura universitaria, así como que poseen un dominio sobrado de la misma.

Pero a la experiencia docente se le une la antigüedad en el lugar en el que se ejerce el cargo. Es decir, las académicas que ejercen responsabilidades en nuestras Universidades son profesionales con un importante nivel de experiencia docente, pero también con una antigüedad apreciable en la institución en la que desarrollan sus funciones.

Atendiendo a este último aspecto, la mayor representación de mujeres (más del $30 \%$ ), lleva en la institución entre once y quince años, mientras que más del $25 \%$ tienen una permanencia en sus 
centros de entre dieciséis y veinte años. Si analizamos estos últimos datos en relación con el correspondiente a la experiencia docente, podemos extraer una conclusión que no por esperada deja de ser interesante. Existe una tendencia generalizada en cuanto a que las mujeres que ocupan cargos en las Universidades poseen una importante experiencia como docentes y han desarrollado su actividad, tanto de docencia como de gestión, en una única institución, lo que no significa que el cargo desempeñado haya sido siempre el mismo.

De este modo, nos encontramos con una realidad en la que el hecho de contar con experiencia y antigüedad en la institución a la hora de desempeñar responsabilidades resultan aspectos claves, así como que existe cierta tendencia a cambiar en el cometido de las mismas, debido al desempeño de cargos diferentes. Resulta interesante apreciar como un gran número de académicas inicia el desarrollo de sus funciones de gestión como secretarias de Departamento, para pasar con posterioridad a cargos de supuesta mayor responsabilidad. Parece como si tuvieran que demostrar su valía paso a paso y no se les otorgara la confianza necesaria de inicio a la hora de proponerles determinados puestos. También podría ser que no se sientan con la propia confianza como para presentarse a ciertos cargos, o que consideren que pueden tener pocas opciones de ser elegidas para los mismos por el hecho de ser mujeres. Sea de una o de otra forma, lo que sí resulta evidente, y lo demuestran los datos, es que la mayor parte de las mujeres que están ejerciendo la dirección de un Departamento han pasado con anterioridad por la secretaría del mismo.

En la época que desarrollamos nuestra investigación sobre la mujer en la dirección y gestión de las organizaciones universitarias (2003-2005), más de la mitad de las académicas que participaron en el estudio estaban en su primera legislatura en el cargo que ocupaban, que no era necesariamente la primera responsabilidad académica que desempeñaban, como ya hemos comentado. En la tabla número 2 presentamos la distribución de los cargos más relevantes ocupados por mujeres. Podemos observar que la mayor frecuencia corresponde a las directoras de Departamentos, seguidas por las vicedecanas. 
TABLA 2

DISTRIBUCIÓN POR CARGO

\begin{tabular}{|c|c|c|}
\hline Cargo & Frecuencia & Porcentaje \\
\hline Vicerrectoras & 5 & $3,7 \%$ \\
Gerentes & 1 & $0,7 \%$ \\
Directora adjunta Rector & 1 & $0,7 \%$ \\
Directora Secretariado & 1 & $0,7 \%$ \\
Decanas & 13 & $9,6 \%$ \\
Vicedecanas & 30 & $22,1 \%$ \\
Secretarias Facultad & 3 & $2,2 \%$ \\
Directoras Departamentos & 38 & $28 \%$ \\
Secretarias Departamentos & 12 & $8,8 \%$ \\
Directoras Grupos de Investigación & 9 & $6,6 \%$ \\
\hline
\end{tabular}

En relación con los cargos que habían desempeñado antes, la categoría «secretaria de Departamento» fue la que recibió mayor número de respuestas. A continuación, y con porcentajes muy igualados, nos encontramos con quienes habían desempeñado previamente el cargo de «vicedecana», el de «directora de Departamento», «secretaria de Facultad», «directora de servicio de Facultad», incluso, entre las vicedecanas, algún que otro vicedecanato diferente al que ocupaban en aquel momento.

La mayoría de estos cargos fueron — según se desprende de la pregunta relativa a la permanencia en la institución de la que formaban parte- desempeñados en la misma Universidad a la que pertenecían las participantes del estudio en el momento de su realización.

Si nos fijamos ahora en los resultados que aparecen en el informe La Universidad española en cifras, elaborado a partir de las páginas web de las distintas Universidades Públicas en enero-febrero de 2007 y revisado en junio de 2007 (<http://www.usc.es/smucea/IMG/pdf/2007-mujeres-Universidad-publica.pdf $>$ ), la mayor representación femenina en el desempeño de cargos unipersonales se produce en los vicerrectorados $(28,9 \%)$. 
El hecho de que tanto los vicerrectorados como los vicedecanatos, en uno y otro estudio, sean los cargos con mayor porcentaje de mujeres puede ser consecuencia de la designación de dichos puestos en respuesta a la voluntad política académica de equilibrar la presencia de mujeres y hombres en los cargos universitarios, pues los rectorados y decanatos, cargos electos, siguen estando en manos de los hombres. No obstante, a pesar de que en los cargos que responden a una política de elección y no de designación, el porcentaje baja considerablemente, no menos cierto es que la representación de la mujer en tales puestos varía mucho en función de la rama de conocimiento, incrementándose en la dirección de escuelas universitarias - situación propiciada por el desempeño de dicho cargo en enfermería y trabajo social-, así como en los Departamentos de Humanidades y Ciencias Sociales y Jurídicas.

Por el contrario, los cargos unipersonales en ramas de conocimiento relacionadas con las enseñanzas técnicas y experimentales son ocupados fundamentalmente por hombres. También resulta muy baja la representación de la mujer en las gerencias de las Universidades. Tal vez pueda servir como explicación a este hecho una posible baja autoeficacia en cuanto a desempeños que tradicionalmente se han considerado como masculinos. En este sentido, la investigación de Hackett (1999) nos viene a mostrar que existe cierta creencia femenina de considerarse menos eficaces en campos como la tecnología y la ciencia en general. También Sarrió et ál. (2002) al referirse a este tema, aluden al fenómeno que Watzlawick, Beavin y Jackson (1991: 96) denominaron profecía autocumplida: «Se trata de una conducta que provoca en los demás la reacción frente a la cual esa conducta sería una reacción apropiada». De este modo la creencia compartida de que las mujeres pueden desempeñar unos trabajos y no otros, puede llevar a que ellas mismas lleguen a creer tal circunstancia, incluso a que no pueden desempeñar determinados puestos, dando así cumplimiento a la profecía.

Por último, una consideración especial merece el hecho de que solo el 6,6\% de las mujeres participantes en nuestro estudio tenía responsabilidades en la dirección y gestión de los grupos de investigación a los que pertenecía. 
Este hecho relevante se especifica en las conclusiones del informe Las mujeres en la Universidad de Sevilla (<http://.sacu.us. es/doc/Igualdad_Conclusiones.pdf>), cuando se hace referencia a que una de las facetas del quehacer universitario en la que consideramos necesario resaltar nuestra presencia es en las tareas de investigación y no tanto en su realización material, como en la responsabilidad de su dirección y gestión de los recursos asignados. Los datos muestran que se ha ido incrementando el porcentaje de mujeres en estos niveles, pero que este aún no se corresponde con nuestra proporción dentro del profesorado universitario ni, posiblemente, con nuestro grado de preparación para ello».

\subsection{El perfil personal y familiar}

En la medida que las diferencias de género se explican cada vez menos en función de enfoques centrados en la persona, se toma cada vez más conciencia de que son factores de tipo contextual los que están incidiendo en la realidad de tales diferencias.

Si bien es cierto que las desigualdades existentes entre hombres y mujeres a la hora de compartir el cuidado de los hijos y las responsabilidades de la casa se han estrechado en los últimos tiempos, no menos cierto resulta que todavía queda bastante camino por recorrer. Según el Instituto de la Mujer (2006), en nuestro país, durante 2004, el porcentaje de hombres ocupados con responsabilidades en las tareas domésticas fue del $16,1 \%$, frente al $63,4 \%$ de mujeres en las mismas condiciones de ocupación. De este modo, mientras que se ha incrementado el número de mujeres que desarrollan su trabajo fuera de casa, no ha disminuido demasiado en cuanto a su carga de responsabilidad dentro de ella, lo que supone un mayor esfuerzo, que casi siempre se refleja en su carrera de desarrollo profesional.

En cuanto a los datos personales y familiares concretos de las mujeres que respondieron el COMECADU (Cuestionario de opinión de mujeres que ejercen cargos directivos en la Universidad), hemos de comentar que la mayoría de ellas $(48,3 \%)$ se sitúan en el intervalo comprendido entre los 36 y los 45 años de edad, aunque 
el punto álgido se nos presenta entre los 41 y 45 años. Estos datos son coherentes con los expresados en el apartado anterior al referirnos al perfil profesional. Por el contrario, observamos que no existen mujeres en la muestra de la investigación que se hallen por debajo de los 33 años de edad. Otro dato a resaltar es que existe el mismo porcentaje de mujeres que ocupan cargos de gestión en el intervalo comprendido entre los 33 y 35 años $(8,5 \%)$ que en el comprendido entre 56 y 60 años.

Respecto a otros datos personales y familiares, en un $69,9 \%$ de los casos, las mujeres que ocupan cargos en nuestras Universidades viven en pareja o casadas, y el $19,9 \%$ se encuentran solteras. El $37,5 \%$ no tiene ningún hijo a su cargo y el $49,3 \%$ sí los tiene, porcentaje que se reparte entre las que tienen un hijo (14,7\%) y las que tienen dos $(34,6 \%)$. Respecto a otras cargas familiares, solo un 5,1\% de las mujeres encuestadas tiene que atender, además, a otras personas que están a su cargo, como padres, abuelos, suegros...

Con referencia a la ayuda que reciben en las tareas domésticas, al margen del papel que pueda jugar en las mismas su pareja u otras personas que convivan en la casa, el $75 \%$ de las mujeres que participaron en la investigación confirmaron disponer de ayuda doméstica externa (un/a asistente/a). Un 10,3\% manifiesta no contar con esa ayuda y el $7,4 \%$, aunque reconoce no disponer de ayuda externa, afirma que cuenta con la colaboración de su pareja y/o de sus hijos.

Si analizamos los perfiles biográficos de algunas de las mujeres que participaron en el estudio encontramos afirmaciones tan rotundas y curiosas como la siguiente: «estoy convencida de que los divorcios aumentan cuando tienes un cargo de gestión, yo todavía no estoy divorciada, pero...» (A. 01; 153-155).

$\mathrm{Y}$ es que suele ocurrir que los notorios esfuerzos de las mujeres que ocupan cargos en nuestras Universidades por llevar adelante su función de la mejor manera sean casi paralelos a la ausencia de reconocimiento de los mismos. No es raro que esta ausencia de compensación incida en la menor permanencia de la mujer en el cargo, o en su deseo de abandonarlo en cuanto acabe su mandato. Son testimonios que nos dejan patente la idea de que ejercer la gestión uni- 
versitaria supone - al menos, para una mujer - abandonar muchas otras cosas. Entre los aspectos de sus vidas que reconocen afectados, merecen contemplarse tanto sus otras funciones como docentes e investigadoras, como su propia vida personal y familiar.

Otra afirmación curiosa, en relación con el freno que suponen en el desarrollo profesional de una mujer sus características personales y familiares, tiene que ver con el cuidado y tutela de sus hijos/as. En algunos casos, la misma opción de tenerlos se ve condicionada por la necesidad de consolidar un puesto con anterioridad a la decisión de ser madre:

[...] yo tengo una niña ahora, hasta no haber finalizado una especie de carrera académica, y eso sí lo hice quizá como condición femenina, tal vez si hubiese sido hombre no me lo hubiese cuestionado tanto (E. 01; 138-139).

En otros casos, se reconoce la pérdida de oportunidades de desarrollo por el tiempo de dedicación a los hijos/as:

Los hombres, en general, no tienen hijos, [...] yo digo que mi marido no tiene hijos, los hijos los tengo yo, y quien ha llevado siempre la familia he sido yo, entonces él puede dedicarse a lo que más le interese (P. 01).

En definitiva, por regla general, la mujer suele dar mayor importancia al ámbito familiar que el hombre, al ser este más ambicioso, y anteponer otros intereses, incluidos los profesionales, al propio ámbito familiar. Esto no quiere decir que todos los hombres sean iguales, pues también existen los que no ambicionan el poder, pero lo frecuente es que haya más ambición en el hombre que en la mujer, de ahí que la mayor parte de los órganos de gobierno de las Universidades españolas estén ocupados por los primeros.

Y es que la influencia del género en el desarrollo profesional ya viene desde el momento en que la mujer inicia su trabajo en la Universidad. Suelen ser momentos en los que se acumula bastante trabajo, lo que junto a la falta de experiencia y, en su caso, la aceptación de cargos de gestión, hace que se tengan que postergar otras opciones de vida relacionadas con lo personal y familiar. Son más 
mujeres que hombres las que no llegan a alcanzar determinados puestos y grados por el hecho de tener que dar respuesta, como mujeres, a determinadas tareas, por lo que, aunque se ha avanzado bastante en cuestión de género, siguen existiendo ciertas diferencias que impiden la consecución de metas concretas.

En síntesis, podemos caracterizar al grupo de mujeres participantes en el estudio como un conjunto de personas de edad mediana, que compartían su vida con otra persona y que contaban con ayudas en la realización de las tareas domésticas, lo cual les dejaría cierto tiempo para dedicarse a tareas de gestión anexas a su función como docentes universitarias.

\subsection{Una mirada al futuro}

Nos hemos referido en este capítulo a datos descriptivos sobre las mujeres que ocupan cargos en las Universidades españolas. Dichos datos, en relación con otros aspectos tratados en esta misma obra fueron complementados con la información extraída en la segunda fase de la investigación, cuyo diseño completo se ha mostrado prometedor para futuros estudios, especialmente en cuanto a la combinación de estrategias cuantitativas y cualitativas. Desde nuestro punto de vista, dichos estudios deberían en el futuro $a$ ) establecer las diferencias que sobre los aspectos estudiados muestran los hombres que ejercen la dirección de este tipo de organizaciones; b) ampliar el análisis del liderazgo de las directivas a un rango más amplio de organizaciones universitarias, especialmente en lo que se refiere a sus culturas organizativas y estructuras de poder; y $c$ ) realizar un seguimiento longitudinal de los procesos de transformación emprendidos por las directivas en el contexto de sus organizaciones.

Tanto la información aportada por estadísticas públicas con datos desagregados por sexo como los datos cuantitativos aportados a partir de los resultados de nuestro estudio demuestran un desequilibrio entre los cargos directivos de las Universidades españolas, en cuanto a su ocupación por hombres y mujeres. Esto nos debe llevar a una reflexión en la que debemos preguntarnos por las raíces y causas de esta situación. 
Es cierto que hoy día las mujeres están más representadas en todas las esferas de la vida social, así como que hemos avanzado bastante en cuanto a una mayor igualdad de la mujer. Incluso podemos decir que ya no existen campos vedados para las mujeres. Tenemos gobiernos paritarios, mujeres ocupando cargos de responsabilidad en las Fuerzas Armadas, en el poder Judicial, etcétera. Por otra parte, ha habido avance también en materia de protección hacia la mujer y la familia. Sin embargo, que más mujeres ocupen posiciones de poder no significa que haya terminado la discriminación. En la Universidad en concreto, los escalafones más altos siguen ocupados en su mayoría por los hombres. Y eso se explica en gran medida porque ellos están avocados de manera casi íntegra a sus carreras profesionales, mientras que la mujer sigue combinando lo académico con lo laboral y familiar. El techo de cristal sigue existiendo. Aunque también es verdad que cada vez más personas presionan sobre él y le están abriendo grandes grietas. Las expectativas de la mujer en el mundo universitario cada vez cuentan con mejores perspectivas. Si logramos conciliar lo máximo posible, el futuro va a resultar muy positivo.

Una gran institución como la Universidad, al igual que una bien organizada sociedad, solo puede darse en el contexto de una mancomunada acción de hombres y mujeres, en un contexto no discriminatorio y de verdadera igualdad. Como venimos diciendo, mucho se ha avanzado, muchas son las grietas que empiezan a aparecer en el techo de cristal, pero sigue siendo necesario crear más programas de fomento para mujeres, así como normas legales de igualdad de oportunidades y de no discriminación. También es importante que las instituciones tomen conciencia de promover la ocupación de cargos directivos con mujeres. De hecho, las que los están ocupando cuentan con una experiencia y perfil más que notables para garantizar una buena gestión, a pesar de los condicionantes y dificultades a que se tienen que enfrentar. El camino por recorrer es aún largo y no está exento de dificultades, pero transitarlo y allanarlo son retos que merece la pena abordar. 


\section{Referencias bibliográficas}

AGUT, S. y P. MARTín (2007), «Factores que dificultan el acceso de las mujeres a puestos de responsabilidad: una revisión teórica», Apuntes de Psicología, 25 (2), 201-214.

BARBerá, E., M. SARRió y A. RAMOS (coords.) (2000), Mujeres directivas: Promoción profesional en España y en el Reino Unido, Valencia: Universidad de Valencia, Instituto Universitario de Estudios de la Mujer.

BuRke, R. (1997), «Women on Corporate Boards of Directors: a Needed Resource», Journal of Business Ethics, 16 (9), 909-915.

Dayly, C., S. Certo y D. Dalton (1999), «A Decade of Corporate Women: Some Progress in the Boardroom, None in the Executive Suite», Strategic Management Journal, 20 (1), 93-99.

HACKETT, G. (1999), «La autoeficacia en la selección y desarrollo profesional», en A. Bandura (ed.), Auto-Eficacia: cómo afrontamos los cambios de la sociedad actual, Bilbao: Desclée De Brouwer.

InSTITUTO DE LA MUJER (2006), «Estadísticas correspondientes al primer trimestre de 2006», en Mujer en cifras (<http://www.mtas.es/mujer/ mujeres/cifras/>).

Sarrió, M., E. Barberá, A. Ramos y C. CANDEla (2002), «El techo de cristal en la promoción profesional de las mujeres», Revista de Psicología Social, 17 (2), 167-182.

Watzlawick, P., J. BEAVIn y D.D. JaCKson (1991), Teoría de la comunicación humana, Barcelona: Herder.

WOLF-WeNDEL, L., y K. WARD (2003) «Future prospects for women faculty: negotiating work and family», en B. Ropers-Huilman (eds.), Gendered Futures in Higher Education. Critical Perspectives For Change, Nueva York: State of New York University Press. 


\title{
CAPÍTULO 4 LA INCORPORACIÓN DE LAS MUJERES A LA GESTIÓN UNIVERSITARIA: UNA RESPUESTA A LAS CRISIS INSTITUCIONALES
}

\author{
Julián López Yáñez
}

¿Están contribuyendo las mujeres que acceden a la dirección de las organizaciones de enseñanza superior a promover cambios en ellas? Si hemos de responder en virtud de los resultados de nuestra investigación, en particular de la fase cualitativa de esta, tenemos que decir rotundamente que sí. Efectivamente, el perfil que predominaba en los ocho casos estudiados fue el de directivas innovadoras, más que el de gestoras. Dicho de otro modo, la mayoría de las directivas orientaron su gestión, en los casos estudiados, a la promoción de importantes cambios que transformaron visiblemente sus Departamentos, Facultades y Universidades. En lugar de acomodarse en la estructura formal y dedicarse al mantenimiento o la gestión de lo ya establecido, esta fue claramente la tendencia que observamos.

Este capítulo tratará de ofrecer algunos detalles acerca de cómo lo hicieron, acerca del perfil de gestoras que adoptaron, del modo en que las circunstancias - difíciles casi siempre- de sus organizaciones influyeron sobre ellas y acerca de las bases o modalidades de ejercicio del poder sobre las que levantaron su liderazgo. En todo caso, podemos adelantar que nuestra investigación puso de manifiesto una especial habilidad por parte de la mayoría de las directivas protagonistas de los ocho casos estudiados para conducir 
sin traumas estos cambios y preservando en buena medida la cohesión social y un ambiente favorable de trabajo. Al parecer estos logros fueron conseguidos mediante estilos de liderazgo bastante flexibles, construidos sobre la base de un uso alternativo de variadas fuentes de poder. Todo ello nos permitirá discutir el papel innovador que las mujeres desempeñan y podrían desempeñar en la educación superior.

A nadie se le oculta que las organizaciones universitarias están atravesando en estos momentos una época turbulenta. La llamada sociedad del conocimiento ha visto en ellas una pieza fundamental. Los países desarrollados tratan denodadamente de hacer que sus economías dependan más de las nuevas tecnologías de la información y la comunicación y menos de sectores como la industria o la construcción, los sectores privilegiados en la anterior revolución. La investigación y el desarrollo —el famoso I+D— de nuevos productos y servicios que se adapten como un guante a los nuevos usos y costumbres sociales, tremendamente cambiantes en sociedades hiperconectadas, globalizadas, constituyen las estrellas emergentes de la nueva economía. La Universidad no es la única que investiga, claro está, pero lo lleva haciendo desde hace mucho tiempo, con gran intensidad y con relativa autonomía - aunque cada vez menor- lo cual hace que sus resultados se vean rodeados de un halo de credibilidad. La mayor parte de los países desarrollados ha promovido cambios extraordinarios en sus sistemas de apoyo y explotación de la investigación científica y tecnológica. En los últimos años ha cambiado casi todo: la forma en que se investiga, se publica y difunde la investigación; la forma en que esta se conecta con los sectores productivos; la forma en que se relacionan, colaboran y compiten los equipos y centros de investigación; etcétera, etcétera.

Pero no solo se necesita investigación para las nuevas sociedades y sus pujantes economías. También se necesitan profesionales que las gestionen y desarrollen. Y la sociedad se ha vuelto más exigente, en este sentido, respecto a la Universidad como institución formativa. El resultado de todo ello está casi a diario en los medios de comunicación: rediseño global de la educación superior, de la duración de los estudios y de la conexión entre ellos, nuevas Universidades, nuevas carreras, nuevos planes de estudio, transforma- 
ción de las estructuras y planes de estudio existentes, cambios en los enfoques formativos (de los objetivos a las competencias), en las metodologías docentes, en los sistemas de evaluación y de rendimiento de cuentas, etcétera.

Es en este contexto social e institucional donde hemos estudiado y hemos conocido el liderazgo ejercido por algunas mujeres directivas universitarias. No sorprenderá, por tanto, que digamos que en la mayoría de los casos las circunstancias que rodearon el acceso a la dirección de estas mujeres y su desempeño fueron difíciles. La dificultad venía habitualmente asociada al hecho de que la organización afrontaba cambios importantes cuando ellas accedieron a la dirección, o bien tuvieron que afrontar inmediatamente, de diferentes maneras, cambios que estaban pendientes desde la etapa anterior. En este sentido, nuestros hallazgos coinciden con los de Acker (2005) quien analizó casos de mujeres líderes de Facultades universitarias procedentes de tres países diferentes y encontró que dichas mujeres afrontaron dos importantes desafíos: $a$ ) ser parte de la primera generación de mujeres - pocas - implicadas en la gestión universitaria y b) trabajar en un contexto de tendencias globales que han hecho el trabajo de académicos y gestores más difícil que en épocas pasadas.

Así pues, veremos en esta sección, por ejemplo, como Leonor asumió la dirección de un Departamento fuertemente marcado por la personalidad del director anterior, pero amenazado a su vez por las tensiones disgregadoras que explotaron tras la salida de este. También veremos como Diana asumió su cargo de decana en el marco de importantes transformaciones de su Universidad y en medio de fuertes tensiones entre el profesorado, las cuales provocaron la división en dos del único Departamento que tenía originariamente la Facultad. Por su parte, Emma vivió la escisión de su Facultad al inicio de su carrera; de esa escisión salió la nueva Facultad en cuya dirección participa como vicedecana. A Irene le tocó reunir en su Departamento, como directora, a dos áreas de conocimiento que estaban vinculadas a Departamentos diferentes. Ofelia ha dirigido un Departamento del que ha sido prácticamente la fundadora en el marco de una Facultad muy joven (seis-siete años) y de un centro universitario que ha adquirido ese carácter hace poco. 
Podemos decir con rotundidad que en ningún caso las directivas analizadas accedieron a cómodos cargos de gestión. Por el contrario, todos ellos revestían una gran complejidad y requirieron, en mayor o menor medida, su implicación, al mismo tiempo que pusieron a prueba sus habilidades como gestoras, e incluso como personas.

Por otro lado, a las mencionadas dificultades institucionales se añadieron las del desarrollo profesional y académico. Algunas directivas compaginaron sus cargos con las fuertes exigencias que la Universidad impone en los momentos iniciales de dichas carreras, y todas con la dedicación a las tareas familiares, atravesando por momento cruciales de indefinición y conflicto de rol (Lea y Leibowitz, 1992; Erkut, 2001; Wolf-Wendel y Ward, 2003). En dos casos -Pilar y Ana- ocurría que las carreras en las que se habían formado no eran las mismas que aquellas en las que iniciaban su andadura como profesoras universitarias. Ello implicó que su iniciación académica fue aún más costosa de lo normal y plagada de las incertidumbres propias del hecho de sentirse extraña en aquel lugar y de los recelos de sus compañeros. En otro caso, el de Berta, la procedencia era de otro país y las incertidumbres provenían de la necesidad de adaptación a una cultura diferente.

Pero precisamente porque las circunstancias de acceso al cargo revistieron todas estas dificultades que hemos señalado brevemente, sorprende en cierto modo constatar que la mayoría de las protagonistas de nuestros casos comenzaron a ejercer cargos de gestión muy pronto desde su incorporación a la Universidad. Nada menos que seis de ellas comenzaron a asumir cargos académicos precisamente cuando debían compaginarlos con sus esfuerzos para adquirir la situación de funcionarias. Tan solo Irene y Pilar eran ya catedráticas y estaban, por lo tanto, en una posición consolidada al acceder a la dirección de sus respectivos Departamentos. En este sentido, desde nuestro punto de vista, la necesidad de aceptación y de integración en el grupo aparece como una de las motivaciones importantes en el acceso a cargos de gestión. Quizás esta necesidad se vea reforzada en el caso de las mujeres debido a su percepción de las organizaciones formales, especialmente las burocráticas, como lugares hostiles o alejados de su forma de ver el mundo y de abordar los problemas (Hargreaves, 1996). 


\subsection{Directivas que promueven cambios en circunstancias difíciles}

En esta sección — de las dos que contiene el presente capítulodiscutiremos algunas de las ideas expresadas arriba sobre el potencial de cambio que ofrecen las mujeres directivas a organizaciones, como las universitarias, que atraviesan épocas turbulentas. La discusión tomará como base los casos analizados en nuestro estudio y en concreto tres aspectos: $a$ ) la forma en que accedieron a la dirección, b) las circunstancias institucionales que rodearon dicho acceso, y c) los cambios y los demás procesos organizativos que emprendieron. Para ello, iremos ofreciendo un resumen de dichos casos, reunidos en tres apartados según sus afinidades.

\subsubsection{Jóvenes escuderas}

Los tres primeros casos, que veremos a continuación, ilustran una modalidad de acceso muy interesante que encontramos y que podríamos denominar «Jóvenes escuderas al servicio de un gran señor». Bajo esta fórmula, el acceso a la dirección se produce a modo de sucesión, o bien de acompañamiento, de un directivo varón, a menudo de uno que ha dejado una profunda huella o impronta en la vida del Departamento o de la Facultad en cuestión. Concretamente, Berta comienza su andadura en la gestión como jefa de estudios junto a un director del Departamento muy ocupado, que la necesita para descargar sobre ella ciertas tareas; por su parte, Emma se postula a vicedecana por su buena relación con el decano, en un momento en el que cree que debe implicarse más en su centro; y finalmente, Leonor apoya primero la gestión del «fundador» del Departamento y luego, cuando este se retira, ocupa su cargo; en parte continuando su legado y en parte introduciendo novedades importantes tanto en la forma como en el contenido de su gestión.

\section{Emma}

Emma es profesora titular de Universidad en un Departamento relativamente grande, que engloba diversas áreas de conocimiento y que es el único de la Facultad en la cual ocupa el cargo de 
vicedecana, desde hace once años. Se trata de una Facultad del ámbito de las Ciencias Sociales y Jurídicas de una Universidad pública. Emma accedió al cargo de vicedecana poco tiempo después de ser contratada, a petición del decano, con el cual mantenía una buena relación y con el que había trabajado con anterioridad en otros proyectos. Este decano desempeñó un papel decisivo en la fundación de la Facultad y es considerado uno de los personajes más relevantes que esta ha tenido en su corta historia.

Cuando Emma accedió al cargo de vicedecana era joven y se sentía con fuerzas y con ganas de asumir retos como este, a pesar de que tuvo que hacer compatible el cargo con las exigencias de su carrera académica: tesis doctoral, titularidad, docencia en diferentes asignaturas, etcétera. Probablemente dicha motivación contribuyó a que su gestión fuera muy bien valorada por la gran mayoría de sus compañeros. Cuando dicho decano dejó el cargo, el nuevo le pidió que siguiera en el puesto, a lo cual Emma accedió, compatibilizando este nuevo periodo de gestión con su maternidad y la crianza del bebé.

Sus primeros momentos como académica, así como su gestión estuvieron marcados por la constitución de su centro como nueva Facultad, al escindirse de la Facultad matriz. De manera unánime, los entrevistados consideraron este momento trascendental en la configuración actual del Departamento y de la Facultad. Ello implicó el traslado a un nuevo edificio, histórico y habilitado ex profeso para dar acogida a la nueva Facultad. Además, la creación de una nueva Facultad facilitó un proceso de consolidación y estabilización de la plantilla. Al mismo tiempo, se puso en marcha una nueva titulación que era reclamada también por otros centros universitarios, lo cual trajo bastantes quebraderos de cabeza al Departamento y a la Facultad. La labor de Emma desde entonces y su habilidad conciliadora fueron claves importantísimas para la superación de tales problemas y para la llegada del actual tiempo de bonanza:

La verdad que ahora mismo vivimos una etapa muy de recoger cosecha, de cosas que se han ido haciendo, estamos en una situación envidiable y lo sabemos, una Facultad pequeña, con buenos recursos, y entonces ahora la cuestión es mejor. (Jesús, 209-210; 216-218). 
Los inicios fueron duros porque [...] había que ponerla en marcha [la nueva titulación], no había profesorado, había que contratarlo, yo me encargué de contactos con profesores, cosas que un vicedecano no tendría que hacer pero como era el inicio había que hacer de todo, reuniones con rectores, con vicerrectores, [...] hacer horarios, cuadrar horarios, hacer programas, cuadrar programas, visitar otras Facultades; los primeros años me llevaron mucho tiempo y esfuerzo... (Emma, 90-96).

[...] Con sus épocas difíciles, cuando ella empezó fue con un montón de críticas, de palos por todas partes, un sector de [la nueva titulación] no estaba de acuerdo que esto estuviera en [esta Facultad], incluso apoyado por cierto sector de la Facultad, esto fue muy complicado para ella... (Marcelo, 216-219).

Más tarde hubo diversos movimientos tendentes a dividir el único Departamento que constituía y constituye la Facultad en tantos Departamentos como áreas de conocimiento había dentro de él. Emma y los dos equipos decanales en los que ha participado eran contrarios a dicha división y tuvieron que gestionar las tensiones subyacentes a los diferentes intereses del profesorado.

\section{Berta}

Berta es directora de un Departamento pequeño en el campo de las Humanidades, en el que lleva trabajando desde su creación. Berta participó en el proceso de constitución de la Facultad en la que dicho Departamento está encuadrado, en una Universidad privada de una gran ciudad. Fue desde los inicios que empezó a ocupar cargos académicos. De hecho fue la primera mujer que lo hizo en esta Universidad. Su interés por la docencia y las nuevas metodologías hizo que el decano de la Facultad que se estaba constituyendo como tal la propusiera para el cargo de jefe de estudios. Desde entonces no ha abandonado las labores de gestión.

La importancia de la jerarquía y un fuerte componente meritocrático parecen ser rasgos dominantes de la cultura de esta Universidad. El clima social es satisfactorio en general. Los grupos de alumnos son reducidos y esto proporciona a las relaciones entre profesores y alumnos una gran cercanía. Por otra parte, el hecho de que en el actual equipo rectoral haya tres vicerrectoras se ha vivido como un gran cambio. 
Entre los profesores hay dos colectivos claramente diferenciados. Uno de ellos, más estable y con dedicación exclusiva a la docencia, hace de esta actividad su seña de identidad, mientras que el otro, menos estable pero con un halo de prestigio basado en su estatus profesional, es criticado por el primero por su relativamente escasa implicación en la actividad docente. Los que se definen a sí mismos como profesores —en lugar de profesionales liberales- ocupan la cúpula fundadora y con más poder en el Departamento de Berta y son acusados de cierto favoritismo por los demás. Sin embargo, ello no parece comprometer demasiado el buen clima que se vive en el Departamento. En este sentido merece destacarse que el Secretario del Departamento pertenece al grupo de docentes que mantiene nexos con la actividad profesional extra académica. Parece, por tanto, que pese a ciertas reticencias mutuas, las relaciones entre ambos grupos no son problemáticas.

Al margen de estas diferencias, cabe afirmar que los profesores del Departamento realizan su tarea de una forma relativamente coordinada. Se trata sin embargo de una coordinación informal, basada en la buena voluntad y las relaciones personales entre los docentes. Berta reconoce esta debilidad de los mecanismos formales de coordinación y la atribuye a la diversidad existente entre los profesionales y sus diferentes grados de dedicación a la docencia. Por su parte, algunos de los entrevistados atribuyeron este problema a un déficit de autoridad de la directora. Berta reconoce que prefiere buscar el acuerdo o convencer antes que imponer su criterio.

\section{Leonor}

Leonor lleva casi veinte años como miembro de un Departamento constituido por alrededor de veinte profesores, en una Universidad pública de una región periférica. Ha ocupado la dirección del Departamento durante cuatro años. Hace apenas uno que abandonó el cargo, al finalizar el segundo de los periodos de dos años para los cuales resultó elegida por la mayoría de sus compañeros. Antes de ser directora, sin embargo, ya había desempeñado el cargo de secretaria del Departamento. 
Leonor fue precedida en la dirección por Pura (que ahora acaba de reasumir el cargo) y esta, a su vez, por Leandro, el fundador del Departamento y director del mismo durante nada menos que diecisiete años. Pura y Leonor han ejercido el liderazgo de manera muy diferente a Leandro - a pesar de la identificación de ambas con su figura-, que adoptó un estilo fuertemente carismático y, en buena medida, autocrático, lo que resulta muy interesante para los propósitos de nuestra investigación.

Cuando se constituyó el Departamento de Ecología (nombre simulado), en 1978, Leandro era el único catedrático del mismo, así que fue nombrado de oficio por las autoridades. Luego afrontó varias elecciones en las que obtuvo la mayoría hasta abandonar el cargo en 1995 por enfermedad. Los testimonios recogidos rodean a Leandro de un halo heroico: «dio su vida al Departamento», «era una persona muy enérgica, muy transgresora, que le infundió vida al Departamento», «era capaz de arrastrar», «desde que se fue no se ha vuelto a hacer nada en común», «ninguno tenemos la capacidad de liderazgo que él tenía...». Leandro era capaz de atraer proyectos relevantes al Departamento y le dio un impulso decidido a la investigación. La gran mayoría de los profesores se implicaron intensamente en estos proyectos fundacionales, dándose en el grupo una motivación y un sentimiento de pertenencia muy altos.

En los primeros momentos de su mandato, Leandro apoyó la llegada al Departamento de Leonor, Pura y otros profesores jóvenes, con el apoyo de los cuales construye su propio «imperio». Este imperio solo se desbarataría años más tarde, tras la enfermedad irreversible de Leandro y su baja del Departamento. A partir de ese momento, la cohesión que su figura logró se debilita y sus colaboradores compiten con los opositores por la hegemonía. Una de las pugnas más importantes tiene lugar cuando ambos grupos apoyan a sus líderes respectivos para conseguir una plaza de catedrático que es convocada. A pesar de todo, el grupo de los seguidores de Leandro sigue siendo el mayoritario y por eso Leonor y Pura se alternan en la ocupación del cargo durante los años posteriores. En todas las elecciones obtuvieron la mayoría absoluta de los votos del Consejo de Departamento. 
Pese a lo identificadas que siempre se mostraron Leonor y Pura con la figura académica y con el perfil personal de Leandro, ellas han actuado en todo momento de manera muy diferente como directoras. Ambas han estrechado las redes de relación social entre sus colaboradores y, aunque las relaciones con los opositores no son cordiales, al menos han conseguido que las reuniones del Consejo del Departamento se desarrollen sin dramas y con diálogo, aunque se discrepe. Precisamente en esta etapa la discrepancia está visible, a diferencia de la etapa de Leandro, donde no lo estaba, aunque existía. Sin embargo, algunos se quejan de que la otrora férrea cohesión impuesta o lograda por el fundador se ha convertido ahora en una amalgama de pequeños reinos de taifas, o células constituidas por los diferentes grupos de investigación (cuatro grupos), cada uno de los cuales está compuesto por un reducido número de profesores (entre tres y cinco). Estos grupos cuentan con bastante autonomía, al estar la mayor parte de sus proyectos de investigación financiados por fondos externos que son gestionados por el propio grupo.

Entre tres de estos grupos hay una cierta afinidad en relación con sus intereses académicos, sintiéndose de algún modo sucesores del fundador. La postura del cuarto grupo es, por su parte, abiertamente disidente respecto a la cultura dominante. Este grupo no parece encontrar «su hueco» en el Departamento: «hay otras líneas que ellos no quieren que prosperen...». Aunque sus posiciones críticas hacia la dirección del Departamento son matizadas («admitiendo que no sean malas [las directoras]»), se muestran disconformes con el monopolio en la dirección de la cultura dominante («encuentro que es muy malo que se estén repitiendo los mandatos»... «puede haber otras maneras»... «en la dirección debe haber mucha apertura, que sea muy cambiante, que todos nos involucremos»).

Tanto Pura como Leonor tienen a gala que no imponen nunca una decisión, que no actúan «piramidalmente». La mayor parte de sus compañeros lo reconoce; sin embargo, algunos se quejan de una gestión «excesivamente formal». Otros alegan que adoptan un perfil meramente administrativo y que el Departamento no participa en las decisiones importantes en el ámbito de la Facultad o de la Universidad. Leonor reconoce que dedica la mayor parte del tiempo al papeleo, pero alega que es inevitable. 
Lo que más resaltan sus partidarios es que Leonor y Pura han evitado, tras la marcha de Leandro, que los conflictos fueran a más y que «la sangre llegara al río». Parece ser cierto porque la división no ha trascendido a los recién llegados, los cuales se llevan muy bien entre ellos, con independencia del grupo donde están adscritos. En todo caso, tras la época turbulenta de la refundación, el Departamento ha ido recuperando la calma poco a poco y, salvo algunas dificultades aisladas, la gestión del mismo se desarrolla actualmente sin sobresaltos ni graves problemas.

En los tres casos anteriores encontramos lo que parece ser un modelo en el proceso histórico de las mujeres en el acceso a puestos de gestión en una organización como la universitaria, en la que el estatus de catedrático —el rango más alto- está desigualmente repartido entre hombres y mujeres, aunque la tendencia se encamina poco a poco a neutralizar dicha desigualdad. El proceso se inicia cuando algún varón reclama a alguna mujer que lo acompañe como escudera en el proceso de gestión. Esta mujer se encuentra en los inicios de su carrera universitaria. La mujer acepta, animada por las posibilidades de una mayor integración en su unidad, y paulatinamente encuentra que sus características personales - y también probablemente su condición femenina- se acoplan especialmente bien a las tareas y funciones que se le reclaman. Con el tiempo su gestión se independiza de la de su mentor y adquiere el protagonismo como directiva.

¿Qué lleva - podemos preguntarnos- a un directivo universitario a buscar la colaboración —entregándoles importantes responsabilidades - de profesoras jóvenes, recién llegadas a la organización y con escasa experiencia, no solo en lo que se refiere a la gestión, sino también en lo académico? Varias respuestas nos parecen probables. En primer lugar, quizás se les antojan elementos más moldeables que los académicos con experiencia. Y también menos contaminados por la cultura o por las posiciones establecidas en la confrontación por el poder. Por otra parte, vienen con la motivación del recién llegado. Y ello por una doble razón. Por un lado porque son jóvenes y entusiastas: como Berta, que cree poder cambiar la forma 
de enseñar. Pero quizás también porque son mujeres y sienten el vértigo de estar abriendo las puertas que han estado cerradas o solo levemente entreabiertas para la mitad de la población. Así pues, llegan con una gran energía que el directivo de turno puede aplicar al desarrollo de su propia gestión. O cree al menos poder hacerlo.

Pero quizás su condición de mujer les esté empujando a la gestión por razones menos visibles. Quizás el liderazgo de estos directivos varones se haya estado estrellando una y otra vez con determinados problemas, precisamente por su carencia de determinado tipo de habilidades; habilidades que las mujeres a las que están invitando a compartir el poder sí poseen. O quizás porque la manera de visualizar dichos problemas no servía ya para abordarlos e intuían que la mirada de las mujeres podía serles útil. Probablemente el liderazgo heroico, altamente visible, individualista de Leandro había dejado ya de ser útil al Departamento cuando Leonor y Pura se incorporaron a este. Quizás fue útil para fundar un Departamento en el marco de una Universidad jerarquizada y tradicional y no tanto para la Universidad que se avecinaba.

A cambio, ¿qué hace que estas jóvenes académicas acepten cargos de responsabilidad en momentos particularmente difíciles y exigentes de sus carreras académicas e incluso de su vida familiar? Algunas razones ya las hemos mencionado. En primer lugar quieren cambiar una organización que no les gusta o que creen poder mejorar. En segundo lugar desean convertirse lo más rápidamente posible en «uno de los nuestros», es decir, tratan de facilitar su integración en un entorno complejo y que no siempre se ha mostrado receptivo a la presencia de la mujer en él. Lo más interesante es que por mucho que se esfuercen los directivos de mayor estatus por mantener a estas jóvenes directivas dentro de la disciplina de su propio modelo de gestión, como hemos comprobado en los tres casos anteriores, ellas siempre fueron, tarde o temprano, más allá. Efectivamente, una vez abierta la puerta a una mirada diferente en la forma de abordar los problemas, dichos directivos no pudieron - 0 no se esforzaron en ello- evitar que tras el éxito la fórmula prosperara y las directivas se hicieran con todo el poder, apoyadas por la mayoría de sus compañeros. 
En definitiva, si esta hipótesis - la de un cierto acople en la coyuntura actual entre las necesidades de la organización y de los directivos en el poder y las necesidades de integración de las mujeres que se incorporan a dicha organización-puede ser sostenida en alguna medida, resultaría que los cambios que están experimentando las Universidades en la sociedad actual - y las dificultades derivadas de estos cambios- estarían impulsando la liquidación de una desigualdad histórica: el acceso de la mujer a los puestos de responsabilidad, al menos en los que respecta a la institución universitaria. A río revuelto, ganancia de, en este caso, pescadoras.

\subsubsection{Unidos para promover el cambio}

Sin embargo, no es solo como escuderas o escoltas de un directivo varón que las mujeres académicas están asumiendo responsabilidades de gestión. También lo hacen de modos más directos o explícitos, de manera concertada con otros hombres y mujeres y utilizando los mecanismos institucionales —democráticos en mayor o menor medida- que la organización pone en sus manos. Es el caso de los tres que vienen a continuación. El de Diana es el más particular porque la concertación de fuerzas es protagonizada por un grupo de mujeres que se une decidida y explícitamente para tomar el poder en diferentes instancias de su Universidad; poder que hasta ese momento había sido ocupado casi en exclusiva por hombres. Sin embargo también Ofelia y Ana ponen su esfuerzo al lado de otros compañeros - mujeres y hombres - para provocar un cambio en las políticas de gestión de su Departamento y su Facultad, respectivamente.

\section{Diana}

Diana es decana en una relativamente pequeña y joven -27 años- Universidad pública. Dicha Universidad ha experimentado notables transformaciones en los últimos años. En particular, ha crecido notablemente, se ha trasladado a un nuevo y moderno campus y ha descentralizado sus estructuras y servicios administrativos, lo cual ha dado más poder a los decanos, en detrimento de los directores de los Departamentos. 
Diana es profesora de esta Universidad desde 1990. Durante los primeros años como profesora debió compaginar el desarrollo de su carrera académica con la puesta en marcha de las asignaturas de su perfil docente, las cuales se vieron modificadas muy pronto por la implantación de un nuevo plan de estudios, lo que supuso una importante tarea añadida. Sin embargo, a pesar de ello, Diana encontró tiempo y ganas muy prematuramente — desde 1993- para desempeñar actividades de gestión. Se trataba al principio de cargos honoríficos, hasta acceder en 1999 a la secretaría de su Departamento. No fue esta, sin embargo, una decisión exclusivamente personal, sino que formó parte de un plan concebido por un grupo de mujeres de su Departamento - que siempre había estado dirigido por hombres - para optar progresivamente a diversos cargos, tanto en el Departamento como en la Facultad, que habían quedado o iban a quedar vacantes. Muy pronto este lobby o grupo de poder da sus frutos y Diana llega a ser vicedecana en un equipo de gobierno de la Facultad en la que la decana es Pina, otro destacado miembro del mismo. Más adelante, cuando Pina recibe el ofrecimiento de ocupar la vicerrectoría de Relaciones Internacionales, la cual acepta y ocupa hasta el presente, Diana es elegida decana con un equipo que trata de dar continuidad a los proyectos iniciados en la etapa anterior y en el que también están presentes algunos hombres.

Como para muchas otras jóvenes académicas, los cargos de gestión supusieron para Diana la oportunidad de una rápida integración en un contexto ocupado mayoritariamente por hombres, aunque ello le acarreara importantes esfuerzos de conciliación de sus variadas ocupaciones con la vida familiar. Pero Diana encontraría dificultades añadidas. Ella asumió la dirección de la Facultad en un momento delicado, dado que acababa de producirse la división formal de su Departamento en dos nuevos Departamentos, algo que se había estado preparando durante largo tiempo y que estuvo precedido por una etapa de conflictos en el marco de una fuerte micropolítica.

Diana había sido elegida como decana siendo la candidata del grupo (área de conocimiento) mayoritario en el Departamento anterior a la división. Su propuesta como candidata se justificó por el hecho de que había sido una de las personas menos significadas en 
las luchas internas y, por tanto, podía granjearse un cierto reconocimiento también por parte de «la oposición». El líder de esta oposición reconoció que con Diana «las cosas se han tranquilizado», que «se ha recuperado la posibilidad de hablar y de hacer cosas juntos» y que «la situación va camino de cambiar». También que Diana «quiere hacerlo bien» y que una de sus mayores preocupaciones es «ser aceptada por todos».

\section{Ofelia}

Ofelia es directora de un Departamento del ámbito de las Ciencias Sociales de una Universidad pública española, de tipo pequeño y de reciente creación (quince años). Antes de dicha fundación todas sus unidades dependían de otra Universidad cercana. Se trata de una Universidad orientada predominantemente hacia la docencia, en la que la investigación no ha adquirido aún un papel importante.

El Departamento que dirige Ofelia es uno de los tres que componen la Facultad, que se encuentra localizada en el centro de la ciudad y alejada del campus universitario, lo que proporciona a sus miembros una sensación de aislamiento y falta de integración en la vida universitaria. Dicha Facultad procede de la transformación de una antigua escuela universitaria, lo cual, unido a lo anterior, ha conformado una cultura particular:

[Una cultura] en la que conviven profesores que provienen de la antigua Escuela con profesores jóvenes contratados directamente por los diferentes Departamentos universitarios que componen la Facultad [...] una cultura de escuela, de hermetismo, de una relación muy familiar, [en la] que todo el mundo se sabe la vida de todos, [en la que se pasa] de estar trabajando en torno a 40 ó 50 profesores de distinta procedencia a una Facultad. (Saturnino 03S_08,123-125).

Cuando Ofelia se incorpora como docente al Departamento encuentra al mando el fundador del mismo, el cual aparece dibujado en la memoria colectiva como una persona non grata, bajo cuya dirección se vivió un clima un tanto enrarecido. Cuando este director pasa a ocupar un puesto de vicerrector, Ofelia comparte equipo como secretaria con el nuevo director que resulta elegido. Curiosamente, cuando llevan poco tiempo en el cargo, hay una nueva rota- 
ción de puestos y el director fundador pasa de la vicerrectoría a una dirección general en el gobierno autónomo y el director del Departamento pasa a ocupar la vicerrectoría vacante. Esta situación lleva a Ofelia a asumir la dirección del Departamento durante un periodo aproximado de dos años, hasta que se convocan nuevas elecciones en las que resulta elegida para el puesto que ya desempeñaba en funciones.

Ana

Ana se desempeña actualmente como vicedecana en una Facultad relativamente nueva del área de las Ciencias Sociales a la que había llegado once años antes, cuando la primera promoción de alumnos se encontraba realizando su tercer curso. Ha pasado los últimos cinco años ejerciendo cargos de gestión. Aunque muy pronto, desde su incorporación, recibió ofertas para integrarse en diferentes puestos de responsabilidad, ella prefirió declinar tales ofertas hasta conseguir su plaza, justificándose precisamente en su condición de profesora contratada. Pero a partir de ese momento - seis años después su llegada- no pudo negarse, a pesar de que el grupo que la convocaba no era afín a ella.

Curiosamente, su profesión no se corresponde con los estudios que se dictan en la Facultad en la que trabaja. Esta condición de advenediza en un campo profesional que no era el suyo le valió, inicialmente, algunos recelos de parte de sus compañeros. No se trataba de recelos personales hacia Ana, sino de una resistencia institucionalizada a la entrada de personas ajenas al campo disciplinar específico de la Facultad. Ello parece explicarse por el momento fundacional que atravesaba la organización y por las tensiones inherentes al proceso de definición de un proyecto propio y de búsqueda de una identidad. En ese contexto, se entiende que quienes se consideraban padres fundadores desearan preservarla de toda posible desviación de los fines iniciales.

Esto, unido a las dificultades inherentes a la carrera académica, hace que Ana recuerde aquellos años como momentos difíciles. En este contexto, su incorporación a las labores de gestión universitaria puede interpretarse como un modo de «ganarse la confian- 
za» de los compañeros. Como contrapartida, puede postularse que, para ellos, funcionaba como una manera de poner a prueba a la profesora que venía "de fuera», de comprobar si era de los nuestros. A esto hay que añadir que estamos hablando de un campo del conocimiento y profesional bastante masculinizado, tanto en lo que se refiere a los estudiantes como al profesorado del centro. Esto hizo aumentar los esfuerzos que Ana debió realizar para ganar su lugar en la Facultad.

Tras el periodo inicial, marcado por las mencionadas tensiones fundacionales, el funcionamiento del centro va estabilizándose. Es entonces cuando asume la autoridad el nuevo equipo decanal, del que Ana forma parte. Este equipo decanal, al que lo que «le preocupa es el alumno, que esto funcione» (Eugenia, entrevista 03; 144) es visto por los estudiantes como «ilusionado, con ganas de trabajar [...] haciendo un montón de proyectos que antes no se llevaban a cabo...» (Almudena, entrevista 04; 26-27). La gestión de este equipo concita el acuerdo y la satisfacción de la mayoría y hace que en la actualidad se viva «un momento dulce» (Paco, entrevista 06; 189-194).

Ante esta nueva situación, no es de extrañar que Ana se encuentre «bien en el Departamento en el cual estoy, me siento muy a gusto» (Ana, entrevista 01; 75-76). Sin embargo, en opinión de Ana, el desempeño de su cargo como vicedecana constituye un gran esfuerzo que se ve escasamente compensado y supone para una mujer abandonar «muchísimas» otras cosas. Esto determina, sin duda, su postura ambigua en relación con el ejercicio de la gestión de la que afirma que le gusta pero quiere dejar cuando finalice el periodo para el que ha sido elegida.

Como puede verse en los tres casos anteriores, los problemas y dificultades que Diana, Ofelia y Ana tuvieron que abordar como directivas fueron tan importantes, como mínimo, como los que trataron Emma, Berta y Leonor. Y del mismo tipo que ellas, con la exigencia añadida que reclamaba el desarrollo de sus incipientes carreras académicas. En estos tres casos los problemas estaban planteados antes de su llegada a la gestión universitaria y fue precisamente la toma de conciencia sobre esos problemas y sobre la 
necesidad de resolverlos lo que impulsó a estas académicas a unir sus fuerzas a las de otros compañeros para lograr una posición de autoridad que les permitiera abordarlos.

Posteriormente, una vez llegadas al poder, las mujeres de nuestro estudio fueron capaces de lograr cambios significativos, percibidos con satisfacción por una mayoría de los miembros de la organización. Esto puede ser atribuido a varios factores, entre los que destaca en primer lugar una lectura adecuada de las características culturales que presentaban sus instituciones -en línea con los hallazgos de Kezar y Eckel (2002)—. Esta sensibilidad respecto al contexto les permitió probablemente priorizar adecuadamente los problemas, por un lado, y encontrar el estilo de liderazgo adecuado para afrontarlos (este último aspecto será tratado con detalle más adelante). Esto es especialmente manifiesto en los casos de Diana, por un lado, y en los liderazgos sucesivos de Leonor y Pura, por el otro. Todas ellas se mostraron hábiles y eficaces en la gestión de la conflictividad latente $-\mathrm{y}$ a veces manifiestade sus respectivas unidades. Y todas ellas también contribuyeron a evitar en buena medida las tendencias disgregadoras características de las estructuras de poder — como las universitarias - fuertemente politizadas.

No tenemos evidencias suficientes para generalizar una conclusión definitiva en este sentido, ni era el propósito de una investigación como esta basada en el estudio de casos, sin embargo, pensamos que debemos preguntarnos e indagar en el futuro sobre las siguientes preguntas: ¿Es posible que la mirada de las mujeres sobre las organizaciones y las relaciones sociales esté especialmente indicada para las transformaciones que las organizaciones universitarias están afrontando en estos momentos? ¿Es posible que algunas formas de ejercer el poder características de las mujeres directivas sean particularmente adecuadas para llevar a cabo la clase de cambios que sus organizaciones universitarias necesitan?

A nosotros desde luego nos parece que parte del éxito de estas directivas en su gestión y de la satisfacción que dicha gestión provocaba por lo general en los demás miembros de la organización 
tenía que ver no tanto con sus características como líderes cuanto con el acople entre dichas características y las de sus propias organizaciones educativas. Como hemos planteado en otro lugar (Sánchez Moreno y López Yáñez, 2003) la Universidad como organización posee una estructura débilmente acoplada. Esto quiere decir que su estructura no es el único patrón creador de ordenamiento organizativo, ni siquiera a veces el más poderoso. En estas organizaciones, las relaciones sociales y sus estructuras emergentes, informales y dinámicas, constituyen el principal factor de orden y también de desorden. Y se trata de estructuras por lo general más influyentes que las estructuras formales, en lo que se refiere a la creación de pautas colectivas de conducta y de pensamiento. Pues bien, quizás esas estructuras débilmente acopladas requieran, especialmente en estos momentos, formas «blandas» de ejercicio del poder, es decir, modos que no se apoyen predominantemente en la estructura formal, sino en el establecimiento de redes sociales y comunitarias, que impulsen la implicación y la creatividad del resto de los miembros de la organización.

En la medida en que las directivas parecen más proclives a la adopción de formas blandas de liderazgo, su elección para ocupar cargos directivos no sería meramente fruto del azar. De alguna manera, el sistema social presente en toda organización formal estaría buscando a través de ellas fórmulas que puedan abordar ventajosamente los problemas y los retos que las organizaciones universitarias tienen planteados en estos momentos.

\subsubsection{Directivas con una posición académica consolidada}

Irene

Irene ha sido directora durante ocho años — dos periodos completos- de un Departamento del área de Ciencias de una Universidad española, aunque en el momento en que realizamos nuestro estudio había dejado de ocupar el cargo. Cuando lo hizo, su carrera académica estaba ya consolidada, sus hijos eran mayores y, por tanto, la exigencia de dedicación a los asuntos domésticos era menor. Por tanto, este es un caso bien distinto a los de las anterio- 
res directivas, las cuales compaginaron el desempeño de cargos directivos con la iniciación de sus carreras académicas y la formación de una familia.

La de Irene es una Universidad joven —unos quince años han pasado desde su creación- que poco a poco se ha ido consolidando, hasta multiplicar el número de alumnos por diez. Su Departamento es numeroso en profesorado, puesto que incluye tres áreas distintas de conocimiento, aunque estas funcionan de un modo bastante autónomo, lo cual asemeja mucho el caso al siguiente que examinaremos, el de Pilar. Curiosamente, también como en dicho caso, Irene fue empujada a ser directora del Departamento por su condición de catedrática. Solo cuatro profesores lo eran en aquel momento. Uno de ellos — su marido - era el director saliente, otro ocupaba un cargo en la Universidad y el tercero en cuestión no parecía contar con mucha popularidad. Así que Irene accedió a las presiones y se presentó, saliendo elegida.

Durante el primer periodo de su mandato como directora tuvo que gestionar un Departamento amplio, heterogéneo y, sobre todo, dividido, a causa de las tensiones propias de la fase fundacional de su Universidad, en el que había que recomponer unas relaciones sociales muy conflictivas y debilitadas, por una parte, y ordenar las cuestiones administrativas por otra. Todo ello en el marco de un funcionamiento muy autónomo por parte de las áreas de conocimiento. En dicho contexto, el foco principal de la dirección de Irene estuvo puesto en el cuidado de las relaciones sociales, limando las asperezas existentes y devolviendo un clima de cordialidad y trabajo relajado al Departamento. Para lograr esa distensión llegó a convocar los consejos de Departamento con el formato de almuerzos de trabajo, en el comedor de la Universidad. Esta estrategia permitió que los problemas se abordaran en un contexto menos hostil y más relajado, en el que los temas informales sirvieron de nexo y plataforma para llegar a los formales. Esta estrategia se continuaba con una campaña que ella denomina de saludo y que consistía precisamente en saludar siempre a todos los miembros del Departamento, aunque ellos no le devolvieran el saludo, hasta que finalmente lo conseguía. 
Irene consiguió también gestionar la adscripción a su Departamento de los profesores de la misma área que estaban ubicados en Departamentos diferentes, lo que igualmente ayudó a reducir una fuente de tensión. Así mismo negoció la salida airosa del Departamento de una persona que presentaba comportamientos agresivos y enfermizos y que estaba provocando tensiones y miedos entre sus miembros. Además, se propuso y logró que una mayoría de los profesores de su Departamento participara en los cursos de formación organizados por el Instituto de Ciencias de la Educación (ICE), como una estrategia de motivación que resultó bastante productiva. Todo este proceso recibió el influjo beneficioso de un cambio de equipo rectoral que comenzó a superar las tensiones aludidas propias del periodo fundacional.

Finalmente, Irene llevó a cabo una reestructuración espacial del Departamento mediante la que se lograron nuevos despachos y con ellos mejores condiciones de trabajo y mejor clima social. Podemos decir que Irene utilizó el espacio como un símbolo tangible de un cambio de etapa que proporcionara al Departamento nuevas señas de identidad y nuevos mecanismos de relación entre sus miembros.

[...] había aquí antes problema de espacio muy poco espacio y eso ponía a la gente con los nervios de punta. También con el rector que había entonces, era muy inteligente, yo decía que esto estaba afectando mucho el funcionamiento del Departamento y entonces logré que se hicieran las obras y que hubiera más despachos y ahora ya ha mejorado la cosa. Me parecía que había que llevar la cosa humana que funcionara para que la ciencia funcionara, que todos tuviéramos que estar pacíficos, relativamente amigos, por lo menos no enemigos. (Irene, 3C_01, 239-245).

\section{Pilar}

Pilar es la directora de un Departamento del área de Ciencias formado por tres áreas de conocimiento que funcionan de un modo bastante autónomo. Al mismo tiempo está encuadrada en un Instituto de Investigación autónomo que se financia a través de subvenciones, proyectos y convenios con empresas. Por acuerdo interno, la dirección del Departamento es ocupada cada periodo, de 
manera rotativa, por un profesor de alguna de las tres áreas. En el momento del estudio, Pilar llevaba dos años ocupando el cargo. La auténtica vocación de Pilar es la investigación y no la gestión ni mucho menos. Sin embargo, ella es la única catedrática de su área de conocimiento y cree que el puesto debe ser ocupado por un catedrático, aunque la ley contemple que puedan hacerlo los profesores titulares. Por lo tanto, de nuevo aparece en este caso, al igual que en el de Irene, el componente meritocrático como rasgo fundamental de la lógica o configuración del poder de este tipo de organizaciones. Hemos de recordar que los directores de Departamento son elegidos en primera instancia entre los catedráticos de Universidad y, solo en caso de que ninguno de ellos se presente o reciba el apoyo suficiente, se pasa a la elección entre los profesores titulares.

Pilar tiene una larga trayectoria como profesora universitaria, cuyos momentos más duros fueron sus comienzos. Para empezar, un problema en su familia hacía que sus padres dependieran de ella, así que tuvieron que trasladarse todos para que ella pudiera realizar sus estudios universitarios. Todo ello en una época en la que no era frecuente la presencia de la mujer en las Facultades españolas y mucho menos en las científicas. Por otro lado, el Departamento al que inicialmente logró incorporarse no pertenecía exactamente al campo científico en el que ella se había formado. En consecuencia, tampoco poseía una sólida formación inicial en el tema en el que inició sus estudios de doctorado.

Sin embargo, pronto consiguió una beca de Formación de Personal Investigador (FPI) por cuatro años, que le sirvió para completar su formación y doctorarse. Más adelante, como becaria postdoctoral, se marchó a Estados Unidos, donde continuó su formación durante otros cuatro años. A Estados Unidos se marchó con su hijo de tres años, nacido durante el primer año de su doctorado. Por tanto fue un periodo muy difícil, con un hijo pequeño que cuidar y profundizando en un tema, el de su tesis, que era nuevo para ella. Posteriormente regresó a la Universidad española donde obtuvo su doctorado como profesora adjunta interina, aprobando tres años más tarde la oposición de Profesora Titular de Universidad. Fue 
varios años más tarde cuando se trasladó a la Universidad en la que trabaja actualmente.

A pesar de las difíciles circunstancias que rodearon el comienzo de su carrera académica, no se puede decir en absoluto que el acceso a la labor directiva haya sido difícil. Por el contrario Pilar es la única directiva de nuestro estudio a la que encontramos desarrollando su gestión en circunstancias que podríamos calificar de apacibles. Las decisiones importantes se toman en las respectivas áreas de conocimiento - en particular todo lo que se refiere a la organización de la docencia- las cuales funcionan en realidad casi como Departamentos autónomos. En su momento hubo un intento de convertir ambas áreas en Departamentos separados; sin embargo, dicha separación no se produjo por no contar ninguna de ellas con profesorado suficiente para formar Departamento propio.

A la dirección del Departamento le corresponde, por lo tanto, casi en exclusiva, la gestión de los asuntos administrativos. La principal herramienta para ello es el Reglamento del Departamento, en cuya elaboración intervino Pilar como representante de su área de conocimiento, en torno al año 1990. No es extraño en este contexto que Pilar considere sus tareas como puramente administrativas. Ella piensa que, salvo en contadas ocasiones en las que hay que tomar alguna decisión o hay que intentar poner de acuerdo a determinadas personas, las tareas propias del Departamento pueden ser perfectamente llevadas por un buen administrativo: «Yo me limito a revisar y firmar facturas y lo único que tengo que hacer es decidir cuándo hay que hacer reuniones, tomar decisiones, convocar a la gente si es necesario, etcétera.».

En el Departamento de Pilar no parece haber conflictos o problemas relevantes, dado que los asuntos problemáticos se dirimen en las áreas y estas cuentan con un número reducido de profesores y, por tanto, una estructura casi familiar. Con respecto al cumplimiento de la tarea solo encuentra alguna dificultad en lo que se refiere a la comunicación con el alumnado, que achaca a la diferencia generacional y al hecho de que el profesorado experimentado centre más su atención en la investigación y en los proyectos euro- 
peos e internacionales, con lo que las tareas docentes y las de gestión pueden verse mermadas. Consecuentemente, no concede demasiada importancia a la posibilidad de recibir formación específica para el desempeño de cargos de gestión.

Pudiera ser que las características que observábamos en los seis primeros casos comentados como propias de las mujeres directivas se atenúen en diferente medida cuando estas acceden a la dirección una vez alcanzado un cierto estatus. También podríamos pensar mientras leemos el caso de Pilar que la falta de un entorno exigente y problemático ha conducido su gestión por derroteros más tradicionales que los casos anteriores. En particular, el estilo de liderazgo de Pilar es burocrático en buena medida, con cierto componente autocrático: ella admite que no destaca por su talante negociador y que resulta algo inflexible en determinadas actuaciones, en las que hace valer sus criterios. Esto, como veremos en la última sección de este capítulo, contrasta en gran medida con los estilos de liderazgo del resto de los casos.

Sin embargo, a Irene sí se le presenta un entorno problemático. Ella encontró, como hemos visto, a su Departamento dividido a causa de las tensiones características de la fase de desarrollo inicial que atravesaba su Universidad, con la obligación de gestionar unas relaciones sociales muy conflictivas, propias de un periodo en que los miembros de la organización están desarrollando de manera competitiva sus respectivas trayectorias académicas. Y también con la responsabilidad de poner en orden los aspectos formales del funcionamiento organizativo. En este sentido Irene, a diferencia de Pilar, orienta su gestión en una dirección similar a las directivas más jóvenes y con una posición menos consolidada que ya hemos analizado. Esta dirección tiene que ver con una cuidada atención hacia las relaciones humanas y el clima social de sus unidades y con un estilo decidido de abordar los problemas que entorpecen dichas relaciones.

En todo caso, tanto en Irene como en Pilar podemos reconocer el componente meritocrático que está presente en tantos otros resortes 
de la organización universitaria. Dicho componente meritocrático refuerza su autoridad formal a cambio de restar cierto dinamismo que podemos encontrar en los casos anteriores a estos.

\subsection{Poder y liderazgo de mujeres responsables de instituciones universitarias}

En la sección anterior, mostramos como muchas de las mujeres analizadas en nuestra investigación aparecieron como agentes de cambio en sus organizaciones. En esta sección — dividida en tres apartados- trataremos de explicar qué mecanismos de influencia (poder y liderazgo) utilizaron para ello. Con esa finalidad, en el primer y segundo apartado ofreceremos algunas conclusiones obtenidas a partir de dos cuestionarios utilizados en nuestro estudio. Ambos cuestionarios fueron diseñados ad hoc y dirigidos respectivamente a una muestra más amplia de directivas universitarias y a los miembros de sus organizaciones. Los resultados que mostraremos se refieren a $a$ ) las características y la orientación de su estilo directivo, en el primer apartado, y $b$ ) las bases o fuentes de poder sobre las que construyen su liderazgo, en el segundo apartado. Finalmente, en el tercer apartado, regresaremos sobre los casos de las directivas que presentamos en la primera sección, para ocuparnos esta vez de los liderazgos en acción que desplegaron nuestras protagonistas.

\subsubsection{Estilos de liderazgo}

Para conocer el estilo de liderazgo de las directivas construimos una escala de nueve ítems agrupados en tres factores dentro del cuestionario COMECADU. Los tres factores fueron: 1. Gestión del tiempo y de las tareas; 2. Orientación externa versus interna de la gestión; y 3. Prioridad a los aspectos formales versus informales de la organización. Los ítems tenían una estructura bipolar, con un abanico de respuesta de 1 a 6 , en donde 1 y 6 representaban respectivamente la máxima preferencia hacia cada uno de los polos (ver figuras 1, 2 y 3 ). 
Respecto a la gestión del tiempo y de las tareas, nuestros resultados confirman la idea de un claro predominio de la concepción policrónica respecto a la monocrónica, caracterizado por la realización simultánea de múltiples tareas. Ante diferentes preguntas, las directivas consultadas afirmaron mantener múltiples frentes de acción simultáneos y atender frecuentemente varios asuntos a la vez (ver figura 1).

\section{FIGURA 1}

ESTILO DE LIDERAZGO. FACTOR 1

\section{Factor 1: Gestión del tiempo y de las tareas}

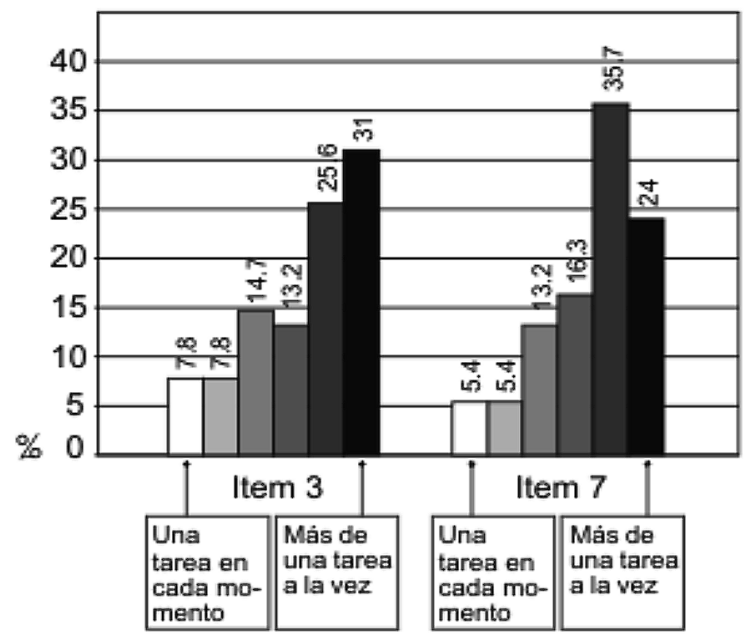

En lo que respecta al factor 2, las directivas consultadas se orientaron con absoluta claridad hacia los aspectos internos de la organización frente a las relaciones con el exterior. Así, en la figura 2 puede verse que descartaron prácticamente la atención a la imagen externa para dar toda la prioridad al funcionamiento interno (ítem 4); y que concedieron bastante poca importancia a la relación con otras organizaciones para dedicarse a los asuntos propios (ítem 8). Sin embargo, las respuestas estuvieron más equilibradas ante el ítem 5, el cual planteaba la alternativa entre el bienestar de los miembros, por un lado, y el cumplimiento de las tareas y de los acuer- 
dos adoptados, por el otro. Esta respuesta es congruente con la importancia concedida por las mujeres directivas en general al clima y a las relaciones entre los miembros de la organización. Podríamos inferir, a partir de las respuestas a los tres ítems de este factor, que el bienestar de los miembros es considerado un asunto interno de igual importancia que la actividad propia de la organización.

FIGURA 2

ESTILO DE LIDERAZGO. FACTOR 2

Factor 2: Orientación externa vs. interna

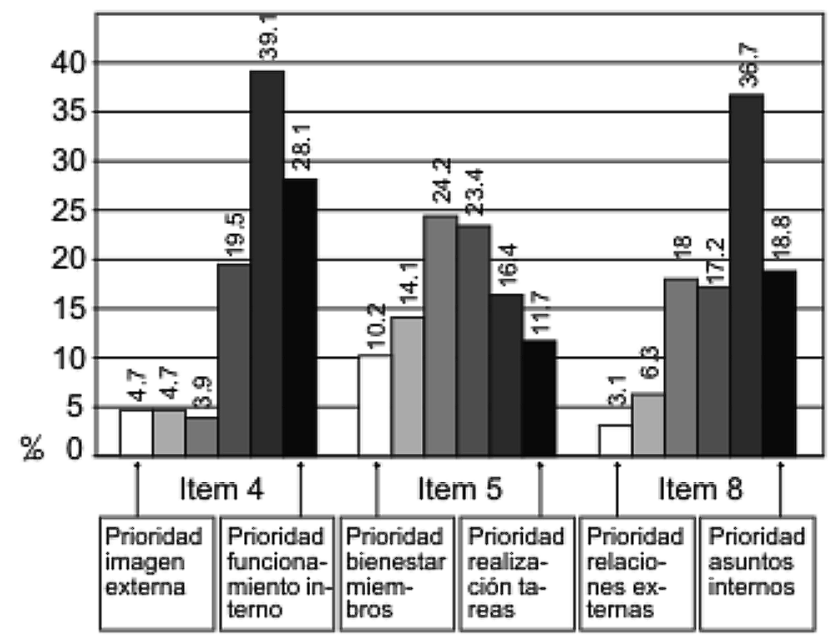

Finalmente, en lo que respecta al factor 3, las directivas respondieron eligiendo sistemáticamente las opciones que priorizaban los aspectos informales sobre los formales. Sin embargo, en un marcado paralelismo con las respuestas al ítem 5, que acabamos de comentar, el item 1 mostró un significativo equilibrio entre los dos polos (formal/informal), algo que no ocurrió en los otros ítems de este factor. En este ítem 1 hubo un empate virtual entre las tres opciones relativas a la prioridad de los compromisos académicos y las tres opciones relativas a la prioridad del clima organizativo $(49,7 \%$ y $50,5 \%$ respectivamente, ver figura 3$)$. Por el contrario, las 
directivas priorizaron claramente los acuerdos internos sobre las normas formales (ítem 2), los aspectos éticos sobre la eficacia (ítem 6) y la atención a las personas sobre la toma de decisiones (ítem 9).

FIGURA 3

ESTILO DE LIDERAZGO. FACTOR 3

Factor 3: Organización formal vs. informal

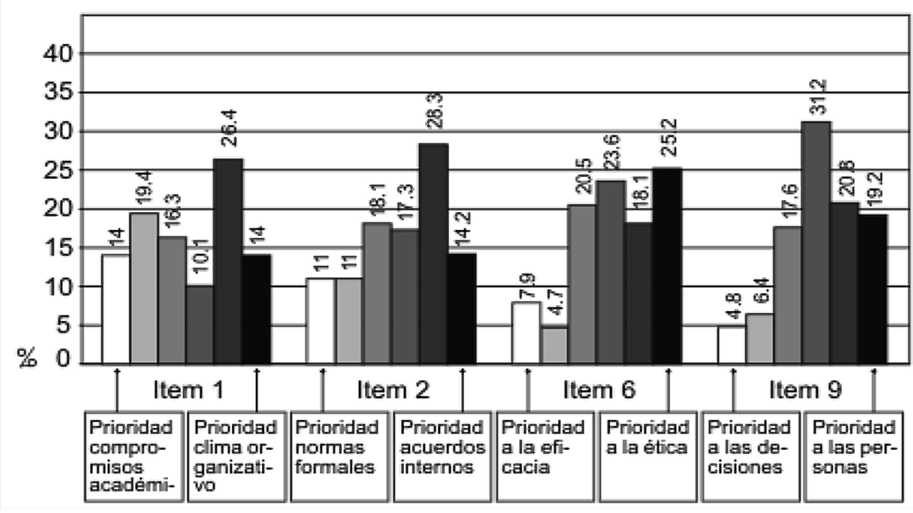

\subsubsection{Bases de poder sobre las que las directivas gobiernan sus organizaciones}

Desde nuestro punto de vista, las características expuestas en la sección anterior sobre el liderazgo de las directivas de nuestro estudio, deben ponerse en relación con las modalidades de influencia o de ejercicio del poder que desplegaron. Para nosotros, las nociones de influencia y poder son equivalentes y más amplias que la de liderazgo, que tiene que ver con las formas de ejercicio del poder basadas en el factor humano o, si se prefiere, en las relaciones sociales. El poder, la capacidad de influir sobre los demás es algo accesible a muchos agentes, no solo a los directivos o a los líderes. Para ello disponen de una amplia variedad de fuentes o bases (explícitas o implícitas, legítimas o no) sobre las que establecerán relaciones competitivas con determinados agentes y colaborativas con otros. 
Esta idea asume el carácter dinámico, en permanente construcción del poder, en oposición a la reificación operada por la teoría tradicional en torno al concepto de liderazgo.

Nosotros nos propusimos indagar acerca de las bases de poder utilizadas por las mujeres directivas en la Universidad. Asumimos la hipótesis de que estas darían con su conducta prioridad a unas bases sobre otras. Sin embargo, contra lo esperado, las participantes en nuestro estudio utilizaron todas las bases de poder disponibles, y eligieron entre unas y otras en función del problema o tarea que nosotros les planteábamos. Concretamente, para cada situación les propusimos un abanico de elección de respuesta cuya estructura subyacente contemplaba, basándonos en Mintzberg (1992), cinco tendencias o estilos de liderazgo: autoritario (las opciones en que la Directora actúa de forma personalista, según su propio criterio o amparada en el cargo asignado); meritocrático (cuando apela al conocimiento experto o profesional de alguien para apoyar sus decisiones); burocrático (cuando legitima su actuación en el respeto de la norma); ideológico (si apela a los valores compartidos, para fundamentar sus posiciones); y político (cuando trata de establecer alianzas con los compañeros, generalmente a nivel personal). Los enunciados que dieron lugar a las respuestas ante cada ítem pueden verse en la tabla 1.

\section{TABLA 1}

\section{ENUNCIADOS DE LA ESCALA SOBRE BASES DE PODER}

\begin{tabular}{|c|c|}
\hline $\begin{array}{c}\text { Ítem 1. Usted ha de gestionar un } \\
\text { asunto en el que se presentan posicio- } \\
\text { nes contradictorias... }\end{array}$ & $\begin{array}{c}\text { Ítem 5. Cuando se incorporan nue- } \\
\text { vos miembros a su grupo, lo primero } \\
\text { que hace es... }\end{array}$ \\
\hline $\begin{array}{c}\text { Ítem 2. En una reunión del grupo } \\
\text { que usted coordina se produce un } \\
\text { enfrentamiento entre dos miembros... }\end{array}$ & $\begin{array}{c}\text { Ítem 6. Si tiene que liderar a un } \\
\text { grupo que se encuentra desmotivado y } \\
\text { muestra gran apatía... }\end{array}$ \\
\hline $\begin{array}{c}\text { Ítem 3. Ante las críticas respecto a } \\
\text { sus actuaciones o criterios... }\end{array}$ & $\begin{array}{c}\text { Ítem 7. Si prevé que una próxima } \\
\text { reunión institucional va a ser tensa... }\end{array}$ \\
\hline $\begin{array}{c}\text { Ítem 4. Cuando toma decisiones } \\
\text { importantes... }\end{array}$ & $\begin{array}{c}\text { Ítem 8. En cuanto a las relaciones } \\
\text { entre los miembros del grupo o la orga- } \\
\text { nización que lidera, usted opina... }\end{array}$ \\
\hline
\end{tabular}


A partir de los resultados obtenidos (ver figura 4) podemos llegar a las siguientes conclusiones:

FIGURA 4

BASES DE PODER UTILIZADAS POR LAS DIRECTIVAS EN SU GESTIÓN

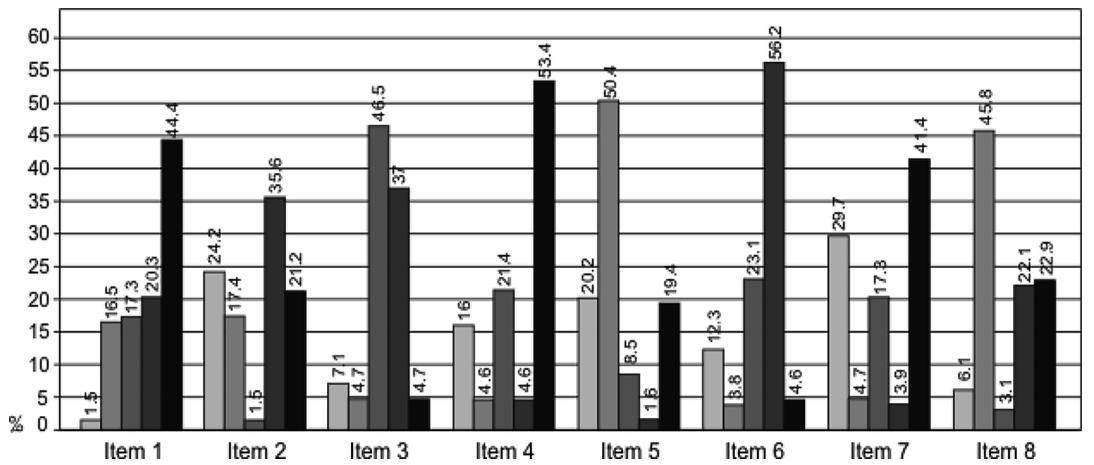

Ítem 1. Gestión de posiciones contradictorias

Las directivas consultadas prefieren las estrategias de componente político a la hora de gestionar asuntos en los que se presentan posiciones contradictorias entre los participantes. Concretamente prefirieron, con un 44,4 \% la opción de persuadir y negociar con las diferentes partes una salida favorable. En muy significativo también el bajo porcentaje de elección que obtuvo la opción en la que predomina el componente burocrático.

Ítem 2. Respuesta ante enfrentamientos entre los miembros del grupo

Lo más significativo de este ítem es el bajo porcentaje de elección que obtiene la estrategia de componente meritocrático (1,5\%), que consistía en solicitar la participación de un mediador cualificado, haciendo valer el criterio profesional. La frecuencia de elección de las demás opciones está bastante distribuida, aunque predomina la opción ideológica con un $35.6 \%$, la cual consistía en pedir a los implicados que se ajusten a los principios y valores que las consultadas creen necesario mantener. 


\section{Ítem 3. Actitud ante las críticas recibidas}

Sin embargo, en este ítem la opción más elegida es la que presenta un componente meritocrático, que consiste en presentar argumentos técnicos o profesionales, relativos a la eficacia en el cumplimiento de los objetivos, con un 46,5\%. Es seguida en porcentaje de elección por la opción de componente ideológico: organizar reuniones en las que participen las personas implicadas y se manejen argumentos ideológicos que aclaren su visión de la organización, con un $37 \%$ de elecciones. Entre estas dos opciones se reparten la gran mayoría de las respuestas $(83,5 \%)$.

Ítem 4. Modo de tomar decisiones

A la hora de tomar decisiones importantes, las mujeres consultadas prefieren de forma mayoritaria las estrategias políticas (53,4\%) concretamente las que consisten en intentar negociar previamente y buscar los apoyos necesarios. A bastante distancia le siguen en porcentaje de elección las opciones con un componente meritocrático (21,4\%) y burocrático (16\%); mientras que son prácticamente residuales las opciones de componente autocrático e ideológico, ambas con un 4,6\%.

Ítem 5. Actitud ante la incorporación de nuevos miembros

Este es uno de los pocos ítems (solo dos de los ocho que componen esta parte del cuestionario) en donde predomina el componente de autoridad en las elecciones de las consultadas. Ante la llegada de nuevos miembros a la organización, estas prefieren mayoritariamente $(50,4 \%)$ orientarlos personalmente acerca de los fines, objetivos y actividades del grupo. Parece notarse aquí la preferencia de las mujeres gestoras por las relaciones sociales directas y su predisposición a implicarse personalmente mediante este tipo de estrategias. Le siguen en importancia, con porcentajes similares, dos opciones con componentes bastante diferentes: la opción burocrática $(20,2 \%)$ y la opción política $(19,4 \%)$.

Ítem 6. Conducta ante un grupo desmotivado y apático

Ante un grupo apático las consultadas se inclinaron mayoritariamente por la estrategia en la que prima el componente ideológi- 
co $(56,2 \%)$, que consiste en involucrar a los miembros del grupo mediante el diálogo y creando la necesidad de trabajar en equipo. De nuevo se aprecia en esta estrategia una predilección por el manejo de las relaciones sociales, antes que las normas (opción burocrática, con un 12,3\%), la referencia a la autoridad (opción autocrática, con un $3,8 \%)$ o la opción política con un matiz competitivo $(4,6 \%)$.

Ítem 7. Estrategia ante los conflictos

Ante un conflicto (en este caso, una reunión previsiblemente tensa) las mujeres consultadas prefirieron la opción de componente político, al igual que cuando se trataba de afrontar posiciones contradictorias (ítem 1) y cuando se trataba de tomar decisiones importantes (ítem 4). La opción consistente en mantener reuniones previas con los agentes clave recabó el $41,4 \%$ de las elecciones. Sin embargo, le sigue en importancia (con un significativo 29,7\%) otra opción de signo bastante diferente: aquella que tiene un componente burocrático y que consiste en documentarse legalmente y preparar la estrategia ajustándose en todo momento a lo regulado por la normativa. En muy pocas ocasiones, las mujeres consultadas esgrimen su autoridad $(4,7 \%)$ o prefieren la referencia a argumentos ideológicos $(3,9 \%)$.

Ítem 8. Actitud respecto a las relaciones interpersonales en la organización

Como en el ítem 5, el predominio de la opción de autoridad en este ítem $(45,8 \%)$ trae implícita una preferencia por la implicación personal y directa en el ámbito de las relaciones sociales y la preferencia por las relaciones informales sobre las formales, dentro de la organización. El enunciado de esta opción así parece mostrarlo: «Me encargo personalmente de ese tema, haciendo de moderadora y conciliadora mediante contactos informales». Las opciones de componente ideológico y político obtuvieron también porcentajes de elección significativos: $22,1 \%$ y $22,9 \%$ respectivamente.

Por otro lado, tampoco los seguidores reconocieron un estilo único de gestión de sus directivas en el cuestionario de contraste. 
Con una marcada coincidencia con las respuestas de ellas (como muestra la tabla 2) las estrategias que creen que adoptarían sus directivas parecen hallarse en relación con el tipo de situación o problemática con la que se encuentran. En los dos casos en los que apreciamos divergencias las directivas han indicado que actuarían desde una tendencia más próxima a un estilo autoritario mientras que los profesores señalaban que probablemente sus directoras actuarían desde un planteamiento político.

Ante esta constatación, puede plantearse que una característica compartida por estas mujeres en el ejercicio de la gestión es la de asumir un estilo flexible, que se adapta al contexto y a la situación, algo coincidente con los rasgos que la literatura al uso atribuye al liderazgo femenino, ligados a la capacidad de adaptación a las diversas circunstancias, así como al interés por el grupo y su bienestar.

TABLA 2

ESTILOS DE LIDERAZGO PREDOMINANTES DESDE EL PUNTO DE VISTA DE DIRECTIVOS Y SEGUIDORES

\begin{tabular}{|l|c|c|c|}
\hline & Directivas & Profesores & Coincidencia \\
\hline $\begin{array}{l}\text { Actitud ante posiciones } \\
\text { contradictorias entre los miembros }\end{array}$ & Política & Política & SÍ \\
\hline $\begin{array}{l}\text { Enfrentamiento entre los } \\
\text { miembros del grupo }\end{array}$ & Ideológico & Ideológico & SÍ \\
\hline Actitud ante las críticas recibidas & Meritocrática & Meritocrática & SÍ \\
\hline $\begin{array}{l}\text { Modo de tomar decisiones } \\
\text { importantes }\end{array}$ & Político & Político & SÍ \\
\hline $\begin{array}{l}\text { Actitud ante la incorporación } \\
\text { de nuevos miembros }\end{array}$ & Autoritaria & Política & NO \\
\hline $\begin{array}{l}\text { Conducta ante un grupo } \\
\text { desmotivado }\end{array}$ & Ideológica & Ideológica & SÍ \\
\hline Estrategia ante los conflictos & Política & Política & SÍ \\
\hline $\begin{array}{l}\text { Actitud respecto a las relaciones } \\
\text { interpersonales }\end{array}$ & Autoritaria & Política & NO \\
\hline
\end{tabular}


En definitiva, se evidencia la tendencia de las mujeres consultadas a mostrar un estilo flexible en la gestión de las diversas situaciones, adaptándose a las exigencias de cada una más que adoptando un estilo estable de ejercicio del rol. Podemos decir que (tabla 3):

TABLA 3

CARACTERÍSTICAS SITUACIONALES DEL USO DE DIFERENTES BASES DE PODER POR PARTE DE LAS DIRECTIVAS

\begin{tabular}{|c|c|}
\hline $\begin{array}{c}\text { Predomina una tendencia } \\
\text { hacia... } \\
\ldots \text { un estilo político... }\end{array}$ & $\begin{array}{c}\text { Para gestionar posiciones contradictorias } \\
\text { Como manera de tomar decisiones } \\
\text { En la gestión de los conflictos }\end{array}$ \\
\hline$\ldots$ un estilo ideológico... & $\begin{array}{c}\text { Ante enfrentamientos } \\
\text { entre los miembros del grupo } \\
\text { Para motivar al grupo }\end{array}$ \\
\hline$\ldots$ un estilo meritocrático... & Ante las críticas \\
\hline$\ldots$ un estilo burocrático... & $\begin{array}{c}\text { Para intervenir en enfrentamientos } \\
\text { entre miembros del grupo }\end{array}$ \\
& $\begin{array}{c}\text { Ante la incorporación de nuevos miembros } \\
\text { Ante los conflictos }\end{array}$ \\
\hline $\begin{array}{c}\text { f.una tendencia hacia... } \\
\text { personal de la autoridad... }\end{array}$ & $\begin{array}{c}\text { Ante la incorporación de nuevos miembros } \\
\text { Respecto de las relaciones interpersonales } \\
\text { en la organización }\end{array}$ \\
\hline
\end{tabular}

Así pues, nuestros resultados apoyan la conclusión del estudio de Gillett-Karam (1994) (citado por Glazer-Raymo, 1999), el cual plantea que las destrezas de liderazgo tienen que ver más con variables situacionales que con aquellas ligadas al género. Como hemos comprobado, las participantes en nuestro estudio utilizaron todas las fuentes de poder disponibles ante circunstancias problemáticas de diversa índole, sin mostrar una clara predilección por ninguna de ellas. Esta diversidad y variedad de estilos podría estar ligada a otra característica atribuida por una de las entrevistadas a las mujeres: un mayor pragmatismo y un modo más resolutivo de encarar los problemas de la organización, frente a una visión más estratégica de los hombres, lo cual implicaría un estilo más marcadamente político en ellos. 
En todo caso, como nos sugiere Glazer-Raymo (1999), debemos revisar nuestros modelos de liderazgos académicos, con el fin de reflejar la experiencia de las mujeres y aprender de los aspectos novedosos que presenta su forma de dirigir, como por ejemplo, su fuerte orientación hacia las personas, los grupos y las relaciones, que detallaremos en la sección siguiente. Quizás ello contribuya a algo tan necesitado en estos tiempos como el fortalecimiento de la cultura de la colaboración y el compromiso en las instituciones universitarias.

Otra característica atribuida a las mujeres sería una mayor capacidad y orientación hacia el trabajo multitarea, es decir, hacia el trabajo en paralelo (varios asuntos al mismo tiempo) frente al trabajo en serie que los informantes señalan como más propio de los varones. En palabras de una de las directivas entrevistadas, la mujer admite interferencias. Ello confirmaría la tesis de una visión predominantemente policrónica (Hargreaves, 1997) de las mujeres en el modo de abordar las tareas organizativas, algo que puede estar vinculado a la exigencia que plantean las tareas del hogar, muchas de las cuales requieren ser desarrolladas de modo simultáneo.

\subsubsection{Liderazgos en acción}

A continuación volveremos sobre los casos presentados en la primera sección. Esta vez los examinaremos desde el punto de vista de los estilos de liderazgo que adoptaron. En este sentido, uno de los rasgos que veremos más claramente desplegados por las mujeres participantes en nuestro estudio es su orientación hacia las relaciones sociales, confirmando así uno de los aspectos que despierta mayor consenso en la literatura especializada. Bensimon (1993) explica dicha orientación planteando que las mujeres perciben el mundo no tanto como algo físico sino encarnado en personas y expresado de manera psíquica y social y que ello es congruente con un gobierno de ese mundo más a través de las necesidades sentidas que mediante un control racional.

Por otro lado, en muchos casos hemos encontrado esta orientación hacia el mundo social combinada con un perfil de fuerte exigencia —incluida la autoexigencia—y de autoridad. Es decir, hemos 
encontrado en un número importante de directivas la tendencia a combinar los aspectos sociales y técnicos del ejercicio de los cargos de gestión. De acuerdo a lo planteado por la literatura, se trata de un perfil - bastante maternal, por cierto- que conjuga la autoridad con la delicadeza o diplomacia en el manejo de las situaciones. Estas mujeres dialogan, buscan el acuerdo, tratan de limar posiciones divergentes pero, llegado el caso en el que se hace imposible llegar a una solución pactada, no dejan las decisiones eternamente suspendidas en espera de un acuerdo o consenso. Creen que ocupan ese puesto para tomar decisiones y consideran que no hacerlo es incurrir en una falta de responsabilidad. Podríamos afirmar que explotan las relaciones sociales mientras construyen el marco adecuado donde los problemas pueden ser resueltos. Sin embargo, cuando las posibilidades de acuerdo se cierran en este ámbito, pasan a utilizar los controles de autoridad o los burocráticos para que las tareas puedan seguir adelante.

\section{El liderazgo de Emma}

La Facultad de Emma es de tamaño medio y en ella impera un buen ambiente de trabajo, colaboración entre las áreas dentro del Departamento, y ausencia de problemas o conflictos importantes, hasta el punto de que la mayor parte de los asuntos se deciden por consenso, sin necesidad de llegar a votación alguna. El personal valora la gestión que desarrolla el equipo decanal y este suele considerar las aportaciones y sugerencias que se le realizan desde todos los sectores. En este contexto, independientemente de que más tarde volvamos sobre ello, Emma es considerada una buena gestora, una persona dialogante que sabe escuchar, con una gran capacidad para las relaciones sociales, pero, al mismo tiempo, con una importante dosis de firmeza:

[...] habilidades sociales que yo no tengo, y esas las tiene Emma, una es la escucha activa y la asertividad al mismo tiempo... (Adela, 89-90). [...] es una mujer pragmática efectivamente, que resuelve las cuestiones que se presentan, tiene buen trato, tiene más o menos aciertos en concreto, está por la labor, tiene buen trato, eficaz... (Fernando, 114-116). [...] tiene también la capacidad social que por ejemplo yo no tengo, tiene una capacidad de trabajo muy fuerte porque está llevando todo el trabajo. (Marcelo, 89-90). 
[...] la facilidad que te da para trabajar, siempre está a tu disposición, la tienes siempre ahí, te puede respaldar e intenta ayudarte. (Lucía, 71-72).

Emma tiene una sensibilidad muy especial de estar muy pendiente de todo el mundo, [...] yo creo que tiene una sensibilidad y un don de gentes que le hace estar llevando muy bien la escuela. (Jesús, 136-139)

El estilo de liderazgo de Emma se apoya en sus habilidades sociales, diplomacia, y énfasis en la participación en la toma de decisiones. Se trata de un estilo participativo y democrático que puede llegar a combinarse con el uso de la autoridad en determinadas circunstancias.

Está considerada como buena diplomática, utiliza mucha mano izquierda a veces para mediar en los conflictos (Juan, 98-100).

Yo creo que me iría casi más a la parte autoritaria en el caso de Emma y eso es lo que más me gusta precisamente de ella, y lo que también me asusta a veces, porque como te decía antes yo creo que un decano en un momento determinado tiene que tener mano izquierda como se suele decir para manejar las cosas... (Marcelo, 123-133).

[...]más o menos hábil, cada uno tiene su estilo, hay estilos muy distintos, aquí en el ámbito universitario tiene que ser muy cooperativo, el tipo de gestión que se tiene que hacer aquí no es el de la empresa que fabrica ladrillos y tal, por lo tanto exige tener la habilidad para implicar a la gente, para convencerla, para presentar las cosas de manera que la gente participe y demás, eso es importante, y luego ser una persona flexible [...] [Emma] tiene un carácter fuerte a la vez, que no es incompatible con lo que estoy diciendo, tiene un carácter fuerte y toma de decisiones a lo que corresponde a su campo y cuando discutimos la política, las cuestiones generales de la Facultad ella tiene una opinión formada y la expresa claramente sin ningún tapujo... (Daniel, 40-45;77-85).

Emma es un buen compendio de todo ello, su estilo de dirección es próximo, no es autoritario ni mucho menos, en principio deja trabajar y deja iniciativa a los que trabajan con ella... (Juan, 31-34).

\section{El liderazgo de Berta}

Algunos de nuestros informantes opinaban que el liderazgo de Berta responde a ciertos estereotipos maternales, ligados a la evitación del conflicto y del enfrentamiento. Así, si hay problemas, no los pone de manera clara sobre el tapete, sino que intenta lograr acuer- 
dos al margen de las instancias formales y de los contextos públicos, mediante relaciones cara a cara. Es decir, busca el consenso con «mano izquierda»y, aparentemente, suele lograrlo, aunque esta estrategia no satisfaga a todos. En concreto, algunos preferirían que la toma de decisiones descansara más en las instancias organizativas y normas formales. Es decir, que fuera menos adhocrática y menos dependiente de factores personales. Son los mismos que también preferirían que fuera más exigente o reivindicativa ante las autoridades de la Universidad.

Estos profesores critican la gestión de Berta por el hecho de que no se haya ocupado de resolver el conflicto latente entre los dos colectivos de profesores, sino de convivir con él aunque minimizando su impacto sobre la vida académica. Incluso estos reconocen que es su estilo maternal — preocupado por las personas y por el clima social de la organización- el que facilita que el conflicto encubierto no aflore de manera disfuncional, compensando este con cierto bienestar que ella contribuye a generar con su actitud cálida y protectora. En definitiva, Berta es respetada como profesional y como directora, aunque no siempre se comparta su forma de ejercer la gestión.

En este sentido, es indudable que posee cualidades como gestora que la mayoría de sus compañeros valora: siempre intenta satisfacer las demandas que se le presentan; su «puerta siempre está abierta» y resulta una directora asequible, que trata de ayudar a todos. Por otro lado, se le reconoce una mente organizada, así como capacidad para delegar las tareas en las personas adecuadas. Su forma de dirigir combina la autoridad propia de quien se sabe en condiciones de decidir — dada la cultura jerárquica dominante en su Universidad - con un persuasivo empleo de las habilidades personales. Sobre esta base parece fundar un modo de ejercer el liderazgo que le ha permitido mantener la cohesión de un grupo dispar a lo largo de casi tres décadas.

El liderazgo de Leonor... y de Pura

De algún modo, los liderazgos sucesivos de Pura y Leonor en la dirección del Departamento han debido tener un papel fundamental en la construcción de una trama social de sostén que ha impedido 
que los conflictos generados en el proceso fundacional y durante la transición hayan creado un ambiente insostenible. Pura, la directora actual, habla del tipo de liderazgo que se hizo necesario tras la marcha del fundador, en un Departamento muy diverso, que ha exigido a las dos directoras el estar muy atentas a las diferentes sensibilidades de los grupos que lo componen.

Podemos ver la combinación de estilos de ambas directivas como una auténtica estructura de poder institucionalizada que se ve reforzada tanto por el apoyo que les presta la mayoría de los miembros del Departamento, como por la débil y «deportiva» presión que ejerce la minoría en la oposición. Ellas apenas ejercen su influencia desde la autoridad, desde la jerarquía. Por el contrario, operan combinando ciertos controles burocráticos con un amplio conocimiento e intervención sobre las redes sociales y los grupos informales. Y ello a pesar de que esta especie de renuncia a la autoridad formal representa a veces una dificultad, puesto que las formas «blandas» de poder son interpretadas como debilidad por algunos miembros, en opinión de Pura.

Por tanto, estamos más bien ante una estructura de poder de base meritocrática/burocrática con un importante componente micropolítico, en la medida en que los grupos de investigación funcionan además como coaliciones que negocian de manera informal la agenda e incluso las decisiones a adoptar en las reuniones formales. Es sobre estas bases de poder que Leonor y Pura han evitado parte de las tendencias disgregadoras características de las estructuras de poder fuertemente politizadas. Parecen haber ayudado a esta contención de la escalada de los conflictos algunos de los valores asumidos por estas mujeres en el ejercicio de la dirección, especialmente el compromiso («queremos al Departamento») y la honradez, entendida como una modalidad de compromiso ético. Y también han jugado un papel importante ciertas dosis de diplomacia y el uso intensivo de las relaciones sociales y del diálogo, en lugar de aplicar el rodillo de la mayoría en cualquier circunstancia.

\section{El liderazgo de Diana}

Diana basó su gestión desde el primer momento en el trabajo en equipo, por eso el proceso de formación de su equipo de gobierno fue 
muy importante para ella. El criterio que utilizó fue muy diferente al de la decana anterior, que había elegido a sus colaboradores tratando de mantener un siempre difícil equilibrio entre los Departamentos y áreas de conocimiento presentes en la Facultad. Para Diana, por el contrario, lo prioritario era la complicidad y la armonía entre los miembros del equipo. La importancia concedida a estos aspectos hace que se disguste seriamente ante el abandono de uno de sus vicedecanos para ocupar otro cargo de gestión. También lo demuestran las condiciones con las que ha tratado de crear un clima de trabajo satisfactorio. Por ejemplo, el equipo tiene reuniones sistemáticas todos los miércoles, las cuales comienzan con café y galletas o pasteles que sus miembros aportan. Con cierta frecuencia almuerzan juntos y en alguna ocasión se han «encerrado» a trabajar durante una jornada completa en una apartada y tranquila casa rural que han alquilado para la ocasión.

Pero además, Diana mantiene una amplia red de colaboradores informales cuya importancia en dicha red no está directamente determinada por la posición que esas personas ocupan en el organigrama. Por ejemplo, Marta, una de las responsables administrativas de la Facultad, es una pieza importante de dicha red. Se trata de la responsable del área de alumnos, y no es casualidad que la atención a los alumnos y la escucha frecuente a los representantes de estos sean uno de los ejes de su gestión. Además Marta conoce a fondo esta Universidad casi desde sus inicios, conocimiento que también adquiere una especial importancia para el modo de gestión reticular e informal que adopta Diana. Pero la red se extiende también a otros profesores de su Departamento o de la Facultad que no forman parte de su equipo, a estudiantes, a otros miembros de la administración y, por supuesto, a miembros del equipo rectoral, como Pina, con la que mantiene inmejorables relaciones.

Además de la importancia concedida al trabajo en equipo y a la construcción de una amplia y difusa red de colaboradores, el estilo de gestión de Diana se caracteriza también por su preocupación por integrar hasta el límite de lo posible las diferentes sensibilidades que existen dentro de la Facultad. Esto significa desplegar un programa con objetivos claros y un estilo de dirección firme en determinados aspectos, pero a la vez flexible en otros, precisamente para 
evitar volver a situaciones conflictivas. Sin embargo, Diana asume que hay momentos en los que la búsqueda de consenso se topa con barreras infranqueables, requiriéndose entonces decisiones que, según ella, los directivos deben adoptar con firmeza y convicción, puesto que «la máxima satisfacción es ver que algo sale adelante». Encontramos que es precisamente esta combinación de firmeza y cierta directividad, por un lado, y de amplio despliegue de relaciones sociales y diplomacia, por el otro, la que caracteriza esencialmente el estilo de gestión de Diana. El componente directivo o de autoridad en su estilo de gestión fue puesto de manifiesto por diferentes entrevistados: «ella es firme en sus convicciones»; «tiene una forma de trabajar más directa»; "a mi me dicen que soy un poco mandona» (la propia Diana). El resultado es un estilo «activista» y «resolutivo» — «eficaz» dirá uno de los entrevistados- que no espera mucho tiempo con los problemas sobre la mesa, sin resolver y no teme adoptar decisiones arriesgadas siempre que cuente con el apoyo de su propio equipo.

Uno de los problemas principales señalados por Diana en su acción de gobierno resultó de gran interés para nuestro estudio. Su equipo decanal estaba compuesto al $100 \%$ por profesores -mujeres y hombres - titulares o asociados, con la total ausencia de los catedráticos (todos ellos varones). Según Diana, los hombres «siguen dominando por detrás, porque son catedráticos, porque son lo que fueron, porque tienen un prestigio, pero sobre todo porque son catedráticos». Los investigadores pudimos comprobar esta pauta implícita de dominio desplegada por «los catedráticos» en una reunión de una Junta de Facultad a la que se nos permitió asistir como observadores. En dicha reunión, este grupo se valió de una curiosa estrategia para el mantenimiento de una posición hegemónica: el humor. Los catedráticos, en un ambiente distendido, acapararon la mayor parte del tiempo disponible de reunión mediante intervenciones verbales en las que de manera muy frecuente intercambiaban bromas entre sí. De hecho se convirtieron en los protagonistas de la reunión, debiendo realizar la decana esfuerzos constantes para cortar sus digresiones y volver a los temas señalados en el orden del día. No es extraño que Diana sitúe en los privilegios adquiridos por los profesores catedráticos, especialmente los rela- 
cionados con la elección de horarios/asignaturas, algunos de los problemas más importantes que encuentra en su gestión.

\section{El liderazgo de Ofelia}

En primer lugar, una característica que destaca en Ofelia es su inmensa capacidad de trabajo y de organización. Dicen que no se cansa nunca, que es capaz de trabajar catorce o quince horas diarias; se implica en las tareas de los compañeros echándoles una mano de manera que la gente sabe que cuenta con ella no como directora sino también como compañera e incluso, después de haber solicitado entrega de tareas, si no se han cumplido, ella asume la responsabilidad del trabajo y lo termina personalmente. Hasta el punto de que en muchas ocasiones le cuesta delegar. Es muy absorbente con el trabajo y muy minuciosa. Muy exigente consigo misma. A esta actitud de autoexigencia, dedicación y entrega a la gestión puede haber contribuido de manera decisiva su afán por demostrar que se encontraba en el cargo por sus propios méritos; y también su afán por demostrar su valía personal, superando así una imagen de frivolidad y superficialidad que según ella tenía inicialmente entre sus propios compañeros y que atribuye a su juventud, a su condición de mujer y a su manera de vestir poco tradicional:

[tuve que] demostrar que tengo mis ideas claras, mis valores, mis principios, que tengo mis normas, que me las sé y que no cambio de opinión. (Ofelia 03S_01,3366-373).

En segundo lugar, Ofelia manifiesta un equilibrado estilo en el que combina las habilidades sociales con la exigencia y la autoridad:

[...] es un estilo más femenino, es una persona que escucha, no sé cómo explicarlo, es más socializadora, pero es una persona directiva a la vez, cosa que yo agradezco, es una persona muy clara, dice: las cosas tienen que ir por aquí, y nos empuja a trabajar en una dirección [...] es una persona muy organizada, muy trabajadora, muy estricta [...] y sabiendo que ella está a cargo de un Departamento muy complicado. (Francisco 03S_02, 68-74).

Sus compañeros piensan que gestiona con originalidad, iniciativa, talante humano, equidad (Jaime 03S-03, 60). Este aspecto de 
la equidad o imparcialidad es mencionado por varios de nuestros informantes: «intenta ser lo más neutral posible y evita el posicionarse a favor de uno si eso significa ponerse en contra de otro» (Francisco 03S_02115-122); «es una directora que la gente ve como bastante imparcial» (Alberto 03S_04, 138-139); «es una persona muy neutral, demasiado» (Rosela 03S_05, 48-52); «no se pone de parte de nadie» (Piedad 03S_07, 74-89). Muchos valoran su persistente actitud de escucha, de negociación y de búsqueda de consenso. Ante cualquier conflicto o dificultad, prefiere reunirse con los implicados y tratar de resolver el problema antes que dejarlo que se enquiste o que el malestar quede latente en el grupo. Esto ocurre, por ejemplo, ante consejos de Departamento que se presentan complicados o conflictivos.

Se destacan otras habilidades sociales en la manera de gestionar de Ofelia, como que es entusiasta, muy amable y afable — «el trato es bueno, es cordial» (Marta 03S-06, 35-36) — o que sabe discernir la amistad y las cuestiones profesionales. Ella misma considera que ha aprendido a ser menos exigente y rígida para volverse más comprensiva y dialogante; y que poco a poco está aprendiendo a delegar, algo que no le resulta fácil. El bienestar de los miembros del Departamento, la búsqueda de un clima social relajado y donde impere la confianza, está entre sus objetivos prioritarios.

En definitiva, Ofelia se maneja bien en las distancias cortas, en el cuerpo a cuerpo; sin embargo, su presencia aparece más difuminada en los foros públicos. En este sentido, podemos decir que responde a los estereotipos sobre la predominancia masculina en los ámbitos públicos, mientras que las mujeres prefieren desplegar su gestión «en privado»:

[...] sabe llegar... [sin embargo] no le constato ninguna intervención pública en la que haya levantado la mano y se haya tirado un palique... Cuando está en público con un montón de gente no es una persona que destaque [...] es una persona más bien discreta. (Saturnino 03S_08, 403-410).

En definitiva, Ofelia es hábil para mediar en conflictos, tiene mano izquierda para desenvolverse en situaciones difíciles o conflictivas y posee habilidades de comunicación, empatía y relación 
interpersonal. Sin embargo, combina estos aspectos con un cierto ejercicio de la función directiva de corte personalista, utilizando la autoridad como base de influencia, implicándose directamente en la ejecución de las tareas, supervisando, tratando de garantizar que dichas tareas se realicen a tiempo y correctamente, asumiendo personalmente la responsabilidad, etcétera. En este estilo entre político y basado en la autoridad, diálogo y toma de decisiones no se encuentran divorciados, sino que se dan habitualmente la mano.

\section{El liderazgo de Ana}

Ana ha optado por un estilo de liderazgo que, según ella misma, prioriza la autoridad sobre las habilidades sociales. Esta postura ante el desempeño de su función como gestora no es, sin embargo, señalada como origen de tensiones. Por el contrario, los entrevistados coinciden en calificar de grato el clima generado por el equipo que ella dirige.

Hay también acuerdo general en el reconocimiento de cualidades como el equilibrio y la tranquilidad ante situaciones de conflicto, el ser «una gran trabajadora» (Juan, entrevista 02; 60), la «voluntad de ayudar» (Almudena, entrevista 04; 62), la cualidad de decir «las cosas a la cara, practica[r] la prevención desde el punto de vista de la actuación, dice lo que hay que hacer cuando existe una normativa que refleja perfectamente que hay que realizarlo...» (Arturo, entrevista 08; 80-82). Esta atención a las normas no limita, sin embargo, su capacidad para responder a una situación imprevista, ante la que «tiene una cabeza fría, se mantiene serena...» (Juan, entrevista $02 ; 192-193)$. Su carácter exigente en lo que se refiere al cumplimiento de las normas está muy presente, tanto en los testimonios de Ana como en los de sus compañeros. Ella asegura que tuvo que reconducir el funcionamiento de un decanato en el que «todo era en plan colega» (Ana, entrevista 01; 92). Esta necesidad de modificar un modo ya establecido de operar puede haberle exigido, en los primeros momentos de su gestión, apelar a la autoridad como modo de ejercer su cargo. Transcurrido el tiempo, en cambio, podría estar apoyándose más en el empleo de estrategias acordes con un estilo de corte interpersonal. 
Ana modifica su estrategia de liderazgo en función del «tipo de conflicto» (Juan, entrevista 02; 188) que se le presente. Esta adecuación a las circunstancias puede considerarse como un indicador de cierta «mano izquierda» en el ejercicio de la gestión.

El equipo del que Ana forma parte está integrado por tres mujeres y dos hombres. Uno de ellos, el decano, es identificado por Ana como un importante apoyo en la realización de la tarea y también su estilo de liderazgo se orienta hacia la búsqueda del consenso y hacia el trabajo en grupo. Sin embargo, esta forma de operar se encuentra a veces con dificultades, ya que la división original entre los miembros del profesorado no se ha borrado por completo: «unos somos los buenos y los otros, los malos...» (Carmela, entrevista $07 ; 108)$.

Cabe suponer, por tanto, que bajo la apariencia del consenso y la armonía entre estos grupos, subyace una situación de relativo equilibrio entre fuerzas enfrentadas. Profesores como Ana, que ocupan un lugar de relativa vulnerabilidad a causa de su peculiar historia en el centro son, paradójicamente, quienes ocupan lugares de autoridad en él.

\section{El liderazgo de Irene}

Irene manifiesta un estilo de liderazgo que combina disciplina, rigor y sistematicidad con tolerancia, afabilidad y orientación hacia los problemas de la gente. Cuando ha sido directora del Departamento ha procurado que las cosas se hicieran bien, pero al mismo tiempo se ha preocupado del bienestar de las personas que trabajaban bajo su dirección. Esto significa que en ocasiones ha sido estricta e intransigente, pero al mismo tiempo velaba por el bienestar de todos los miembros del Departamento. Ha hecho compatibles el orden y la reglamentación en el funcionamiento rutinario con la mejora del clima social. Al mismo tiempo, se ha implicado de forma muy directa en la gestión, tomando decisiones, asignando tareas y recursos, etcétera y esto ha hecho que poco a poco los miembros del Departamento hayan ido confiando cada vez más en Irene, hasta el punto de despreocuparse en buena medida y delegar toda la responsabilidad en la directora. 
Cabe destacar que, durante los años que ha ocupado el cargo, Irene se ha sentido psicóloga y casi sacerdotisa, en el sentido de que ha tenido que atender a muchas personas que venían a consultarle y pedirle consejo, no solamente sobre cuestiones relacionadas con las tareas académicas, sino más bien y sobre todo, acerca de asuntos personales. A ello han contribuido su afabilidad y tolerancia, cualidades que varios entrevistados le reconocen, así como ciertas habilidades sociales propias de su condición de mujer.

Otra de las claves en su estilo de gestión ha sido la potenciación del trabajo en equipo y, para ello, empezó eligiendo a un equipo directivo plural, representativo de diferentes tendencias en el Departamento. En su mayoría se trataba de compañeros jóvenes que le proporcionaran una visión renovadora, una mirada diferente. Ninguno de ellos poseía una posición destacada dentro del Departamento. También incluyó elementos difíciles o conflictivos, potenciales saboteadores, a los que prefería ver en sus filas que en la oposición:

[...] he tenido, por decirlo de alguna manera, buen ojo con el equipo porque busqué unas personas que parecían grises porque nunca se habían metido en nada pero que yo había observado en la Junta de Departamento su criterio me gustaba pero que no eran los cabecillas, bueno ahora tengo que decir que uno de ellos ha sido decano, o sea que funcionó, lo hizo muy bien. Otro que, por cierto, se murió, era conflictivo, entonces decidí [unirlo] también al grupo. (Irene, 3C_01, 166-178).

En definitiva, los entrevistados pusieron de manifiesto la habilidad de Irene para mediar en los conflictos, su mano izquierda y sus habilidades de comunicación, de empatía y de relación interpersonal.

Como hemos podido comprobar, nuestras directivas adoptaron mayoritariamente un estilo de liderazgo basado en la comunicación franca, abierta y directa, así como en la consideración de los problemas y necesidades personales de los miembros de la organización en equilibrio con los requerimientos de la tarea. El único caso que se aparta de este esquema es el de Pilar, que ya comentamos brevemente en la primera sección de este capítulo. 
Es probablemente la tendencia de las directivas a mantener un equilibrio entre la orientación hacia las personas y hacia las tareas lo que las conduce a buscar, como plantea Marshall (1990) formas creativas de resolución de conflictos, alejadas de las estrategias tradicionales basadas en los controles burocráticos. Esta tendencia proporciona al liderazgo de las directivas no tanto «visibilidad» como «profundidad». En efecto, comprobamos que el estilo de liderazgo de buena parte de las directivas analizadas no adoptaba una alta visibilidad en un sentido autoritario o bien ideológico. Los casos de Diana y Ofelia son paradigmáticos en este sentido. Por el contrario, se movían más bien en la línea de sombra de las relaciones interpersonales, multiplicando los contactos cara a cara y asumiendo las preocupaciones de los otros como la base de su actuación.

Por otro lado, esta orientación hacia las relaciones sociales y la preocupación por las personas fueron compatibles con un estilo resolutivo en la toma de decisiones. Si hay un perfil que predomina en los casos analizados es el que combina el despliegue de habilidades sociales, con la exigencia —incluida la autoexigencia- y la autoridad. Incluye una preocupación por la búsqueda del diálogo, del acuerdo y por limar las posiciones divergentes. Sin embargo, si el consenso no es posible no se arredran en tomar decisiones aunque puedan levantar la oposición de un sector. Se trata por cierto de un perfil bastante «maternal», que conjuga la autoridad con la delicadeza o diplomacia en el manejo de las situaciones.

Finalmente, también hemos encontrado una fuerte implicación personal en las tareas, algo que aparece también en otros estudios (Loden, 1987). Algunos entrevistados en el caso de Diana destacan la especialmente intensa implicación de las directivas _Diana incluida- en las tareas y que incluso lo hacen «con más pasión», lo cual implica un mayor desgaste. Leonor por su parte ha llegado a percibir que «mi vida personal y mi vida profesional es la misma». Es decir, vive por y para el Departamento con el que ha contraído un compromiso personal. 


\section{Referencias bibliográficas}

ACKER, S. (2005), «Gender, Leadership and Change in Faculties of Education in Three Countries», en J. Collard y C. Reynolds (eds.), Leadership, Gender and Culture in Education. Male and Female Perspectives, Maindenhead: Open University Press.

Bensimon, E.M. (1993), «A Feminist Reinterpretation of President's definition of leadership», en J. Glazer, E.M. Bensimon y B.K. Towsend (eds.), Women in Higher Education: A Feminist Perspective, Needham Heihts, MA: Gin Press.

ERKuT, S. (2001), Inside Women's Power: Learning from Leaders, Boston: Center for Research on Women, Wellesley College, y Winds of Change Foundation.

Glazer-RAYmo, J. (1999), Shattering the Myths. Women in Academe, Baltimore: The Johns Hopkins University Press.

Hargreaves, A. (1996), Profesorado, cultura y postmodernidad, Madrid: Morata.

- (1997), «Cultures of Teaching and Educational Change», en B.J. Biddle, T. Good e I. Goodson (eds.), International Handbook of Teachers and Teaching, Dordrecht: Kluwer Academic Publishers.

KEZAR, A., y P.D. ECKEL (2002), «The Effect of Institutional Culture on Change Strategies in Higher Education: Universal Principles of Culturally Responsive Concepts», Journal of Higher Education, 73(4), 435-460.

LeA, D., y Z. Leibowitz (eds.) (1992), Adult Career Development. Concepts, Issues and Practices, Alexandria: The National Career Development Association.

Loden, M. (1987), Dirección femenina. Cómo triunfar en los negocios sin actuar como un hombre, Barcelona: Hispano-Europea.

Marshall, J. (1990), Women Managers. Travellers in a Male World, Chichester: John Wiley \& Sons.

MintzBeRG, H. (1992), El poder en la organización, Barcelona: Ariel.

SÁNCHEZ MORENO, M., y J. LÓPEZ YÁÑEZ (2003), «Condiciones organizativas de la enseñanza en la Universidad», en C. Mayor (coord.), Enseñanza y aprendizaje en la Educación Superior, Barcelona: Octaedro.

Wolf-Wendel, L., y K. WARD (2003), «Future Prospects for Women Faculty: Negotiating Work and Family», en B. Ropers-Huilman (ed.), Gendered Futures in Higher Education. Critical Perspectives for Change, Nueva York: State of New York University Press. 


\title{
CAPÍTULO 5 \\ ALGUNAS CONCLUSIONES \\ QUE ORIENTAN LA PRÁCTICA
}

\author{
Marita Sánchez Moreno
}

Los capítulos precedentes han dado buena cuenta del papel que las directivas desempeñan en la transformación de las organizaciones universitarias españolas en este momento de profundas reformas en la educación superior. Nuestro objetivo en este último capítulo se centra en ofrecer al lector una perspectiva de conjunto, una síntesis que le facilite la integración de todas las ideas expuestas previamente y le ayude en la comprensión global de la temática. Además, es nuestro propósito presentar, a la luz de los conocimientos adquiridos derivados de nuestro trabajo en el análisis y comprensión del liderazgo ejercido por mujeres responsables de la gestión universitaria, algunas propuestas que puedan servir para orientar futuras líneas de trabajo, dirigidas a la mejora de las formas de desempeño de esta labor.

\subsection{Algunas ideas de partida}

Las Universidades españolas han experimentado en los últimos años importantes transformaciones estructurales, en paralelo a un aumento significativo de su producción científica y a una mayor proyección internacional de un número significativo de investigadores y equipos de investigación. Estos cambios exigen nuevos roles en los directivos y gestores y nuevos enfoques de la acción directiva, dado que las características particulares de las 
organizaciones universitarias reclaman liderazgos sofisticados en los que el ejercicio de la autoridad o de la gestión burocrática resulta a todas luces insuficiente (Nidiffer, 2001; Fullan, 2002).

Sin duda, las mujeres tienen algo muy importante que aportar en la búsqueda de estas nuevas configuraciones del liderazgo, dado que, a pesar de su menor presencia en los cargos directivos, diversas investigaciones muestran un alto nivel de satisfacción hacia el liderazgo ejercido por las mujeres en las organizaciones desde la perspectiva de sus miembros (Erkut, 2001; Acker, 2005). Aparentemente, una de las razones esgrimidas parece ser la ventaja que en general tienen las mujeres en el manejo de una variedad de habilidades comunicativas y sociales, especialmente adecuadas para el funcionamiento más participativo, reticular, descentralizado, emergente y democrático característico de las organizaciones actuales y, en especial, de las Universidades (Bensimon, 1993; Calás y Smircich, 1993; Grogan, 1996; Tierney y Bensimon, 1996; Erkut, 2001; Fletcher, 2001).

Precisamente, la definición del tipo de liderazgo necesario en las organizaciones modernas ha constituido la búsqueda principal de una teoría de la organización que en los últimos años ha abandonado casi por completo la idea de las organizaciones como máquinas o burocracias para asumir mayoritariamente la idea de las organizaciones como construcciones sociales (Alvesson y Deetz, 1996; Chia, 2003; Willmott, 2003). Así pues, la incorporación lenta, aunque progresiva, de las mujeres a los puestos de dirección puede constituir un auténtico banco de pruebas para esta teoría de la organización y en especial para la teoría del liderazgo. Además, ello plantea la oportunidad de una alianza táctica entre las tradiciones teóricas feministas y las de estudio de las organizaciones sociales, para el logro de ciertos intereses comunes, como han sugerido diversos autores (Calás y Smircich, 1993; Perreault, 1993; Gherardi, 1995; Yancey Martin y Collison, 2002).

Esta alianza debería permitirnos ir más allá de algunos enfoques que han caracterizado la literatura y la investigación sobre el liderazgo de las mujeres. Una buena parte de esta literatura se ha caracterizado por mostrar el modo en que los valores masculi- 
nos han impregnado el ejercicio del liderazgo en las organizaciones (Blackmore, 1999), mientras que otra parte se ha enfrascado en el intento de definir un estilo femenino de liderazgo que se plantearía como alternativo al masculino. Sin embargo, una corriente cada vez más importante sugiere que, pese a que el género constituye una dimensión constitutiva de la acción en las organizaciones, esta no debería encerrarse en categorizaciones cerradas y homogéneas acerca de lo masculino y lo femenino. Como han sugerido Alvesson y Billing (1992), tanto el liderazgo ejercido por mujeres como el ejercido por hombres es lo suficientemente diverso y contradictorio en la práctica como para reducirlo a un modelo bipolar. Estos autores opinan que agrupar bajo el rótulo de "liderazgo femenino» un conjunto de conductas que consideramos adecuadas para el desarrollo de las organizaciones, además de no sostenerse sobre una base empírica, podría incluso desincentivar, tanto en hombres como en mujeres, la adopción de dichos rasgos. En consecuencia, ello no ayudaría a romper los estereotipos que han atravesado tradicionalmente este campo (Alvesson y Billing, 2000).

También Court (2005) ha cuestionado la reducción del fenómeno género-liderazgo a los modelos masculino y femenino. Al igual que Alvesson y Billing (1992) y otros autores escépticos ante el constructo «liderazgo femenino», Court sugiere que la dimensión género debe ponerse en relación con otras dimensiones que influyen sobre el comportamiento de los líderes, como por ejemplo la clase social o las creencias y la cultura.

En definitiva, los estudios acerca del género en las organizaciones comienzan a superar los enfoques iniciales de las pasadas dos décadas que se centraban en la diferenciación de estilos y características atribuidas a hombres y mujeres. Los nuevos estudios utilizan las aportaciones de una variedad de disciplinas, y toman en consideración tanto $a$ ) las variables situadas en un nivel macro, es decir las condiciones sociales, culturales y políticas que influyen en el liderazgo (Blackmore, 2005), como b) las variables situadas en el nivel medio o institucional, como por ejemplo la historia institucional, la estructura o la cultura organizativa (Mills, 
2002). Estos estudios tienden a adoptar un enfoque más procesual y metodologías basadas en el estudio de casos para explorar las historias de líderes concretos y comprender el modo en que todas estas influencias dan forma a su liderazgo (Bensimon, 1993; Collard y Reynolds, 2005).

A pesar de todo, hay un punto de convergencia entre las investigaciones sobre el papel de las mujeres en las organizaciones y la literatura sobre el liderazgo, el cual tiene que ver con el uso de las habilidades sociales y un enfoque centrado en las personas. En este sentido, el giro hacia los aspectos sociales de la teoría de la organización converge con una buena cantidad de estudios empíricos que señalan que aquellos aspectos, sin ser exclusivos de las mujeres, están con mucha frecuencia presentes en sus estilos de liderazgo (Erkut, 2001; Fletcher, 2001).

La búsqueda de liderazgos distribuidos, dialógicos y centrados en las personas es particularmente necesaria en las organizaciones universitarias, donde las diversas formas de gerencialismo se han mostrado especialmente ineficaces en la creación de culturas innovadoras y creadoras de desarrollo sostenible de la docencia y la investigación (Blackmore, 2005). En ellas adquiere aún más sentido la pregunta acerca de cuál es y cuál podría ser la aportación de las gestoras universitarias y directoras de Departamentos universitarios en la construcción de modos colegiales de trabajo mediante liderazgos sostenibles, visibles y reconocidos. En la misma línea, cabe también preguntarse si las mujeres que ocupan puestos de dirección y gestión en la Universidad pueden representar un impulso a la transformación de estas.

Algunas investigaciones han subrayado el carácter innovador de los liderazgos ejercidos por mujeres. En particular han sido destacados los siguientes rasgos:

- Una tendencia a compartir el liderazgo y a buscar el apoyo de un equipo en el ejercicio de la dirección, a diferencia de los hombres, que actuarían de manera más individualista (Bensimon, 1993). Esta tendencia, menos competitiva que en el caso de los hombres, funciona como inductora de un funcio- 
namiento cooperativo, participativo y democrático, que favorece la apropiación de los logros por parte del conjunto.

- Una tendencia también a minimizar los controles burocráticos, prefiriendo colocarse a sí mismas como referentes, antes que a las normas formales (Aisenberg y Harrigton, 1993). Esto plantea una proposición implícita de alianza o de gestionar conmigo a los seguidores (Coronel Llamas, Moreno y Padilla, 2002), lo cual favorece un clima cooperativo en el trabajo y un sentido de responsabilidad compartida por sus resultados (Loden, 1987).

- Un abordaje intuitivo de los problemas y en especial de las soluciones, sin que ello signifique un menor grado de racionalización, elaboración, o reflexión sobre los mismos. Ello lleva a muchas directivas hacia formas creativas de resolución de conflictos, en las que, según Marshall (1990) están presentes ciertos rasgos: $a$ ) una percepción holística del mundo y de los problemas; $b$ ) el sustrato emocional como forma primera de contacto con el mundo; $c$ ) actitud de crian$\mathrm{za}$ /protección, referida al mantenimiento de la calidad de vida y la satisfacción de los seguidores; $d$ ) continuidad, referida a la duración y la estabilidad de los vínculos, incluso si no resultan satisfactorios; y $e$ ) creatividad y determinación para iniciar transformaciones. En esta misma línea Bensimon (1993) apunta que las mujeres se perciben como interdependientes y se juzgan bajo estándares de responsabilidad y atención a los demás, en oposición a los hombres que se ven como independientes y se juzgan bajo estándares de logros individuales y competitivos.

- Priorización de la calidad y de la ética por encima de la eficiencia o, al menos, no supeditadas a ella (Donovan, 1990; citado en Bensimon, 1993).

- Un amplio despliegue de habilidades y recursos sociales, en particular: a) la escucha, la percepción del otro y la empatía, b) la capacidad para expresar los sentimientos, y para hacer uso de ellos en la toma de decisiones y en la gestión de los grupos, $c$ ) la familiaridad y autenticidad, así como el uso de feed-back en el establecimiento de las relaciones per- 
sonales, $d$ ) el reconocimiento del propio impacto emocional en los demás (Coronel Llamas, Moreno y Padilla, 2002). Estas habilidades y recursos permiten a las directivas establecer modalidades de soft-control sobre los seguidores, es decir, modalidades basadas en la dimensión afectiva, lo que hace posible, según Calás y Smircich (1991), conectar los términos liderazgo y seducción en el análisis del poder ejercido por las mujeres. Ello amplía la importancia concedida a las variables informales y relacionales, en el análisis de las organizaciones y propone nuevos retos a la teoría de la organización.

Todo ello nos parece especialmente importante en unos momentos en los que - como sostiene Acker (2005)— la incorporación de las mujeres a las tareas de gestión coincide con un aumento significativo de la complejidad que afrontan dichas tareas. En este sentido, nuestro estudio trató de poner en relación algunas características del liderazgo que las mujeres participantes desplegaron mientras se encontraban inmersas en procesos de cambio en sus unidades académicas. Por ello, los estudios de caso que realizamos trataron de describir en profundidad las culturas organizativas y las redes de poder establecidas en dichas unidades. Nos interesaba particularmente indagar acerca de la relación existente entre las estrategias que pusieron en juego estas directivas y la cultura instalada en las instituciones ya que, como señalan Kezar y Eckel (2002), cuando las estrategias de cambio violan las normas culturales es difícil que se institucionalicen los cambios acometidos.

Nos parece, por tanto, que la llegada de las mujeres al poder en las organizaciones no solo es algo bueno para las mujeres sino también para las organizaciones. Primero, porque nos da la oportunidad de volver a pensar las formas que el poder reviste en ellas, esta vez desde una perspectiva de género. $\mathrm{Y}$ segundo, porque nos permite analizar en la práctica determinadas formas de liderazgo — características de las mujeres- que podrían considerarse más adecuadas para las organizaciones actuales y más aún para determinado tipo de organizaciones como las educativas. Sin embargo, no deja de sor- 
prender —como ya hemos referido ampliamente en la primera parte de este libro- que el género haya estado ausente, como categoría y como perspectiva, del análisis de las organizaciones.

Es precisamente porque el liderazgo de las mujeres se desarrolla en condiciones difíciles y está condicionado por las barreras tanto culturales o socializadas como por las externas o contextuales (Hawley et ál., 1998) que, en muchas ocasiones, adopta formas creativas, quizás las formas creativas que las organizaciones necesitan para ser más útiles, sostenibles y éticas en la nueva sociedad del conocimiento (Hargreaves y Fink, 2006). Ya Loden (1987) señaló que precisamente las barreras que las mujeres encuentran en su camino profesional las inducen no solo a trabajar más que los hombres, en general, sino también a buscar nuevas alternativas. No podemos, por tanto, desperdiciar el conocimiento que las mujeres directivas están desplegando para la mejora de las organizaciones y también para hacerlas más humanas y manejables.

\section{2. ¿Qué hemos aprendido del trabajo de gestión de mujeres en cargos de gobierno/puestos de responsabilidad en la Universidad?}

Nuestro estudio nos ha puesto de manifiesto muchas de las cuestiones relatadas en la literatura. Cuestiones que en los diferentes capítulos de esta obra se han ido presentando y que ahora vamos a sintetizar y resumir ofreciendo al lector una percepción global de las mismas.

a) En primer lugar hemos aprendido que las mujeres directivas asumen, en general, sus puestos de responsabilidad con la ilusión del recién llegado; al fin y al cabo podemos considerarlas recién llegadas a un mundo tradicionalmente en manos de los hombres. Ello se traduce en que se implican profundamente en las tareas, tanto en lo que se refiere al tiempo que le dedican como a la intensidad que ponen en el empeño. A pesar de dicha implicación, mantienen aparentemente su dedicación a la vida familiar y a las tareas docentes y de atención a los alumnos. La única actividad que dicen abandonar es la investigación, de la cual se mantienen apartadas mientras 
ocupan puestos directivos. El deterioro de la dedicación a las tareas de investigación aparece como una de las principales consecuencias del ejercicio de tareas de gestión universitaria. Cuando ocupan un cargo de gestión, las profesoras siguen dedicando el tiempo necesario a la docencia y a la atención a los alumnos. Sin embargo, las tareas de investigación pasan a un segundo o tercer plano; incluso en ocasiones se posponen conscientemente hasta que finalice el periodo de gestión.

b) Merece destacarse que, si bien nuestras directivas subrayan la ausencia de medios que faciliten el compatibilizar las tareas de gestión con la vida personal y familiar, esto no se suele señalar como un problema relevante. Tal vez esto sea una muestra de la actitud de «evitación del prejuicio», descrita por la literatura (Marshall, 1990), de manera que el tradicional anclaje de las mujeres a la familia no sea visto desde el exterior como una rémora que les impide desempeñar bien su labor. De esta manera, ellas procuran equilibrar las exigencias familiares y profesionales mediante su propio esfuerzo personal (Russell y Burguess, 1998). Sin embargo, el tiempo personal es otro de los aspectos que se ven más afectados cuando se ocupan cargos de gestión.

c) Reconocemos también la frecuencia con la que el fuerte componente vocacional que marca su acceso a la dirección viene unido a una alta autovaloración en el desempeño de su labor: en general, se sienten satisfechas de sus logros. Tampoco es extraño que, en estas condiciones, muchas de ellas asocien dicho desempeño a la consecución de un proyecto, en lugar de asociarlo a una labor puramente gerencial. A menudo se trata de un proyecto de un colectivo al cual ellas representan mientras que, en otras, es un proyecto personal para el cual buscan el apoyo de un equipo, dedicando una parte importante de sus fuerzas a mantener unido y cohesionado dicho grupo. Asimismo, en la orientación de su liderazgo aparece también un fuerte énfasis en los aspectos éticos y de cuidado hacia las personas. En este sentido, ellas destacan la responsabilidad y el sentido ético como dos características valiosas para el ejercicio de la gestión y, además, como características que despliegan en el ejercicio del cargo. 
d) Igualmente, es congruente con este perfil de motivaciones en el acceso al cargo el hecho de que algunos de los problemas más importantes que encuentran las directivas para su desempeño como tales estén ligados a condiciones que conforman la lógica dominante en las organizaciones: el aparato burocrático, por un lado, y las redes de influencia en la sombra que sostienen miembros y grupos con poder, haciendo valer sus derechos adquiridos, por el otro. Ambos se presentan como fuertes barreras a los proyectos de renovación institucional con y por los que algunas de estas directivas acceden al poder.

e) Además, nuestro estudio ha permitido destacar algunas características relevantes presentes en la forma de liderar de las participantes. No obstante, dichas características no permiten caracterizar algo parecido a un liderazgo «femenino». Nuestros resultados corroboran más bien la conclusión del estudio de Gillett-Karam (1994) — citado por Glazer-Raymo, 1999—, en donde se estudiaron los estilos de liderazgo de hombres y mujeres, que plantea que las destrezas de liderazgo tienen que ver más con variables situacionales que con aquellas ligadas al género. Más bien se pueden señalar orientaciones generales que se muestran a través de diferentes estilos de liderazgo. En este sentido, uno de los rasgos más destacados entre las mujeres participantes en nuestro estudio fue su orientación hacia las relaciones sociales, confirmando así uno de los aspectos que despierta mayor consenso en la literatura especializada. Bensimon (1993) explica dicha orientación planteando que las mujeres perciben el mundo no tanto como algo físico, sino encarnado en personas y expresado de manera psíquica y social y que ello es congruente con un gobierno de ese mundo más a través de las necesidades sentidas que mediante un control racional.

La marcada orientación hacia lo social parece predisponer favorablemente a las mujeres directivas para aceptar y utilizar provechosamente la colaboración. El efecto de este rasgo consiste en que los colaboradores se sienten a sí mismos más «visibles» y a las directivas «más cercanas». Se percibe un especial interés por el cuidado de las relaciones sociales entre los miembros del grupo de trabajo 
con una marcada tendencia a combinar los aspectos sociales y técnicos del ejercicio de los cargos de gestión que se reitera ante la pregunta sobre la preocupación por la integración de los miembros, por un lado, y la toma de decisiones difíciles, por el otro. Por eso puede ser que aparezca como un problema significativo para las mujeres directivas tanto el exceso de burocracia como el predominio de un marcado estilo eficientista. Y es que la mujer gestiona y conduce a los grupos poniendo en juego estrategias y habilidades sociales que tienen que ver con las relaciones de comunicación, la mediación en los conflictos, la proximidad, la cercanía, la atención a los problemas cotidianos, la implicación de las personas que configuran el equipo de trabajo...

f) En muchos casos, hemos encontrado esta orientación hacia el mundo social combinada con un perfil de fuerte exigencia y de autoridad. Es decir, hemos encontrado en número importante de directivas la tendencia a combinar los aspectos sociales y técnicos del ejercicio de los cargos de gestión. Un perfil que conjuga equilibradamente la autoridad con la delicadeza o mano izquierda en el manejo de las situaciones. Estas mujeres dialogan, buscan el acuerdo, tratan de limar posiciones divergentes pero, llegado el caso en el que se hace imposible llegar a una solución pactada, no dejan las decisiones eternamente suspendidas en espera de un acuerdo o consenso. Creen que ocupan ese puesto para tomar decisiones y consideran que no hacerlo es incurrir en una falta de responsabilidad. Podríamos afirmar que explotan las relaciones sociales mientras constituyen el marco adecuado en donde los problemas pueden ser resueltos. Sin embargo, cuando las posibilidades de acuerdo se cierran en este ámbito, pasan a utilizar los controles de autoridad o los burocráticos para que las tareas puedan seguir adelante.

No obstante, nuestros resultados muestran claramente que dicha orientación hacia las relaciones sociales podía ser desarrollada por las participantes en nuestro estudio bajo estilos de liderazgo diferentes e incluso antagónicos. Ellas utilizaron todas las fuentes de poder disponibles ante circunstancias problemáticas de diversa índole, sin mostrar una clara predilección por ninguna de ellas. Esta 
diversidad y variedad de estilos podría estar ligada a otra característica atribuida por una de las entrevistadas a las mujeres: un mayor pragmatismo y un modo más resolutivo de encarar los problemas de la organización, frente a una visión más estratégica de los hombres, lo cual implicaría un estilo más marcadamente «político» en ellos.

En todo caso, como sugiere Glazer-Raymo (1999), debemos revisar nuestros modelos de liderazgos académicos a fin de reflejar la experiencia de las mujeres y aprender de los aspectos novedosos que presenta su forma de dirigir, como por ejemplo, esta fuerte orientación hacia las personas, los grupos y las relaciones. Quizás ello contribuya a algo tan necesario en estos tiempos como el fortalecimiento de la cultura de la colaboración y el compromiso en las instituciones universitarias. Cabe preguntarse si el liderazgo ejercido por mujeres se acopla de manera especial a las condiciones particulares de las organizaciones universitarias, en especial de sus Departamentos. Condiciones que en la actualidad están afectadas por el desacople entre la estructura formal y la social, por fuertes tensiones políticas y por un elevado nivel de incertidumbre.

En este aspecto también indagamos en nuestro estudio recabando la opinión acerca de la cultura de colaboración existente en los Departamentos de aquellas personas que trabajan en Departamentos liderados por mujeres.

Les formulamos cuestiones obedeciendo a la presunción de que aquellas organizaciones educativas en las que predomina la colaboración entre los profesionales que las conforman reúnen una serie de características. Estas se refieren a aspectos diversos de la tarea, tales como la definición compartida de objetivos y finalidades organizativas, las concepciones didácticas, la coordinación de la labor docente, la preocupación por la labor pedagógica, etcétera. Todas estas cuestiones las clasificamos en cinco amplias categorías que aparecen recogidas en la tabla siguiente: 


\section{TABLA 1}

\section{CARACTERÍSTICAS DE LAS ORGANIZACIONES CON ESTRUCTURAS CORPORATIVAS}

\begin{tabular}{|c|c|}
\hline \multirow{3}{*}{$\begin{array}{l}\text { VISIÓN } \\
\text { COMPARTIDA }\end{array}$} & Los miembros del dpto. comparten creencias y valores \\
\hline & Los miembros conocen metas y prioridades \\
\hline & Las metas y prioridades del dpto. están establecidas con claridad \\
\hline \multirow{13}{*}{ COLABORACIÓN } & Los profesores planifican en equipo \\
\hline & El dpto. promueve coordinación entre docentes \\
\hline & El dpto. promueve la coordinación con otros dptos. \\
\hline & $\begin{array}{l}\text { Los profesores colaboran informalmente para intercambiar } \\
\text { material curricular }\end{array}$ \\
\hline & $\begin{array}{l}\text { Los profesores colaboran informalmente para intercambiar } \\
\text { técnicas de enseñanza y actividades de aula }\end{array}$ \\
\hline & $\begin{array}{l}\text { Los profesores colaboran informalmente para realizar actividades } \\
\text { científicas }\end{array}$ \\
\hline & $\begin{array}{l}\text { Los profesores colaboran informalmente para compartir } \\
\text { experiencias de investigación }\end{array}$ \\
\hline & Los profesores colaboran informalmente para desarrollar tutorías \\
\hline & $\begin{array}{l}\text { Los profesores colaboran formal e informalmente para } \\
\text { intercambiar material curricular }\end{array}$ \\
\hline & $\begin{array}{l}\text { Los profesores colaboran formal e informalmente para } \\
\text { intercambiar técnicas y estrategias de enseñanza }\end{array}$ \\
\hline & $\begin{array}{l}\text { Los profesores colaboran formal e informalmente para realizar } \\
\text { actividades científicas }\end{array}$ \\
\hline & $\begin{array}{l}\text { Los profesores colaboran formal e informalmente para compartir } \\
\text { experiencias de investigación }\end{array}$ \\
\hline & $\begin{array}{l}\text { Los profesores colaboran formal e informalmente para desarrollar } \\
\text { tutorías }\end{array}$ \\
\hline \multirow{3}{*}{$\begin{array}{l}\text { ÉNFASIS SOBRE } \\
\text { EL APRENDIZAJE } \\
\text { DEL ALUMNADO }\end{array}$} & $\begin{array}{l}\text { Los profesores orientan su enseñanza hacia un aprendizaje } \\
\text { significativo }\end{array}$ \\
\hline & $\begin{array}{l}\text { Preocupación por el aprendizaje en las discusiones de los órganos } \\
\text { colegiados }\end{array}$ \\
\hline & $\begin{array}{l}\text { Los profesores están interesados por el desarrollo de destrezas } \\
\text { superiores en los alumnos }\end{array}$ \\
\hline \multirow{4}{*}{$\begin{array}{l}\text { COLEGIALIDAD } \\
\text { Y PRÁCTICA } \\
\text { REFLEXIVA }\end{array}$} & $\begin{array}{l}\text { Los profesores discuten frecuentemente sobre las dificultades de } \\
\text { los alumnos }\end{array}$ \\
\hline & $\begin{array}{l}\text { Los profesores observan las prácticas docentes de otros profesores } \\
\text { y ofrecen su opinión }\end{array}$ \\
\hline & Los profesores expertos ayudan a los noveles \\
\hline & Preocupación por el rendimiento en encuentros departamentales \\
\hline \multirow{3}{*}{$\begin{array}{l}\text { ESTILO } \\
\text { INSTITUCIONAL }\end{array}$} & Debate y consenso frecuentes en el dpto. \\
\hline & $\begin{array}{l}\text { Manejo de conflictos orientado a conciliación y diversidad de } \\
\text { perspectivas }\end{array}$ \\
\hline & Toma de decisiones basada en la deliberación colectiva \\
\hline
\end{tabular}


Los profesores consultados manifiestan un cierto nivel de acuerdo en cuanto al conocimiento y aceptación de las metas, creencias y valores del Departamento. Únicamente para el 7,7 \% de los encuestados las metas del Departamento no están establecidas con claridad.

Sobre el aspecto de la colaboración existen opiniones bastante homogéneas. En general, parece existir un sentir unánime en torno a esta dimensión, que se manifiesta en un grado de acuerdo medio o bajo ante las diferentes declaraciones propuestas en ella. En términos generales, los profesores tienden a colaborar más informalmente en grupos pequeños para intercambiar materiales curriculares $\mathrm{y}$, sobre todo, para intercambiar sugerencias sobre actividades de aula (algo que no suelen hacer en grupos formales). Asimismo, parece que es más viable que se desarrollen actividades de tutorías con los alumnos en grupos informales que en los formales. En líneas generales, se observan escasos niveles de colaboración y, cuando se dan, se prefiere que sea a través de grupos informales

En cuanto al aprendizaje de los alumnos, podemos señalar que este tópico no forma frecuentemente parte de la discusión de los órganos colegiados del Departamento (33\%); aunque para algo más del $15 \%$ sí es un tema a debate. Sin embargo, un elevado número de profesores manifiesta que en sus respectivos Departamentos los programas tratan de promover la construcción de aprendizajes significativos.

La reflexión sobre la práctica docente a través de diversas estrategias no es una práctica habitual entre los docentes de los Departamentos consultados. Los profesores no tienen oportunidades para observar la docencia de otros colegas y opinar sobre la misma y, además, no estiman relevante esta cuestión o están en desacuerdo con la misma. Igualmente, un porcentaje muy escaso $(2,2 \%)$ de profesores consultados afirma que en su Departamento se ayuda a los profesores noveles a introducirse en la práctica profesional.

Finalmente, en relación con el estilo institucional, es curiosa la unanimidad que existe en manifestar el consenso, el debate y la toma de decisiones basada en la deliberación colectiva como las estrategias puestas en marcha por los Departamentos. Desde nuestro punto de vista estos resultados están en contradicción con algunas cuestiones surgidas con anterioridad. 
En definitiva, podemos concluir diciendo que la mayoría de los miembros de los consejos de Departamentos universitarios conocen y comparten las metas y objetivos propuestos.

Los menores niveles de colaboración, según los profesores de los Departamentos consultados, existen en dos ámbitos: en la docencia, para asegurar la coherencia del currículum (tanto con profesores del mismo Departamento como de otros), y en la promoción de actividades científicas, tanto externa (a través de jornadas y congresos) como internas (compartir proyectos de investigación con sus compañeros). Un mínimo porcentaje de los profesores señala que planifica en grupo asignaturas o materias afines. En términos generales parece que la colaboración se prodiga más en grupos informales que en los formales. El aprendizaje de los alumnos no es un tema que frecuentemente se debata en los órganos colegiados de los Departamentos consultados. El análisis de la práctica docente a través de estrategias reflexivas no es reconocido como una tarea entre los profesores de los Departamentos consultados, siendo más frecuentes los debates sobre los alumnos que sobre el propio trabajo docente.

Cuando nos detenemos en el análisis del estilo institucional surgen cuestiones que se contradicen con las anteriores, ya que los profesores tienden a caracterizar globalmente a sus Departamentos acercándolos más a estilos colaborativos. Sin embargo, cuando han opinado sobre actuaciones concretas en el seno de los Departamentos sus opiniones se alejaban en buena medida de esta perspectiva de trabajo en colaboración.

g) Hemos encontrado otra característica atribuida a las mujeres de nuestro estudio que es una mayor capacidad y orientación hacia el trabajo «multitarea», es decir, hacia el trabajo en paralelo (varios asuntos al mismo tiempo) frente al trabajo «en serie» que los informantes señalan como más propio de los varones. En palabras de una de las directivas entrevistadas, la mujer admite «interferencias». Ello confirmaría la tesis de una visión predominantemente policrónica (Hargreaves, 1997) de las mujeres en el modo de abordar las tareas organizativas, algo que puede estar vinculado a la exigencia que plantean las tareas del hogar, muchas de las cuales requieren ser desarrolladas de modo simultáneo. 
h) Asimismo, una de las constataciones de nuestro estudio hace referencia a la escasa presencia de mujeres en ámbitos de decisión, que dista mucho de ser equilibrada respecto a la de los hombres, a pesar de que casi el $60 \%$ de las licenciaturas las adquieren mujeres. Pese a que son ya varias las décadas en las que se vienen aplicando políticas de igualdad, la presencia de mujeres en los altos cargos de los órganos de gobierno y gestión en la Universidad española dista mucho de rozar la paridad con la de sus homólogos masculinos. En definitiva, los puestos de poder en la Universidad española se conjugan en masculino. Solo el 6,5\% de los rectorados están encabezados por mujeres y únicamente el 13,9\% de las cátedras tienen nombre femenino (Bustelo y Lombardo, 2007).

La mujer universitaria española pospone el acceso a cargos de responsabilidad en su carrera profesional. Diferentes razones contribuyen a este hecho. La atención a la familia por una parte, y la priorización del desarrollo profesional de la pareja, se constata como una de las principales razones de esta circunstancia.

El perfil de la gestora universitaria de la Universidad española es el siguiente: Mujer casada, con un hijo o ninguno, entre 35 y 45 años, que cuenta con ayuda doméstica y que generalmente no tiene a su cargo a personas mayores; que posee una experiencia docente: de entre dieciséis y veinte años, y una antigüedad en la institución de entre once y quince. Este acceso tiene una motivación intrínseca muy vinculada a la satisfacción personal y al desarrollo de un proyecto de grupo. No les mueve a desempeñar un cargo ni el prestigio o la imagen social del mismo, ni la remuneración o liberación de docencia que puede llevar incorporado dicho cargo.

En segundo lugar, hay otros factores que favorecen que la mujer quede peor situada cuando subimos en la escala jerárquica del organigrama de la organización y que se vaya configurando gráficamente el famoso efecto tijera, en el que partiendo de situaciones similares de formación (primer, segundo y tercer ciclo) el número de hombres que van ascendiendo y subiendo de categoría profesional es considerablemente mayor que el de las mujeres, que va disminuyendo. Entre dichos factores podemos identificar, coincidiendo con algunos estudios relativos al tema, la escasa presencia de mujeres en comités de eva- 
luación, concesión de becas, reales academias... Y es que como demostró el estudio de dos científicas suecas - Christine Weneras y Agnes Wold- «para llegar a un mismo lugar, una mujer necesitaba publicar tres veces más que un hombre (El País, 6 de diciembre de 2004)».

Asimismo, cabe percibir una cierta renuncia de cierta parte de las mujeres consultadas a reconocer la operación de mecanismos de discriminación en las organizaciones de las que forman parte. Tal vez, efectivamente, no existan vías directamente orientadas a detener el acceso femenino a los cargos de gestión en los niveles intermedios y poco prestigiados. En cambio, pueden estar operando en los de mayor nivel de acuerdo con lo propuesto por las teorías del «techo de cristal». Dado el perfil de las mujeres consultadas —aún jóvenes en su mayoría- es probable que pocas de ellas hayan, hasta el momento, aspirado a alcanzar puestos de la mayor jerarquía y, en consecuencia, no hayan tenido ocasión de comprobar la existencia de esa invisible barrera.

i) Ahora bien, una vez llegadas al poder, las mujeres parecen lograr cambios significativos, percibidos con satisfacción por una mayoría de los miembros de la organización. En concreto, las directivas analizadas se mostraron hábiles y eficaces por lo general en la gestión de la conflictividad latente o manifiesta de sus respectivas unidades. De algún modo algunos de los liderazgos analizados contribuyeron a evitar en buena medida las tendencias disgregadoras características de las estructuras de poder — como las universitarias- fuertemente politizadas. Este éxito estuvo relacionado al menos con los siguientes aspectos:

1. Una lectura adecuada de las características culturales que presentaban sus instituciones - en línea con los hallazgos de Kezar y Eckel (2002)—. Es posible que la mirada de las mujeres sobre las organizaciones y las relaciones sociales esté especialmente indicada para las transformaciones que las organizaciones universitarias están afrontando en estos momentos. En este sentido, en la elección de las mujeres para ocupar cargos directivos no estaría influyendo solamente el azar, la presión de estas para conseguir mayor visibilidad o el deseo de acabar con las desigualdades del pasado, sino también la capacidad de las mujeres directivas para vincular los aspectos sociales al tratamiento de los problemas. 
2. La adopción de un estilo de liderazgo basado en la comunicación franca, abierta y directa, así como en la consideración de los problemas y necesidades personales de los miembros de la organización en equilibrio con los requerimientos de la tarea.

3. La adopción también de un perfil resolutivo en la toma de decisiones.

4. Una fuerte implicación personal en las tareas, aspectos estos dos últimos que ya hemos comentado.

En definitiva, nuestras conclusiones ponen de manifiesto una especial habilidad en las directivas estudiadas para conducir estos cambios sin traumas y preservando en buena medida la cohesión social $\mathrm{y}$ un ambiente favorable de trabajo. $\mathrm{Al}$ parecer estos logros fueron conseguidos mediante estilos de liderazgo bastante flexibles, construidos sobre la base de un uso alternativo de variadas fuentes de poder.

j) Las diferencias en los estilos de gestión basadas en el género fueron atribuidas a factores personales o culturales y no a la variable de género. Recogemos en el cuadro siguiente las características asociadas a la condición masculina y femenina, en lo que a la gestión se refiere, mencionadas por los participantes en el conjunto de nuestro estudio:

TABLA 2

CARACTERÍSTICAS DE LA GESTIÓN ASOCIADAS A LA CONDICIÓN MASCULINA Y FEMENINA

\begin{tabular}{|l|l|}
\hline HOMBRES & MUJERES \\
\hline Manifiestan apego al poder & Manifiestan menos apego al poder \\
Manifiestan ambición por el poder & Prioridad a la atención familiar \\
Es una tradición asumida que ocupen cargos & Han de conquistar los cargos \\
de gestión & Necesitan hacerlo bien para sentirse bien \\
Necesitan del reconocimiento público & Han de demostrar que saben hacer las cosas \\
No necesitan demostrar nada en su gestión & $\begin{array}{l}\text { Son más minuciosas y van más al detalle } \\
\text { Más prácticas } \\
\text { Presentan menos visceralidad en las } \\
\text { relaciones } \\
\text { Más negociadoras }\end{array}$ \\
& \\
Suelen realizar una tarea tras otra & Capaces de realizar varias tareas a la vez \\
\hline
\end{tabular}




\subsection{Propuestas de futuro}

En relación con las propuestas de mejora sugeridas por los hallazgos derivados de nuestro estudio, entendemos que estas deben plantearse atendiendo a dos tipos de demandas. En primer término, la manifiesta necesidad de reclamar planes de igualdad realistas, que sean ejecutados implacablemente. Aunque la presencia de mujeres en ámbitos académicos ha cambiado y se va equiparando con respecto a la de los hombres, no podemos afirmar que esto sea sinónimo de igualdad ni que hayamos conseguido erradicar las diferencias existentes entre hombres y mujeres en muchos aspectos de la vida universitaria. Sobre todo, la presencia de mujeres en ámbitos de gestión universitaria es a todas luces insuficiente y desigual a pesar de contar con una Ley de Igualdad y de la existencia de estudios — como el realizado por la empresa Catalys sobre las 500 mayores empresas del mundo-que afirman que «las empresas con mayor número de mujeres en sus puestos de dirección obtienen mejores resultados económicos en general (...) La idea es recuperar el talento que se queda fuera cuando las directivas son excluidas, su forma de pensar, de organizar, su modelo de dirigir, es decir, sumar talentos» (El País, marzo de 2008).

Entre las políticas generales para luchar contra la discriminación de género el informe ETAN (Comisión Europea) propone:

- Priorizar acciones de integración de igualdad de oportunidades para mujeres y hombres (mainstreaming gender equality) como medio de alcanzar la excelencia y evitar la pérdida de una élite profesional e intelectual femenina.

- Desarrollar indicadores y estudios de calidad segregados por género y niveles para tener una información actualizada sobre la situación real de discriminación.

- Establecer indicadores objetivos del mérito personal promoviendo la transparencia en procesos de selección y promoción que eviten los sesgos de grupo (redes de padrinazgos, escuelas, camaraderías, etcétera...). Este es uno de los factores de discriminación por sexo, porque las recomendaciones de jefes de grupos de investigación o trabajo, Departamento, o escue- 
la, estadísticamente recaen mayoritariamente sobre discípulos varones en función de valores no siempre relacionados con el mérito.

- Proponer una horquilla de representación del sexo subrepresentado entre el 40 y $60 \%$ en los grupos de poder que toman decisiones de gestión, control y reparto de recursos ya que en la práctica son mayoritariamente masculinos.

- Incrementar la visibilidad de las mujeres destacadas y promover modelos femeninos de éxito para las jóvenes.

- Estudiar en profundidad los procesos que, en cada cultura, originan desequilibrio de género.

- Desarrollar una agenda de priorización de objetivos para corregir el desequilibrio de género y hacer un seguimiento del progreso conseguido con las medidas que se vayan adoptando para optimizarlas y actualizarlas. La integración de género requiere una estrategia a largo plazo para transformar organigramas, estructuras y costumbres.

Estas políticas se materializan $a$ ) diagnosticando y haciendo visible el sexismo; $b$ ) sensibilizando y creando un estado de opinión favorable a la igualdad; $c$ ) promoviendo el acceso en igualdad de condiciones al trabajo y la promoción profesional; $d$ ) organizando las condiciones del trabajo bajo una perspectiva de género y $e$ ) alcanzando una representación equilibrada en los diferentes órganos y niveles de toma de decisiones.

Todas estas nuevas y mejores políticas de apoyo y de conciliación entre la vida familiar y laboral resultan imprescindibles y suponen la intervención de nivel político. Pero también sabemos que para conseguir un cambio en las actitudes y comportamientos además de acertadas intervenciones políticas se necesita un cambio de cultura.

En segundo lugar, y en un nivel más ligado a la formación, parecería deseable impulsar los nuevos modelos de trabajo que tímidamente están empezando a desarrollar las mujeres que acceden a puestos de responsabilidad, cuidando mucho la gestión del tiempo y la implicación de las personas en los equipos de trabajo. Para ello, se reconoce que el diseño, desarrollo e institucionalización de progra- 
mas formativos en gestión puede ser una vía no solo válida sino también necesaria. Por una parte, permitiría introducir en el campo de la gestión universitaria a docentes muy cualificadas en sus respectivos campos disciplinares pero menos conocedoras de las exigencias que los cargos de responsabilidad y toma de decisiones llevan consigo. Y por otra, podría ser un foro para impulsar, poner a prueba y validar modelos de gestión basados en estos nuevos roles que, como decimos, parece que empiezan a funcionar. Finalmente, permitirían extender los nuevos modos de ejercicio del liderazgo que, según parece, podrían no ser exclusividad de las mujeres. Pero detengámonos en este punto y echemos un vistazo al estado de la cuestión.

\subsubsection{La función directiva en las nuevas organizaciones}

Los cambios - tanto de orden social como de posición teórica en la comprensión de las organizaciones- a los que hemos hecho referencia en esta obra exigen nuevos roles en los directivos y gestores de las organizaciones sociales y nuevos enfoques de análisis de la acción directiva. La imagen de gestor eficaz se va quedando cada vez más pequeña e insuficiente para la dirección de las organizaciones modernas.

En este contexto de cambio, una de las cuestiones que demandan respuesta es la de cómo están afectando todos estos desarrollos a la función directiva. Hasta el momento, desde el campo de la investigación se han articulado algunas respuestas referidas a los directivos de los niveles de enseñanza primaria y secundaria. Una revisión de algunas investigaciones internacionales permite concluir que la naturaleza del trabajo de los directores escolares está cambiando como consecuencia de las recientes políticas educativas. Tanto en el ámbito anglosajón como en otros contextos, en el marco de las reformas educativas, se ha publicado una cantidad considerable de trabajos orientados a explorar la naturaleza cambiante del rol directivo (Webb y Vulliamy, 1996; Boyle y Woods, 1996; Whitty y otros, 1999). Tras analizar las reformas acometidas en cinco países, orientadas a potenciar la capacidad de autogestión de las escuelas, se ha llegado a la conclusión de que se está produciendo una diver- 
gencia entre las prioridades gerenciales de los equipos directivos y las preocupaciones educativas de los profesores, lo que a su vez está conduciendo a un distanciamiento cada vez mayor entre director y «dirigidos», así como a la consolidación de unas estructuras de dirección de carácter más vertical. Una consecuencia que se deriva de esta situación es que, ante las nuevas presiones a las que deben hacer frente, los directores abandonan las funciones relacionadas con el liderazgo pedagógico y la colegialidad para asumir otras, más parecidas a las del gerente de una empresa tradicional o a las de un ejecutivo.

Sin embargo, en consonancia con la posición que venimos defendiendo, entendemos que esta visión resulta claramente insuficiente. De hecho, la idea sobre el tipo de liderazgo que es requerido en las organizaciones escolares ha cambiado mucho en los últimos años. Se trata de una visión heredera directa de la profunda reconceptualización del liderazgo que se efectuó en la década de los ochenta, para dar salida a la crisis en la que se habían sumido los estudios organizativos tras las teorías clásicas. Se necesitaba un nuevo enfoque que aportase una comprensión distinta de la idea de liderazgo, que había permanecido prácticamente invariable a pesar de las modificaciones introducidas por cada uno de los enfoques anteriores. Durante este periodo, teóricos y prácticos interesados por el estudio de las organizaciones educativas han tratado de definir las características de un liderazgo instructivo o pedagógico, orientado a desarrollar un ambiente de trabajo productivo y satisfactorio para profesores y alumnos.

Desde las interpretaciones más «amplias» del liderazgo pedagógico se advierte que este abarca el modo en que todos los miembros de la organización ejercen su influencia unos sobre otros, lo que resulta coincidente con las descripciones más difundidas en torno del estilo «femenino» de liderazgo. Como se desarrolló ampliamente en el capítulo segundo de esta obra, los trabajos centrados en el análisis del género como variable que incide en el desarrollo organizativo, unido a una mayor sensibilidad hacia las experiencias de las mujeres en los procesos de gestión (Blackmore, 1996; Riehl y Lee, 1996; Blackmore, 1999; Coronel, Moreno y Padilla, 2002; Sánchez y otros, 2004a, 2004b; Sánchez, 2005; Tomás, 2006; Valcárcel, 2004) resaltan 
otros atributos del liderazgo ejercido por mujeres en las organizaciones, entre los que se encuentran la capacidad de empatía o de priorizar los aspectos sociales del funcionamiento organizativo.

En esta misma línea, otros enfoques han propiciado un replanteamiento de la propia noción de liderazgo. Así, frente a los modelos racionales, entienden el liderazgo como una responsabilidad hacia los otros y como una capacitación de los otros, que busca la cohesión social en la institución (Beck, 1994). También se entiende como «praxis emancipatoria» (Riehl y Lee, 1996), que implica la negociación de metas y propósitos, el abordaje de los conflictos como un aspecto legítimo del trabajo compartido y la búsqueda de espacios y oportunidades para la reflexión crítica.

Uno de los rasgos distintivos del liderazgo pedagógico, siguiendo a Wilson y Firestone (1987), es la combinación de acciones que tienen como referente la estructura burocrática de la organización con aquellas que tienen como referente su estructura cultural o ideológica. El líder se presenta así como un gestor del significado, que transforma la manera en que los miembros de la organización piensan sobre la misma, y promueve valores que proporcionan significados compartidos sobre la naturaleza de dicha organización. Se trata, en definitiva, de un proceso simbólico, que afecta a la identidad de la organización (Bryman, 1996). También la idea de liderazgo transformador pone el énfasis en los procesos culturales y de gestión basada en la institución (Hunt, 1999). Se trata de un tipo de liderazgo que tiene el potencial de alterar el contexto cultural en el que la gente trabaja, de crear consenso en torno a proyectos y visiones colectivas de la identidad institucional y de fortalecer, en definitiva, las relaciones entre los miembros de la organización, creando entre ellos un sentido de pertenencia a la misma. Este concepto asume la idea ya expuesta de las organizaciones como entidades socialmente construidas (Beck y Murphy, 1993; Beck, 1994). Ello exige a los directivos aprender a liderar no desde la cumbre de la pirámide organizativa sino más bien a través de la red de relaciones interpersonales, siendo su base de influencia la experiencia profesional y el imperativo moral, más que la autoridad. En un sentido similar Conley y Goldman (1994) utilizan el término liderazgo facilitador para describir cómo los directores son capaces de liderar sin dominar. 
Tomando como base el trabajo de Burns (1978) sobre el liderazgo político, que estableció una diferencia entre el liderazgo transaccional y el liderazgo transformacional, los estudios sobre el liderazgo orientaron su atención hacia los aspectos culturales de la organización y hacia las relaciones sociales entre los directivos y los demás miembros de esta. El liderazgo transaccional remite a un intercambio entre el líder y los seguidores. En este intercambio, el primero ofrece refuerzos a los segundos a cambio de conformidad con los compromisos y propósitos que el líder establece y de esfuerzos orientados a su consecución. En esta especie de contrato implícito entre líder y seguidores, los motivos que cada uno lleva consigo son individuales y no se alteran, ni implican la búsqueda mutua de propósitos más amplios. El liderazgo transformacional, sin embargo, implica un cambio en las aspiraciones de los seguidores, que van más allá de los propios intereses en beneficio del grupo o la organización. Dicho cambio afecta tanto a los seguidores como al propio líder, elevando los niveles de compromiso con propósitos mutuos y desarrollando sus capacidades para alcanzar tales propósitos. Precisamente Smyth (2001), desde su propia noción de liderazgo educativo o pedagógico, plantea el problema del liderazgo como el de capacitar a los profesores para moverse de una situación de dependencia y no-reflexividad a una en la que se convierten en investigadores activos de sus propias prácticas y de las de sus compañeros. En este sentido, algunos autores han resaltado la adecuación del liderazgo transformador a la noción de las organizaciones como entidades que aprenden (Leithwood, Tomlison y Genge, 1996; Leithwood, Leonard y Sharratt, 1998; Bass, 2000), así como a la del desarrollo organizativo (Hopkins, 2001).

Por otro lado y en concordancia con un tipo de liderazgo facilitador del aprendizaje organizativo, la noción de liderazgo disperso o distribuido viene a contrarrestar las visiones individualistas y heroicas que aún perduran. Peter Senge reconoce que el liderazgo puede proceder de cualquier lugar dentro de la escuela, y que más que estar vinculado a un estatus o posición determinada, tiene que ver con las cualidades únicas que los grupos e individuos llevan a un contexto institucional específico. En este sentido, Senge habla de «ecología del liderazgo» y de «comunidades de liderazgo» (Senge y 
otros, 2000). Del mismo modo, Ogawa y Bossert (1995) plantean el liderazgo como una propiedad organizativa, como algo que fluye a través de las redes sociales que integran la organización. Finalmente, hemos de destacar la perspectiva que está emergiendo alrededor del concepto de liderazgo sostenible, cuyos «siete principios» han enunciado recientemente Hargreaves y Fink (2004). Se trata de una perspectiva que problematiza el liderazgo en cuanto a su capacidad para promover cambio sostenido en las organizaciones educativas (Hargreaves, 2006). Hargreaves y Fink (2000) han dejado claro repetidamente que sostenibilidad no es lo mismo que durabilidad o que simple continuidad. En este sentido, entendemos que, ante el ya descrito incremento de la complejidad interna y externa de las organizaciones educativas actuales, a los directivos les compete la obligación intelectual de comprender el contexto en el que desarrollan la acción directiva, y de comprender la propia organización en tanto que construcción histórica y social. Sin esa comprensión su actuación discurrirá, en cierto modo, ciega y correrá el riesgo de comprometer el trabajo, el desarrollo, la paz o la felicidad de quienes trabajan y viven en el mismo contexto. Sin esa comprensión, y sin la capacidad de análisis necesaria para generarla, cualquier proceso de cambio o de desarrollo de la institución se verá comprometido, si no colapsado, por fuerzas desconocidas o no adecuadamente valoradas. Es una vez garantizada su capacidad para analizar y comprender la complejidad de la vida institucional, cuando los directivos podrán adoptar nuevos roles para ejercer una verdadera influencia sobre los procesos de transformación de las instituciones. En este sucesivo proceso de comprensión y de ejercicio de nuevos tipos de actuación, resulta indiscutible la asistencia de una formación específicamente diseñada para tal fin.

\subsubsection{Formación en gestión}

El profesor universitario español tiene asignado un triple rol: docente, investigador y de gestión. De ellos, el de investigador ha sido el tradicionalmente más valorado y para el que la institución ha previsto mecanismos de formación y desarrollo y a su vez ha sido -y sigue siendo- el más premiado e incentivado. A pesar de esta 
escasa atención que la formación específica del profesorado universitario ha recibido tradicionalmente -fundada, en buena medida, en la convicción de que el conocimiento del área disciplinar de especialización basta para enseñar sus contenidos- hace ya algunos años se viene insistiendo en el rol docente y en una renovación de las ideas en relación con el tópico. Esto se evidencia tanto en el surgimiento de algunas iniciativas de orden práctico como en la aparición de reflexiones sobre una cuestión que autores como Zabalza (2005) no dudan en calificar de «necesidad».

Sabemos que aprender a enseñar es difícil y vienen siendo muchas las voces que desde el ámbito universitario insisten en la necesidad de proporcionar apoyo y ayuda tanto a los profesores que se inician en la carrera profesional docente universitaria como a aquellos otros que aun llevando algunos años de ejercicio profesional necesitan procesos y programas de formación que actualicen y revitalicen sus metodologías y actividades docentes (Mayor y Sánchez Moreno, 1999; De Ketele, 2003; De la Cruz, 2003; Sánchez Moreno, 2003; Marcelo, 2005; Valcárcel, 2005; Zabalza, 2005).

Sin embargo, poco sabemos acerca de los procesos de gestión en la Universidad y, sobre todo, carecemos de programas de formación que faciliten la incorporación de los profesores a los cargos directivos en la Universidad y que les permitan llegar a la máxima responsabilidad en la gestión de los centros con los conocimientos y habilidades suficientes y la confianza necesaria por parte de la comunidad para llevarlos a cabo. La literatura al uso nos aporta información derivada de investigaciones llevadas a cabo en el ámbito empresarial, pero nuestro conocimiento acerca de las instituciones educativas y de sus peculiaridades como tal —estructuras débilmente acopladas (Weick, 1976), autonomía, ambigüedad de metas, ausencias de mecanismos efectivos de control (Sánchez y López, 2002)— nos advierte de la imposibilidad de hacer traslaciones automáticas desde el ámbito empresarial al educativo. En los niveles educativos de primaria y secundaria el estudio de los procesos de dirección y gestión lleva algunos años de trayectoria (Wilson y Firestone, 1987; Smyth, 2001; Coronel, Moreno y Padilla, 2002; Hargreaves y Fink, 2006; Antúnez, 2000, 2002, 2004; Gairín y Villa, 1999; López, Sánchez y otros, 2003; 
Isaacs, 2006) pero insistimos en que no ha sido así en el ámbito universitario, en el que tímidamente van apareciendo algunos trabajos (Tomás y otros, 2005; Sánchez y otros 2004, 2005).

Esto plantea a la comunidad científica el reto de levantar un programa de formación riguroso sobre los procesos de gestión y gobierno en la Universidad, sus características, la identificación de buenas prácticas, la relación compleja existente entre el liderazgo de los directivos y otros aspectos institucionales de las organizaciones educativas, tales como las estructuras de poder, su historia institucional, sus procesos de comunicación y de desarrollo o el aprendizaje y el conocimiento organizativos.

Y, además de diseñarlo, se requiere desarrollar dicho plan de formación específicamente orientado a preparar para el desempeño de la función de gestión, dirigido a cualquier miembro de la comunidad universitaria que acceda a este tipo de cargo y que incluya una formación referida tanto a los aspectos administrativos de la función, como - y fundamentalmente- a aspectos relacionados con la resolución de los conflictos, el liderazgo, el análisis de las culturas organizativas, la negociación, etcétera.

Marcelo (2005) presenta una síntesis de algunos principios básicos orientadores de la formación para el ejercicio de la labor docente que, según entendemos, pueden ser igualmente útiles en el diseño de formación dirigido al desempeño de la función gestora:

- Institucionalidad, en tanto requiere ser reconocida como parte de los planes estratégicos de cada Universidad.

- Diversidad, para adecuarse a la variedad de situaciones profesionales e institucionales posibles.

- Continuidad, ya que debe entenderse como un proceso continuo.

- Transparencia, pues estos procesos deben ser conocidos por todo aquel que así lo desee.

- Integración, de diferentes contenidos como de teoría y práctica y de iniciativas individuales y colectivas.

- Racionalidad y planificación en función de las necesidades.

- Flexibilidad, para adaptarse a las condiciones personales de cada persona. 
- Compromiso profesional y social, en tanto supone tanto un derecho como un deber.

- Participación y gestión del conocimiento a partir de las experiencias de los gestores con mayor trayectoria.

- Excelencia, basada en la evaluación de la calidad de las prácticas.

Además de estas orientaciones generales, otras cuestiones tales como la articulación de los recursos necesarios para el desarrollo y la evaluación de la implantación de este tipo de plan, su difusión y su capacidad de satisfacer las necesidades de la población a la que atiende deben ser contemplados a la hora de diseñarlo.

En este sentido, para una adecuada planificación de esta intervención formativa resultaría aconsejable adoptar como referencia algunas características mostradas por gestores que pueden contribuir a un mejor desarrollo organizativo. La aportación de muchas de ellas se ha visto, en cierto modo, confirmada por los hallazgos de la investigación en relación con el ejercicio de la gestión por parte de mujeres en la Universidad española, a la que venimos aludiendo. Sin embargo, los participantes en el estudio no asociaron al género directamente dichas características. Por lo tanto, podría ser de interés replicar la indagación sobre los estilos de gestión, ampliándola a una población que incluya también hombres gestores, a fin de identificar las «buenas prácticas» en este campo de la labor de los profesores universitarios. El conocimiento de las mismas puede servir de base para la definición de los contenidos de un plan formativo que capacite al profesorado universitario para el desempeño de la gestión en las instituciones universitarias.

De igual modo, para este fin resulta imprescindible, desde nuestro punto de vista, partir de una adecuada detección de las demandas. Tras la realización del estudio que venimos presentando, estamos en condiciones de defender que algunas de las características identificadas como necesarias en un buen gestor se pueden sintetizar en: capacidad para combinar aspectos vinculados a la organización formal de las tareas (orden, organización, claridad en los objetivos y metas, justicia, equidad, neutralidad y capacidad de trabajo) con habilidades sociales (capacidad de comunicación y de relación 
personal). Además, disponemos de una amplia información acerca de las necesidades formativas que las directivas de nuestras Universidades han manifestado y que comentaremos a continuación.

Estas necesidades formativas fueron analizadas a partir de sus respuestas a una relación de características sobre liderazgo en las que se les pedía que señalaran la medida en que pensaban que $a$ ) dicha característica era valiosa para la gestión de las organizaciones universitarias, y $b$ ) ellas mismas poseían o no esa característica. Como puede verse en la tabla siguiente, las características más valoradas para el ejercicio de la gestión según las participantes en nuestro estudio son la responsabilidad, el saber planificar y organizar, tener mano izquierda en situaciones difíciles, seguidas del sentido ético y la habilidad de mediación en conflictos. Podemos decir que los resultados son bastante rotundos en la medida en que las respuestas están muy concentradas en torno a esas opciones.

Las características fueron valoradas y declaradas como poseídas en similar medida, excepto en el caso de habilidades de liderazgo cuyas diferencias entre el grado «bastante/mucho» de valoración y el de completa posesión son las más destacables. Resulta notable también la diferencia entre la valoración y el grado en que se posee en el caso de otras dos características que definen un perfil más técnico de la gestión. Se trata de ejercicio de autoridad y gestión económica y obtención de recursos. Hemos de destacar finalmente que las participantes en nuestro estudio afirman en un 86,7\% poseer «mucho/bastante» la característica sensibilidad, mientras que el $78,7 \%$ de las gestoras consultadas la valoran mucho/bastante para el ejercicio de la gestión.

Las respuestas obtenidas mediante el cuestionario de contraste contestado por los miembros de las unidades dirigidas por las participantes en el estudio muestran bastante acuerdo con las respuestas de estas, aunque señalan por lo general valores ligeramente más bajos en las características que poseen las directivas. Los seguidores también señalan la responsabilidad como una característica muy valiosa y que sus directoras poseen en un grado elevado. En cambio, dinamización de grupos y gestión económica y obtención de recursos aparecen como muy valiosas pero poco poseídas por sus respectivas 
directoras. Recordemos que también las directivas establecían un desfase entre su importancia y el grado en que poseían estas dos características.

Toda esta información sin duda resulta una aportación interesante a tener en cuenta a la hora de confeccionar programas formativos destinados a la gestión de instituciones universitarias. Además, nos parece imprescindible que la selección de los contenidos a tratar en un programa de esta índole se realice a partir de la identificación de prácticas de gestión que incidan positivamente en el desarrollo organizativo, entendido como la capacidad de generar respuestas ajustadas tanto a los requerimientos del entorno como a los valores de la propia organización.

TABLA 3

OTRAS CARACTERÍSTICAS RELACIONADAS CON EL EJERCICIO DE LA GESTIÓN

\begin{tabular}{|l|c|c|c|c|}
\hline \multirow{2}{*}{ CARACTERÍSTICAS } & \multicolumn{4}{|c|}{ VALORADAS/SE POSEEN } \\
\hline & \multicolumn{2}{|c|}{ Poco/Algo } & \multicolumn{2}{c|}{ Bastante/Mucho } \\
\cline { 2 - 5 } & Valoradas & Poseídas & Valoradas & Poseídas \\
\hline Responsabilidad & 0,7 & 0,7 & 97,1 & 95,6 \\
Don de gentes & 8,8 & 22,1 & 89,0 & 74,2 \\
Diplomacia & 8,1 & 30,2 & 89,7 & 65,4 \\
Autoridad & 22,1 & 52,9 & 75,7 & 42,7 \\
Sensibilidad & 18,4 & 9,5 & 78,7 & 86,7 \\
Inteligencia & 10,3 & 12,5 & 86,8 & 82,3 \\
Habilidades de liderazgo & 10,3 & 48,4 & 87,5 & 47,8 \\
Dinamización de grupos & 7,4 & 38,2 & 90,5 & 58,1 \\
Tomar decisiones rápidas & 6,6 & 27,2 & 91,2 & 68,4 \\
y en situaciones difíciles & & & & \\
Comunicación, empatía, relaciones & 3,6 & 13,2 & 91,9 & 81,6 \\
interpersonales & 2,2 & 24,3 & 93,4 & 66,9 \\
Mano izquierda en situaciones difíciles & 3,7 & 20,6 & 92,6 & 74,3 \\
Habilidad de mediación en conflictos & 1,4 & 12,5 & 94,1 & 81,6 \\
Saber planificar y organizar & 14,7 & 45,5 & 81,6 & 49,2 \\
Gestión económica y obtención de & 11,8 & 40,0 & 84,6 & 54,4 \\
recursos & 3,7 & 1,5 & 92,6 & 92,6 \\
Resistencia a las frustraciones & & & & \\
Sentido ético & & & \\
\hline
\end{tabular}




\subsection{Limitaciones y prospectiva}

No queremos cerrar este capítulo sin enunciar brevemente algunas de las limitaciones que hemos detectado en nuestro trabajo. La principal de ellas se refiere a la profundidad que hubiera sido necesaria en la fase de estudio de casos. Aunque contábamos con la información obtenida en la fase descriptiva del estudio, una mayor permanencia de los investigadores en las organizaciones analizadas habría permitido incrementar el rigor y el alcance de nuestras conclusiones. Sin embargo, el diseño de la investigación se ha mostrado prometedor para futuros estudios, especialmente la mencionada combinación de estrategias cuantitativas y cualitativas. Desde nuestro punto de vista, dichos estudios deberían en el futuro $a$ ) establecer las diferencias que sobre los aspectos estudiados muestran los hombres que ejercen la dirección de este tipo de organizaciones; b) ampliar el análisis del liderazgo de las directivas a un rango más amplio de organizaciones universitarias, especialmente en lo que se refiere a sus culturas organizativas y estructuras de poder; y c) realizar un seguimiento longitudinal de los procesos de transformación emprendidos por las directivas en el contexto de sus organizaciones.

\section{Referencias bibliográficas}

ACKer, S. (2005), «Gender, Leadership and Change in Faculties of Education in Three Countries», en J. Collard y C. Reynolds (eds.), Leadership, Gender and Culture in Education. Male and Female Perspectives, Maindenhead: Open University Press.

AisenberG, N., y M. HARRINGToN (1993), «Rules of the Game», en J. Glazer, E.M. Bensimon, y B.K. Townsed (eds.), Women in Higher Education: A Feminist Perspective, Needham Heihts, MA: Gin Press.

Alvesson, M., y Y. Billing (1992), «Gender and Organization: Towards a Differentiated Understanding», Organization Studies, 13 (12), 73-102.

- (2000), "Questioning the Notion of Feminine Leadership: A Critical Perspective on the Gender Labelling of Leadership», Gender, Work and Organization, 7 (3), 144-157.

- y S. DeEtZ (1996), «Critical Theory and Postmodernism Approaches to Organizational Studies», en S.T. Clegg, C. Hardy y W.R. Nord (eds.), Handbook of Organizational Studies, Londres: Sage. 
ANTúNEz, S. (2000), La acción directiva en las organizaciones escolares, Barcelona: Horsori.

- (2002), «Yo tampoco quiero ser director», Organización y Gestión Educativa, 15-18.

- (2004), «El director escolar, la LOCE y los titíes», Aula de Innovación educativa, 43-45.

Arenas, M.G., M.J. Gómez y E. JuRAdo (2007), Pensando la educación desde las mujeres, Málaga: Servicio de Publicaciones de la Universidad de Málaga.

Asplund, G. (1988), Women Managers. Changing Organizational Cultures, Chichester: Wiley \& Sons.

BARNETT, R. (2002), Claves para entender la Universidad en una era de supercomplejidad, Gerona: Ediciones Pomares.

BASs, B.M. (2000), «El futuro del liderazgo en las organizaciones que aprenden», en ICE-Universidad de Deusto, Liderazgo y organizaciones que aprenden. III Congreso Internacional sobre Dirección de Centros Educativos (pp. 331-361), Bilbao: Ediciones Mensajero.

BeCK, L.G. (1994), Reclaiming Educational Administration as a Caring Profession, Nueva York: Teachers College Press.

— y J. Murphy (1993), «Metaphors of the Principalship in the 1990s», en L.G. Beck y J. Murphy (eds.), Understanding the Principalship. Metaphorical Themes 1920s-1990s, Nueva York: Teacher College Press.

Bensimon, E.M. (1993), «A Feminist Reinterpretation of President's Definition of Leadership», en J. Glazer, E.M. Bensimon y B.K. Townsed, B.K. (eds.), Women in Higher Education: A Feminist Perspective, Needham Heihts, MA: Gin Press.

BlACKMORE, J. (1996), «"Breaking the Silence”: Feminist Contributions to Educational Administration and Policy», en K. Leithwood, J. Chapman, D. Corson, P. Hallinger \& A. Hart (eds.), International handbook of educational leadership and administration, Dordrecht: Kluwer Academic Publishers.

- (1999), Troubling Women: Feminism, Leadership and Educational Change, Buckingham: Open University Press.

- (2005), “The Emperor Has No Clothes”: Professionalism, Performativity and Educational Leadership in High-Risk Postmodern Times», en J. Collard y C. Reynolds (eds.), Leadership, Gender and Culture in Education. Male and Female Perspectives, Maidenhead: Open University Press y McGraw Hill.

Boyle, M., y P. Woods (1996), «The Composite Head: Coping with Changes in the Primary Headteacher's Role», British Educational Research Journal, 22 (5), 549-565. 
BRYMAN, A. (1996), «Leadership in organizations», en S.T. Clegg, C. Hardy y W.R. Nord (eds.), Handbook of Organization Studies, Londres: Sage. BuRns, J.M. (1978), Leadership, Nueva York: Harper \& Row. Bustelo, M., y M. Lombardo (coords.) (2007), Políticas de igualdad en España y en Europa: afinando la mirada, Madrid: Cátedra

CALÁs, M.B., y L. SMIRCICH (1991), «Voicing Seduction to Silence Leadership», Organizations Studies, 12(4), 567-602.

- (1993), «Re-writing Gender into Organizational Theoring: Directions from Feminist Perspectives», en J. Glazer, E.M. Bensimon y B.K. Townsed (eds.), Women in Higher Education: A Feminist Perspective, Needham Heihts, MA: Gin Press.

CHIA, R. (2003), «Organization Theory as a Postmodern Science», en H. Tsoukas y C. Knudsen (eds.), The Oxford Handbook of Organization Theory, Oxford: Oxford University Press.

Collard, J., y C. REYNOLDS (2005), «Conclusions and Implications: Towards Emergent Theoretical Perspectives on Leadership, Gender and Culture», en J. Collard y C. Reynolds (eds.), Leadership, Gender and Culture in Education. Male and Female Perspectives, Maidenhead: Open University Press y McGraw Hill.

Conley, D., y P. Golman (1994), «Ten Propositions for Facilitative Leardership», en J. Murphy y K.S. Louis (eds.) Reshaping the Principalship: Insights From Transformational Reform Efforts, California: Corwin Press.

CoRonel Llamas, J.M. (2005), «El liderazgo del profesorado en las organizaciones educativas: temáticas para su análisis e investigación», Revista Española de Pedagogía, 232, 471-490.

- E. Moreno y M.T. PADILLA (2002), «La gestión y el liderazgo como procesos organizativos: Contribuciones y retos planteados desde una óptica de género", Revista de Educación, 327, 157-168.

CourT, M. (2005) «Negotiating and Reconstructing Gendered Leadership Discourses», en J. Collard, y C. Reynolds (eds.), Leadership, gender and culture in education. Male and female perspectives, Maidenhead: Open University Hill y McGraw Hill.

De Ketele, J.M. (2003), «La formación didáctica y pedagógica de los profesores universitarios: Luces y sombras», Revista de Educación, 331, 143-169.

De la Cruz Tomé, M.A. (2003), «Necesidad y objetivos de la formación pedagógica del profesor universitario», Revista de Educación, 331, 35-65.

ERKuT, S. (2001), Inside Women's Power: Learning from Leaders, Boston: Center for Reasearch on Women, Wellesley College y Winds of Change Foundation. 
European Commission (2000), Science Policies in the European Union: Promoting Excellence Through Mainstreaming Gender Equality, en ETAN Expert Working group on Women and Science (<http://www.amites.org/etan.htm>).

Fletcher, J.K. (2001), Disappearing Acts. Gender, Power and Relational Practice at Work, Cambridge, MA: MIT Press.

Fullan, M. (2002), Liderar en una cultura de cambio, Barcelona: Octaedro.

GaIRín, J., y A. Villa (1999), Los equipos directivos de los centros docentes. Análisis de su funcionamiento, Bilbao: Mensajero.

GHERARDI, S. (1995), Gender, Symbolism and Organizacional Culture, Londres: Sage.

GLazer-Raymo, J. (1999), Shattering the Myths. Women in Academe, Baltimore: The Johns Hopkins University Press.

- (2003), "Woman Faculty and Part-Time Employment. The Impact of Public Policy», en B. Ropers-Huilman (ed.), Gendered Futures in Higher Education. Critical Perspective for Change, Nueva York: State University of New York Press.

Grogan, M.E. (1996), Voices of Women Aspiring to the Superintendency, Nueva York: State University of New York Press.

Hargreaves, A. (1996), Profesorado, cultura y postmodernidad, Madrid: Morata.

- y D. Fink (2006), Sustainable Leadership, San Francisco: Jossey-Bass.

Hawley, M., E. Whirter, D. Torres y S. RAsheed (1988), «Assessing Barriers to Women's Career Adjustment», Journal of Career Adjustment, 6 (4), 449-479.

HunT, J.G. (1999), «Transformational/Charismatic Leadership's Transformation of the Field: An Historical Essay», Leadership Quarterly, 10, 129-144

IsAACS, D. (2006), Ocho cuestiones esenciales en la dirección de centros educativos, Pamplona: EUNSA.

KAUFmann, A. (2007), Mujeres directivas: transición hacia la alta dirección, Madrid: CSIC.

KeZAr, A., y P.D. Eckel (2002), «The Effect of Institutional Culture on Change Strategies in Higher Education: Universal Principles of Culturally Responsive Concepts», Journal of Higher Education, 73(4), 435-460.

Leithwood, K., L. Leonard y L. Sharratt (1998), «Conditions Fostering Organizational Learning in Schools», Educational Administration Quarterly, 34(2), 243-276. 
Leithwood, K., D. Tomlinson y M. Genge (1996), «Transformational school leadership», en K. Leithwood y otros (eds.), Educational Leadership and Administration, Dordrecht: Kluwer Academic Publishers.

Loden, M. (1987), Dirección femenina. Cómo triunfar en los negocios sin actuar como un hombre, Barcelona: Hispano-Europea.

López, J., M. SÁnchez, P. Murillo, J.M. Lavié y M. Altopiedi (2003), Dirigir centros educativos. Un enfoque basado en el análisis del sistema organizativo, Madrid: Síntesis

LoRENZo, M. (2005), «El liderazgo de las organizaciones educativas: revisión y perspectivas actuales», Revista Española de Pedagogía, 232, 367-392.

MARCELO, C. (2005), Los principios generales de la FORMACIÓN del profesorado, Encuentro sobre la Formación del Profesorado Universitario, Almería 12 y 13 de diciembre.

Marshall, J. (1990), Women Managers. Travellers in a Male World, Chichester: John Wiley \& Sons.

MAYOR, C., y M. SÁNCHEZ (1999), «Los equipos docentes: contribución formativa a la calidad del profesor universitario», XXI Revista de Educación, $1,157-176$.

Mills, A.J. (2002), «Studying the Gendering of Organizational Culture over Time: Concerns, Issues and Strategies», Gender, Work and Organization, 9 (3), 286-307.

NidifFER, J. (2001), «New Leadership for a New Century», en J. Nidiffer y C.T. Bashaw (eds.), Women Administrators in Higher Education. Historical and Contemporary Perspectives, Nueva York: State University of New York Press.

OGaWA, R.T., y S.T. BosserT (1995), «Leadership as an Organizational Quality», Educational Administration Quarterly, 31 (2), 224-243.

Perreault, G. (1993), «Contemporary Feminist Perspectives on Women and Higher Education», en J. Glazer, E.M. Bensimon, y B.K. Townsed (eds.), Women in Higher Education: A Feminist Perspective, Needham Heihts, MA: Gin Press.

RIEHL, C., y V.E. LEE (1996), «Gender, Organizations and Leadership», en K. Leithwood, J. Chapman, D. Corson, P. Hallinger y A. Hart (eds.), International Handbook of Educational Leadership and Administration, Dordrecht: Kluwer Academic Publishers.

Russell, J., y J. Burgess (1998), «Success and Women's Career Adjustment», Journal of Career Assessment, 6(4), 365-387.

SÁNCHEZ, M., y J. LÓPEZ (2002), «Condiciones organizativas de la enseñanza en la Universidad», en C. Mayor (coord.), Enseñanza y aprendizaje en la educación superior, Barcelona: Octaedro. 
SÁnchez Moreno, M. (1998), «La formación de los directores escolares», en V. Llorent y S. Oria (dirs.), La dirección escolar, Madrid: Bruño.

- (2003), «El asesoramiento», en M. Sánchez Moreno (coord.), Coordinación de la Formación Guía II Proyecto Andaluz de Formación del Profesorado Universitario, Córdoba: UCUA.

- (2005), La mejora de las estrategias de la dirección, Consejería del Gobierno de Cantabría.

- y J. LÓPEZ YÁÑEZ (2003), «Condiciones organizativas de la enseñanza en la Universidad", en C. Mayor (coord.), Enseñanza y Aprendizaje en la Educación Superior, Barcelona: Octaedro.

- y C. MAYOR RUIZ (2003), «Supervisión Clínica como estrategia de aprendizaje entre profesores», en J. Gairín y C. Armengol (eds.), Estrategias de formación para el cambio organizacional, Barcelona: Praxis.

- y otros (2004a), «La mujer en la dirección y gestión de las organizaciones universitarias», en J. López, M. Sánchez Moreno y P. Murillo (eds.), Cambiar con la sociedad, cambiar la sociedad, Sevilla: Servicio de Publicaciones de la Universidad de Sevilla.

— y otros (2004b), «La mujer en la dirección y gestión de Universidades: un estudio en el contexto de España», IV Congreso Internacional sobre Dirección de Centros Educativos, Bilbao: ICE de Deusto.

Senge, P.M., y otros (2000), Schools That Learn, Nueva York: Doubleday.

Sмyтh, J. (2001), Critical Politics of Teachers' Work: An Australian Perspective, Nueva York: Peter Lang.

Tierney, W.G., y E.M. Bensimon (1996), Promotion and Tenure. Community and Socialization in Academe, Nueva York: State Univesity of New York Press.

Toвío, C. (2005), Madres que trabajan: dilemas y estrategias, Valencia: Publicaciones Universidad Valencia.

Tomás, M. (coord.) (2006), Reconstruir la Universidad a través del cambio cultural, Barcelona: Servicio de Publicaciones Universidad Autónoma de Barcelona.

VALCÁRCEL, A. (2004), La política de las mujeres, Madrid: Cátedra.

VALCÁRCEL, M. (2005), La formación, evaluación, reconocimiento e incentivación del profesorado universitario, Encuentro sobre la Formación del Profesorado Universitario; Almería 12 y 13 de diciembre.

WebB, R., y G. Vulliamy (1996), «A Deluge of Directives: Conflict Between Collegiality and Managerialism in the Post-ERA Primary School», British Educational Research Journal, 22 (4), 441-459.

WeICK, K.E. (1976), «Educational Organizations as Loosely Coupled Systems», Administrative Science Quarterly, 1 (21), 1-19. 
Whitty, G., S. Power y D. HalPin (1999), La escuela, el estado y el mercado, Madrid: Morata.

Willmotт, H. (2003), «Organizational Theory as a Critical Science? Forms of Analysis and "New Organizational Forms"», en H. Tsoukas y C. Knudsen (eds.), The Oxford Handbook of Organization Theory: Metatheoretical Perspectives, Oxford: Oxford University Press.

Wilson, B.L., y W.A. Firestone (1987), «The Principal and Instruction: Combining Bureaucratic and Cultural Linkages», Educational Leadership, 45 (1), 18-23.

Yancey Martin, P., y D. Collison (2002), «Over the Pond and across the Water": Developing the Field of Gendered Organizations», Gender, Work and Organization, 9 (3), 241-265.

YANIZ, C. (2005), La formación del profesorado universitario en la Universidad de Deusto, Encuentro sobre la Formación del Profesorado Universitario; Almería 12 y 13 de diciembre.

Zabalza, M. (2005), Programa ANECA de evaluación de los planes de formación docente de las Universidades, Encuentro sobre la Formación del Profesorado Universitario; Almería, 12 y 13 de diciembre. 


\section{ÍNDICE}

Introducción

CAPÍTULO 1. LA UNIVERSIDAD ACTUAL Y LAS MUJERES:

ALGUNAS PARADOJAS (Mariana Altopiedi) ................................ 13

1.1. Introducción................................................................................... 13

1.2. La Universidad actual: continuidades históricas y rupturas.......... 16

1.2.1. La Universidad en el momento actual: una aproximación fenomenológica ................................................................ 17

1.2.2. La Universidad en el momento actual: una aproximación

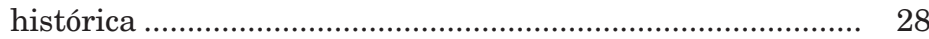

1.3. Las mujeres en la Universidad de hoy ........................................... 32

1.3.1. Las mujeres en los distintos niveles de la Universidad ....... 32

1.3.2. Las mujeres y el poder en la Universidad............................ 40

Referencias bibliográficas...................................................................... 56

CAPÍTULO 2. EL LIDERAZGO A DEBATE: NUEVAS PERSPECTIVAS SOBRE UN VIEJO CONOCIDO (José Manuel Lavié Martínez) ................................................................................ 59

2.1. El liderazgo: «un viejo conocido» .................................................... $\quad 59$

2.2. Liderazgo y género: un diálogo que comienza «contaminado» ........ 61

2.3. El liderazgo femenino: los términos del debate .............................. 64

2.4. Percepciones sobre el liderazgo femenino en la Universidad ......... 69

2.5. ¿Existe, entonces, un estilo femenino de liderazgo? ........................ 71

2.6. A modo de conclusión......................................................................... $\quad 75$

Referencias bibliográficas.................................................................... $\quad 77$

CAPÍTULO 3. EL PERFIL DE LAS MUJERES QUE DESEMPEÑAN CARGOS DE GESTIÓN EN LA UNIVERSIDAD (Paulino Murillo Estepa) ......................................................................

3.1. Un estudio sobre las mujeres que ocupan cargos en las Universidades españolas 
3.1.1. Metodología de la investigación ............................................ 82

3.2. Algunos referentes sobre el tema de estudio ................................... 86

3.3. Opiniones sobre el trabajo de gestión y su acceso al mismo........... 90

3.4. El perfil profesional .................................................................. 95

3.5 El perfil personal y familiar ........................................................... 99

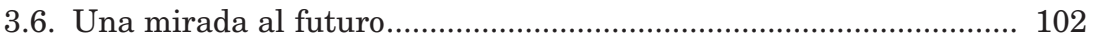

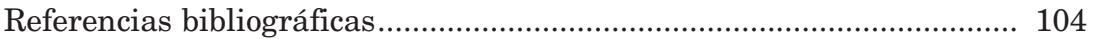

CAPÍTULO 4. LA INCORPORACIÓN DE LAS MUJERES A LA GESTIÓN UNIVERSITARIA: UNA RESPUESTA A LAS CRISIS INSTITUCIONALES (Julián López Yáñez) .................................... 105

4.1. Directivas que promueven cambios en circunstancias difíciles ...... 109

4.1.1. Jóvenes escuderas ................................................................ 109

4.1.2. Unidos para promover el cambio ........................................ 117

4.1.3. Directivas con una posición académica consolidada............. 123

4.2. Poder y liderazgo de mujeres responsables de instituciones uni-

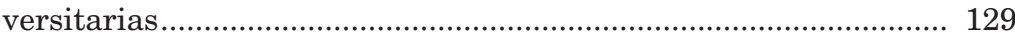

4.2.1. Estilos de liderazgo ............................................................ 129

4.2.2. Bases de poder sobre las que las directivas gobiernan sus

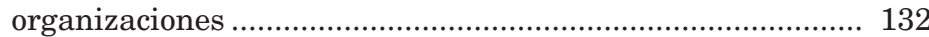

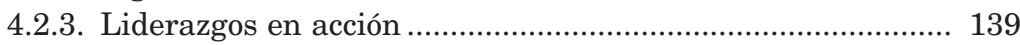

Referencias bibliográficas.................................................................... 152

CAPÍTULO 5. ALGUNAS CONCLUSIONES QUE ORIENTAN LA PRÁCTICA (Marita Sánchez Moreno) .............................................. 153

5.1. Algunas ideas de partida................................................................. 153

5.2. ¿Qué hemos aprendido del trabajo de gestión de mujeres en cargos de gobierno/puestos de responsabilidad en la Universidad? 159

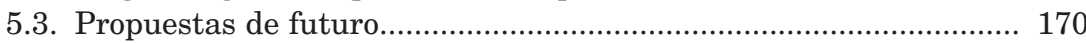

5.3.1. La función directiva en las nuevas organizaciones............... 172

5.3.2. Formación en gestión ............................................................ 176

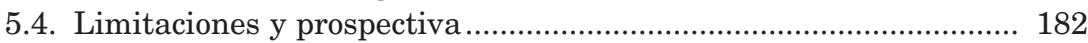

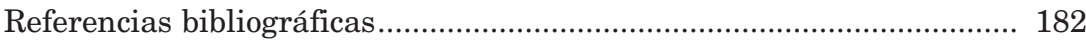


Este libro se terminó de imprimir en los talleres gráficos de GAMBON Gráfico, de Zaragoza, en diciembre de 2009

\section{$\cos 80280$}



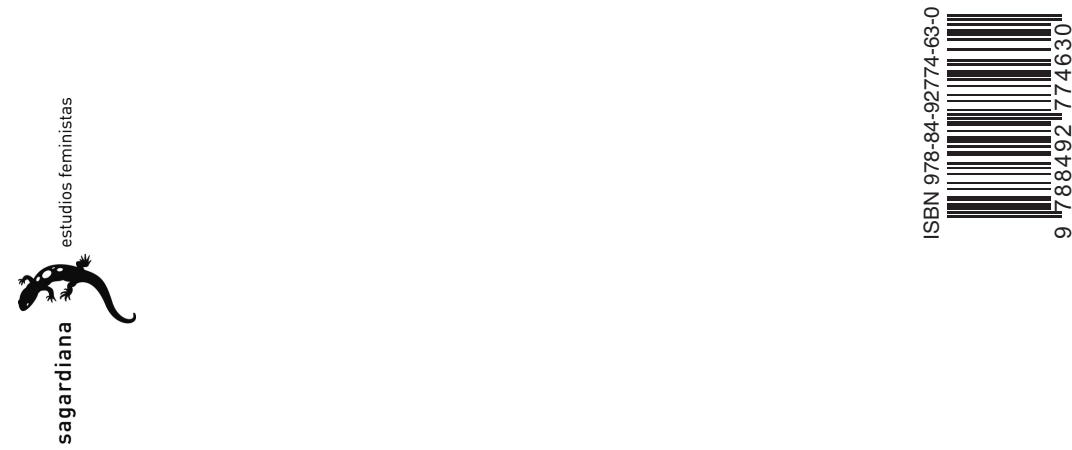

Cl liderazgo ejercido por mujeres ¿se acopla de manera
especial a las condiciones particulares de las organizaciones universitarias? Este es el asunto central del que se ocupa el presente libro. El texto narra como dichas condiciones están en la actualidad afectadas por el desacople entre la estructura formal y la dinámica social, por fuertes tensiones políticas y por un elevado nivel de incertidumbre. En ese contexto se analiza la aportación que las mujeres podrían estar prestando a las universidades como organizaciones. Se trata, en definitiva, de una contribución a los estudios de género y gestión que buscan identificar nuevos modelos y estilos de dirección que hagan más confortable, armoniosa y sostenible la vida en el seno de las organizaciones de educación superior.

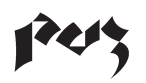

Prensas Universitarias de Zaragoza

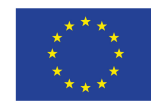

UNIÓN EUROPEA Fondo Social Europeo
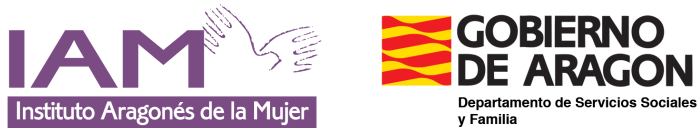